\title{
REAL-TIME ENERGY MANAGEMENT OF AN ISLANDED MICROGRID USING MULTI-OBJECTIVE PARTICLE SWARM OPTIMIZATION
}

\author{
by
}

Aric James Litchy

A thesis submitted in partial fulfillment of the requirements for the degree

\author{
of \\ Master of Science \\ in \\ Electrical Engineering \\ MONTANA STATE UNIVERSITY \\ Bozeman, Montana
}

June 2013 
CCOPYRIGHT

By

Aric James Litchy

2013

All Rights Reserved 


\section{APPROVAL}

of a thesis submitted by

Aric James Litchy

This thesis has been read by each member of the thesis committee and has been found to be satisfactory regarding content, English usage, format, citation, bibliographic style, and consistency and is ready for submission to The Graduate School.

Dr. M. Hashem Nehrir

Approved for the Department of Electrical Engineering

Dr. Robert C. Maher

Approved for The Graduate School

Dr. Ronald W. Larsen 


\section{STATEMENT OF PERMISSION TO USE}

In presenting this thesis in partial fulfillment of the requirements for a master's degree at Montana State University, I agree that the Library shall make it available to borrowers under rules of the Library.

If I have indicated my intention to copyright this thesis by including a copyright notice page, copying is allowable only for scholarly purposes, consistent with "fair use" as prescribed in the U.S. Copyright Law. Requests for permission for extended quotation from or reproduction of this thesis in whole or in parts may be granted only by the copyright holder.

Aric James Litchy

June 2013 


\section{ACKNOWLEDGEMENTS}

I would like to sincerely thank Dr. M. Hashem Nehrir of Montana State University for accepting me into his research group, sharing his expertise, and providing me with the tools to take the next step in life. He is a true professional.

I would like to thank the chair of my department, Dr. Robert C. Maher, my other members of my committee, Dr. Robert Gunderson and Dr. Hongwei Gao, and all the other faculty and staff that have supported me along the way while I have been at Montana State University.

I would like to thank NREL and LBNL for their support, input, and use of their microgrid modeling services, HOMER and WebOpt. For providing the commercial version of HOMER I would like to thank HOMER Energy as well.

I would also like to thank my fellow peers at Montana State University, Ali Pourmousavi, Mohammad Moghimi, Jon Wilson, Nick Havens, Stasha Patrick, Chris Colson, Colin Young, Kevin Marchese, Andrew Cifala, my lab students, and many more that have made the journey insightful and entertaining.

Lastly, I would like to especially thank my family, friends, and the most understanding, patient, and loving wife in the world, Maggie. 
TABLE OF CONTENTS

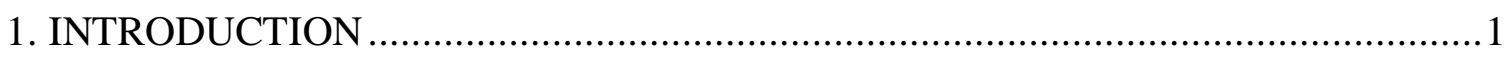

Global and US Electricity Demand, Generation Source, and Emissions Outlook..........1

Global Outlook .................................................................................. 1

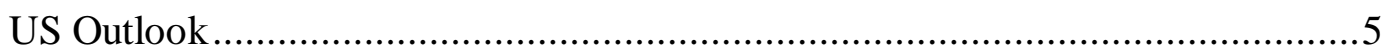

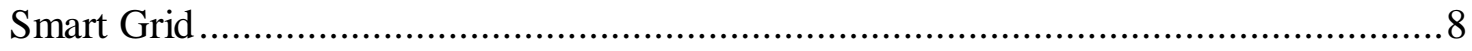

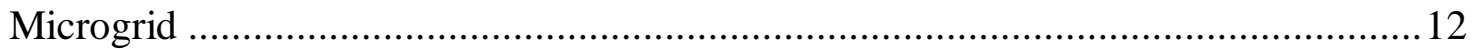

Intelligent Real-time Multi-objective Optimization ........................................... 16

Modern Heuristics................................................................................ 17

Particle Swarm Optimization.................................................................... 18

Multi-objective Optimization ........................................................... 21

Multi-objective Particle Swarm Optimization..............................................23

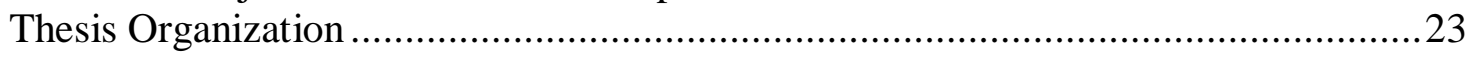

2. TECHNOLOGY SELECTION AND UNIT SIZING ..........................................25

Brief Description of WebOpt and HOMER ...................................................26

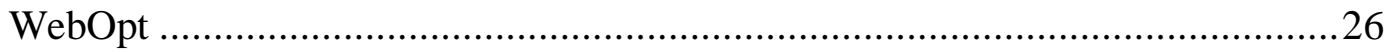

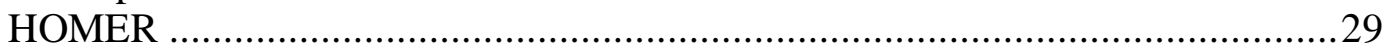

Simulation Setup and Results ................................................................... 32

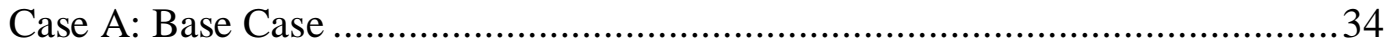

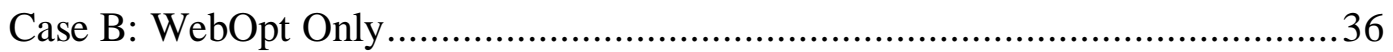

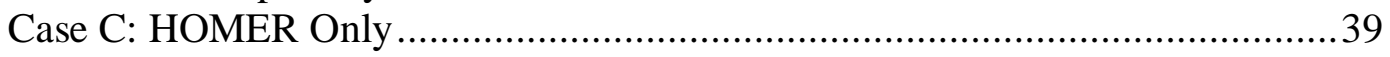

Discussion ........................................................................................... 41

Simulation Model of Final Microgrid Design ............................................. 42

3. ENERGY MANAGEMENT OF MICROGRID ................................................. 44

Formulation of Optimization Problem ........................................................... 44

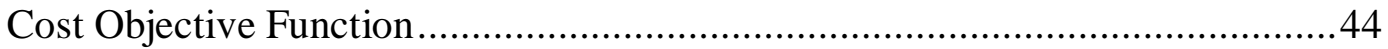

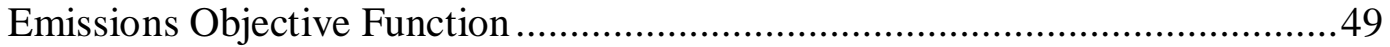

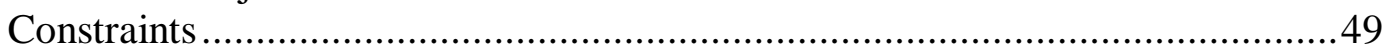

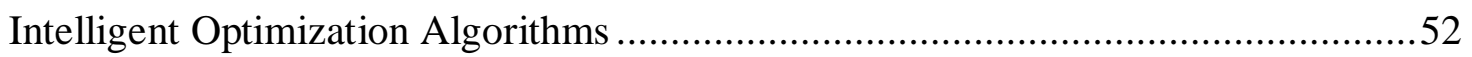

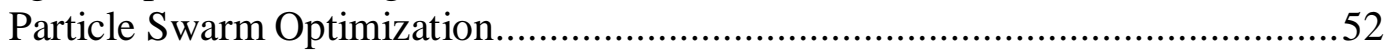

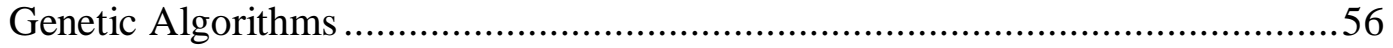

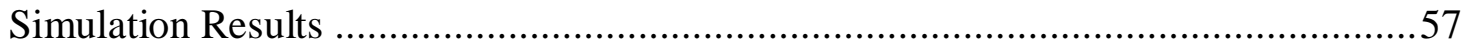

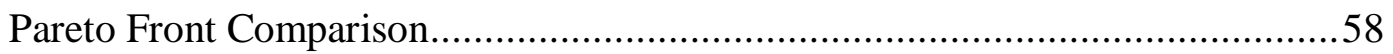

Twenty-Four Hour Energy Management Simulations .................................. 60

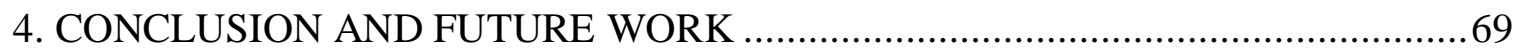


TABLE OF CONTENTS - CONTINUED

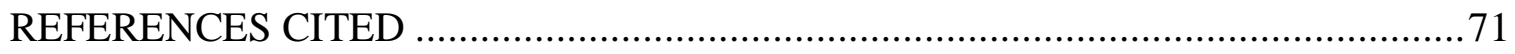

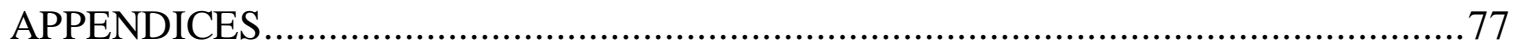

APPENDIX A: Matlab/Simulink Microgrid Models ............................................78

APPENDIX B: Energy Management and Modified MOPSO Algorithm Function 1 ................................................8 88

APPENDIX C: Energy Management and Modified MOPSO Algorithm Function 2 ................................................ 94

APPENDIX D: Energy Management and Modified MOPSO Algorithm Function 3 ..... 
vii

\section{LIST OF TABLES}

Table

1.1. Smart Grid Characteristics..

2.1. Inputs, Outputs, and Assumptions of WebOpt

2.2. Available Technology in WebOpt .28

2.3. Inputs, Outputs, and Assumptions of HOMER . .30

2.4. Available Technology in HOMER. .31

2.5. Case A: WebOpt and HOMER Technology Input Descriptions .34

2.6. Case A: WebOpt and HOMER Results .36

2.7. Case B: WebOpt Technology Input Descriptions .37

2.8. Case B: WebOpt Only Results .37

2.9. Case C: HOMER Technology Input Descriptions . .39

2.10. Case C: HOMER Only Results 40

3.1. Minimum and Maximum Value of Operating Ranges .51

3.2. Table 3.2 Operating Points for Letters A - G in Fig. 3.6 .59

3.3. Total Cost and Emission Values Over the 24 Hour Period .67 
viii

\section{LIST OF FIGURES}

Figure $\quad$ Page

1.1 OECD and non-OECD net electricity generation,

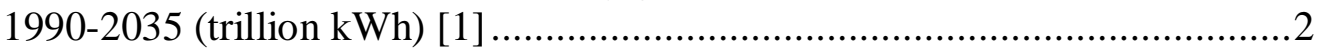

1.2 Non-OECD net electricity generation by region,

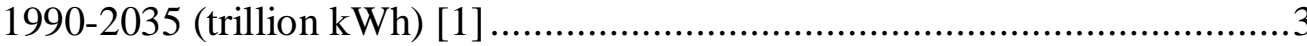

1.3 World net electricity generation by fuel, 2008-2035 (trillion kWh) [1] ....................................................

1.4 Average annual growth of energy-related $\mathrm{CO}_{2}$ emissions in OECD (left) and non-OECD (right) economies, 2008-2035 (percent per year) [1]

1.5 U.S. electricity demand growth, 1950-2035

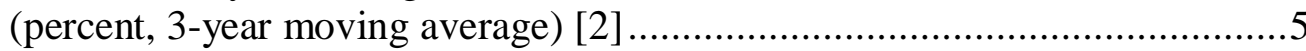

1.6 Electricity generation by fuel, 2010, 2020, 2035 (billion kWh) [2] 6

1.7 Hydropower and other renewable electricity generation, including end-use generation, 2010-2035 (billion $\mathrm{kWh}$ ) [2] .......................6

1.8 Non-hydropower renewable electricity generation capacity by energy source, including end-use capacity, 2010-2035 (gigawatts) [2]

1.9 Annual average Henry Hub spot natural gas prices, 1990-2035 (2010 dollars million Btu) [2]

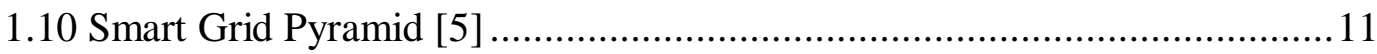

1.11 Sample microgrid architecture [9] ............................................... 13

1.12 Illustration of a hybrid centralized and distributed control paradigm [12] ..................................................... 15

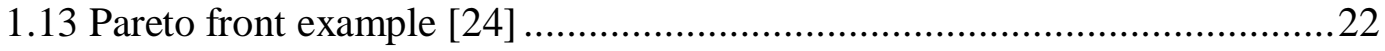


ix

\section{LIST OF FIGURES - CONTINUED}

Figure

2.1 WebOpt area plot example of a typical electrical load demand in summer, met by the different generation sources in a 24 hour period.

2.2 Example of an area plot of the electrical load demand being met by the different generation sources over a 24 hour period from HOMER

2.3 Sample load demand profile for a typical summer day of a medium-sized college in San Francisco, CA

2.4 Block diagram of the designed AC-coupled microgird. The microgrid meets electrical demand through PV, FC, ICE, and Battery sources. The thermal load is met through waste heat from the FC and ICE and the heat generated by the boiler.

3.1 Fuel cell power versus load current characteristic.

3.2 Cost factor vs. battery state of charge for three different scenarios: battery discharging during power demand (a), battery charging during power demand and power available (b)

3.3 Load demand and PV power profiles displaying when power is demanded from additional generation sources and when power is available to storage loads.

3.4 Flow diagram showing the general process of the multi-objective PSO algrotihm. Once the state of the system is determined the process starts

3.5 Flow diagram of the containment of particle positions in order to satisfy the equality and inequality constraints of the optimization problem.

3.6 Comparison of Pareto fronts for the different optimization algorithms 


\section{LIST OF FIGURES - CONTINUED}

Figure

3.7 No optimization energy management case. The top figure displays the power supplied by the different energy sources and the power consumed by the energy storage devices. The bottom figure displays the state of charge of both the hydrogen tank and battery.

3.8 Cheapest Case. The top figure displays the power supplied by the different energy sources and the power consumed by the energy storage devices. The bottom figure displays the state of charge of both the hydrogen tank and battery.

3.9 Least Emissions Case. The top figure displays the power supplied by the different energy sources and the power consumed by the energy storage devices. The bottom figure displays the state of charge of both the hydrogen tank and battery.

3.10 Middle Emissions Case. The top figure displays the power supplied by the different energy sources and the power consumed by the energy storage devices. The bottom figure displays the state of charge of both the hydrogen tank and battery. 


\section{NOMENCLATURE}

$\begin{array}{ll}\text { Symbol } & \text { Description } \\ \text { CHP } & \text { Combined Heat and Power } \\ \text { DER } & \text { Distributed Energy Resources } \\ \text { DG } & \text { Distributed Generation } \\ \text { EMS } & \text { Energy Management System } \\ \text { ES } & \text { Energy Storage } \\ \text { FC } & \text { Fuel Cell } \\ \text { GA } & \text { Genetic Algorithm } \\ \text { HOMER } & \text { Hybrid Optimization Model for Electric Renewables } \\ \text { HX } & \text { Heat Exchanger } \\ \text { ICE } & \text { Internal Combustion Engine } \\ \text { MG } & \text { Microgrid } \\ \text { MOP } & \text { Multi-Objective Optimization Problem } \\ \text { MOPSO } & \text { Multi-Objective Particle Swarm Optimization } \\ \text { OECD } & \text { Organization of Economic Cooperation Development } \\ \text { PSO } & \text { Particle Swarm Optimization } \\ \text { PV } & \text { Photovoltaic } \\ \text { WebOpt } & \text { Distributed Energy Resources Web Optimization Service }\end{array}$




\begin{abstract}
The purpose of this thesis is to design an optimal combined heat and power islanded microgrid, through technology selection and unit sizing software, and perform optimal real-time energy management simulations using intelligent optimization techniques. Two software packages, $\mathrm{HOMER}^{\circledR}$ and $\mathrm{WebOpt}^{\circledR}$, originally developed at the National Renewable Energy Laboratory (NREL) and Lawrence Berkley Laboratory (LBL), respectively, were utilized. Using these programs, different cases were created and compared to justify the selected technologies and their respective prices. The final microgrid design contains renewable and alternative energy generation, hydrogen as an energy carrier, and electric storage. Two intelligent optimization techniques, a modified Multi-objective Particle Swarm Optimization algorithm and a Multi-objective Genetic Algorithm in the Matlab optimization toolbox were used for energy management of the designed microgrid and their performance were compared. Simulation results show the modified Multi-objective Particle Swarm Optimization performs better. It is used to perform 24 hour energy management simulations. The simulation results show the benefits of the real-time optimization and the freedom of choice users have to meet their energy demands.
\end{abstract}




\section{INTRODUCTION}

\section{Global and US Electricity Demand, Generation Source, and Emissions Outlook}

The US Energy Information Administration (EIA) has generated the reports International Energy Outlook 2011 (IEO2011) [1] and Annual Energy Outlook 2012 (AEO2012) of the US [2]. The purpose of these reports is to project energy market data through the year 2035 as a service for energy analysts. Data from these two reports are used to give a brief summary of the global and US outlook on electricity demand, generation sources, and emissions. The projections are a business-as-usual trend estimates and contain uncertainty due to use of simplified models.

\section{$\underline{\text { Global Outlook }}$}

According to [1], the world demand for electricity increases 2.3 percent per year, where net electricity generation goes from 19.1 trillion $\mathrm{kWh}$ in 2008 to 35.2 trillion $\mathrm{kWh}$ in 2035. The Organization of Economic Cooperation and Development (OECD) members will see a reduction in the world net share of electricity consumption from 53 percent in 2008 to 40 percent in 2035 . Fig. 1.1 shows the projected net electricity generation comparison between the OECD members and the non-OECD members. Net electricity generation of non-OECD members increases by an average of 3.3 percent annually compared to just 1.2 percent for OECD members. 


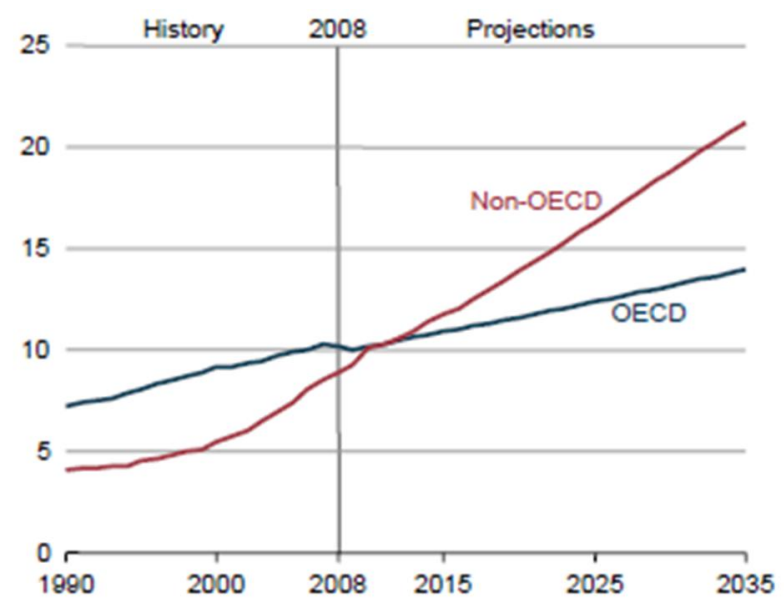

Fig. 1.1 OECD and non-OECD net electricity generation, 1990-2035 (trillion kWh) [1]

The country that influences the non-OECD projections the most is China, as shown in Fig. 1.2. The reasons for larger rates of demand in the non-OECD countries compared to the OECD countries are a combination of larger rates of population and economic growth. The non-OECD GDP is projected to average 4.6 percent per year growth from 2008 to 2035, once again influenced by China (5.7 percent) and India (5.5 percent) the most, whereas the OECD GDP is projected to average 2.1 percent over the same period of time. The projected yearly population growth of the non-OECD members is .9 percent, with Africa (1.7 percent) and the Middle East (1.6 percent) leading the way, compared to just 4 percent for the OECD members. 


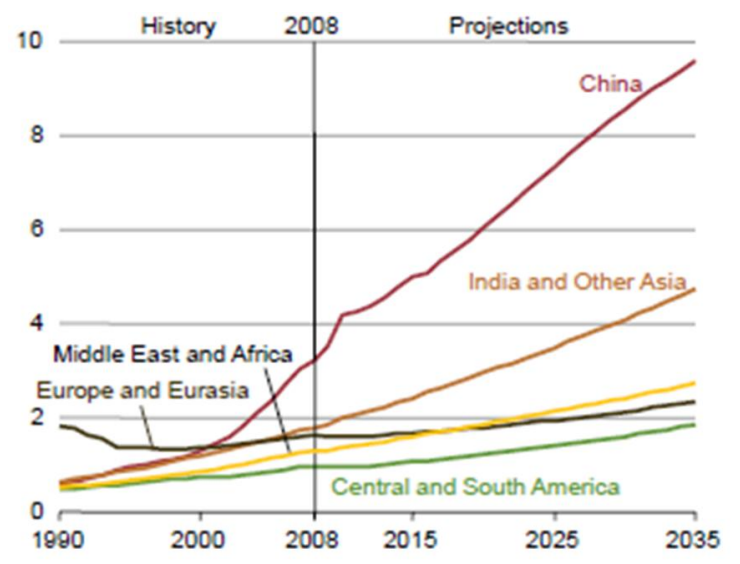

Fig. 1.2 Non-OECD net electricity generation by region, 1990-2035 (trillion kWh) [1]

In order to meet the rising demand in global electricity, all types of generation sources see an increase, except for liquids. Fig. 1.3 shows the net electricity generation by source from 2008 to 2035 . Coal is projected to continue to produce the majority of electricity generation, but its share declines from 40 percent in 2008 to 37 percent in 2035. This is mainly due to the higher growth rates in other generation sources, mainly renewables (3.1 percent), natural gas (2.6 percent), and nuclear (2.4) percent, compared to coal's growth rate (1.9 percent).

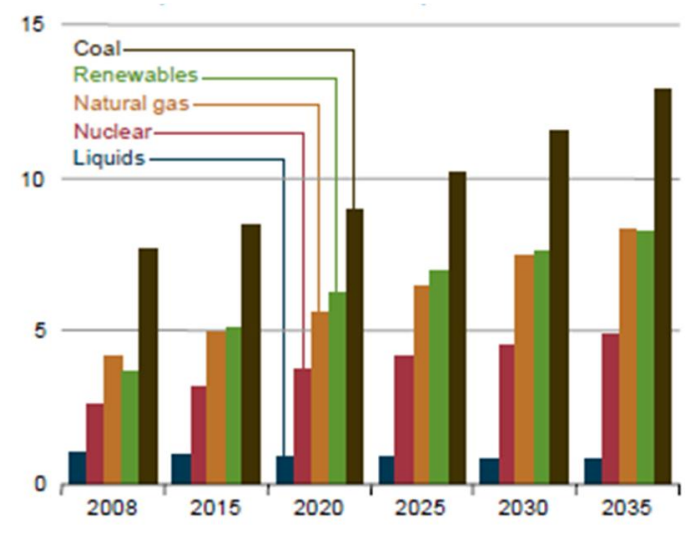

Fig. 1.3 World net electricity generation by fuel, 2008-2035 (trillion kWh) [1] 
In the renewables category, 55 percent of the renewable generation is from hydroelectric power and 27 percent from wind. The non-OECD members largely contribute to the increase in hydroelectric power due to it being more economical than other renewable sources; however, most OECD members have already exploited most of this source of energy. Rising concern of anthropogenic emissions and government policies are the major influencing factors for increased generation from non-hydro renewable sources.

World energy related carbon dioxide $\left(\mathrm{CO}_{2}\right)$ emissions increase from 30.2 billion metric tons in 2008 to 43.2 billion metric tons in 2035 [1]. The majority of this projected growth is due to the increase in demand from the non-OECD members, where most of the demand is met with fossil fuel sources. Fig. 1.4 shows the annual average growth of $\mathrm{CO}_{2}$ emissions in both OECD and non-OECD countries. Non-OECD Asia is projected to see a 74 percent growth in $\mathrm{CO}_{2}$ emissions, with a majority of that due to China's investment in coal-fired power plants to meet their fast rising demand for electricity. An average of $18 \mathrm{GW}$ annually of new coal-fired generation capacity is projected to be added by China from 2008 to 2035 .
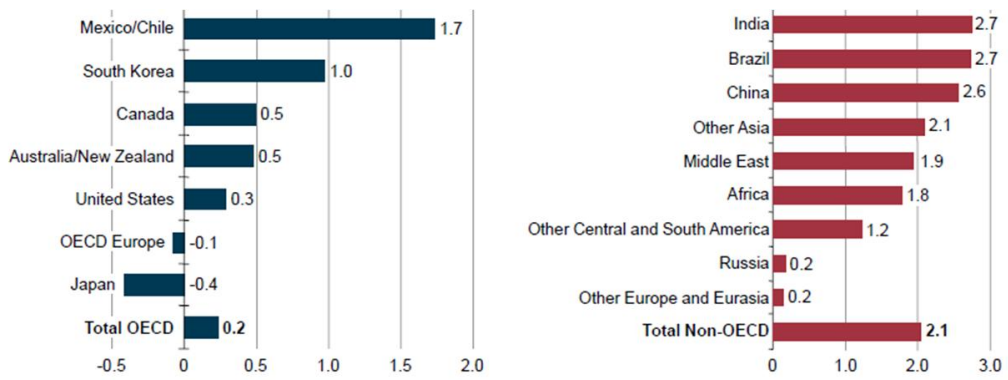

Fig. 1.4 Average annual growth of energy-related $\mathrm{CO}_{2}$ emissions in OECD (left) and non-OECD (right) economies, 2008-2035 (percent per year) [1] 


\section{US Outlook}

The US projections follow similar patterns as the global projections, rising demand in electricity, rising emissions, and larger increases in generation from renewable, natural gas, and nuclear sources compared to coal. The rates of these projections vary greatly compared to most non-OECD members and some fellow OECD members. The US annual rate of growth in net electricity generation is .7 percent compared to the world rate of 2.3 percent. Fig. 1.5 shows the historic and projected electricity demand growth rates.

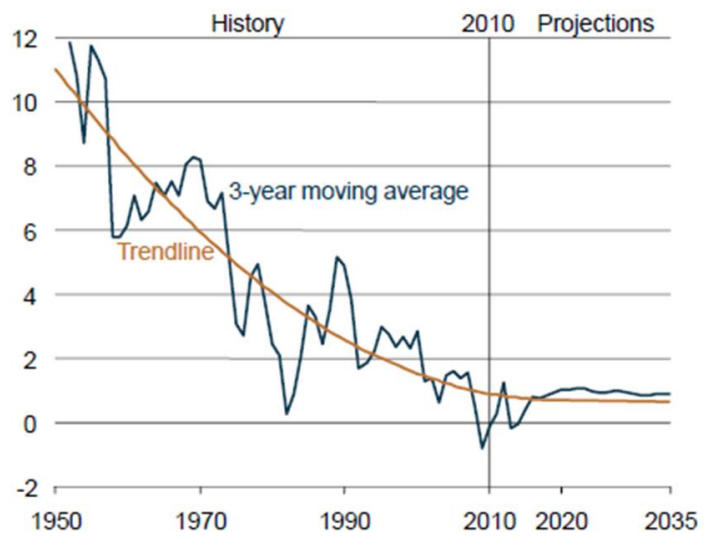

Fig. 1.5 U.S. electricity demand growth, 1950-2035 (percent, 3-year moving average) [2]

Coal-fired generation continues to be the majority supply of electricity in the US but only grows 2 percent from 2010 to 2035 . The share decreases from 45 percent in 2010 to 38 percent in 2035, a much larger decline compared to the global decline. Fig. 1.6 shows the electricity generation by fuel type in the US. 


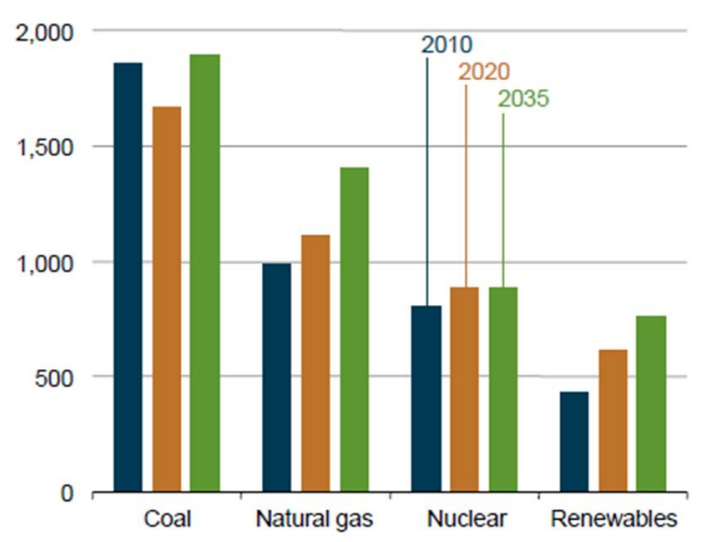

Fig. 1.6 Electricity generation by fuel type in the US, 2010, 2020, 2035 (billion kWh) [2]

Once again, the decreasing share of coal generation is due to large increases in renewable sources (77 percent growth) and natural gas generation (42 percent growth). Currently hydropower still dominates all other renewable sources in the US, but by 2020 it is projected that the combination of the other renewable energy sources will be greater than hydropower, as show in Fig. 1.7. Fig. 1.8 also shows the growth of the different non-hydro renewable energy sources from 2010 to 2035. One can see that in the US wind energy remains the major generation source of the non-hydro renewables.

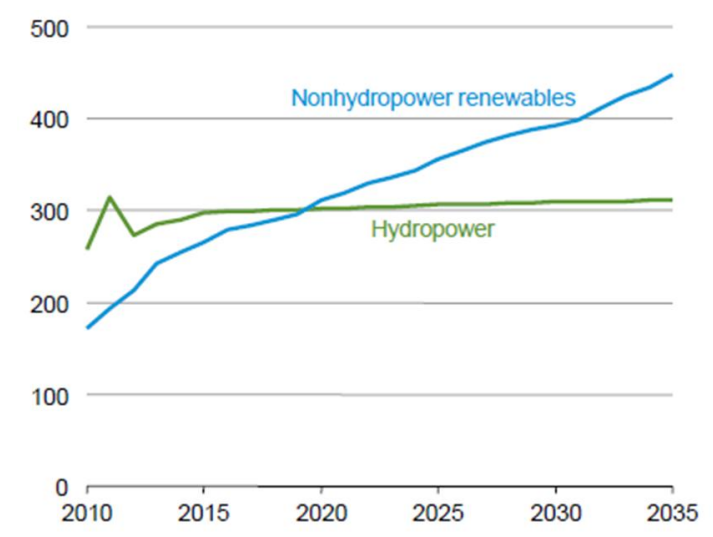

Fig. 1.7 Hydropower and other renewable electricity generation, including end-use generation, 2010-2035 (billion kWh) [2] 


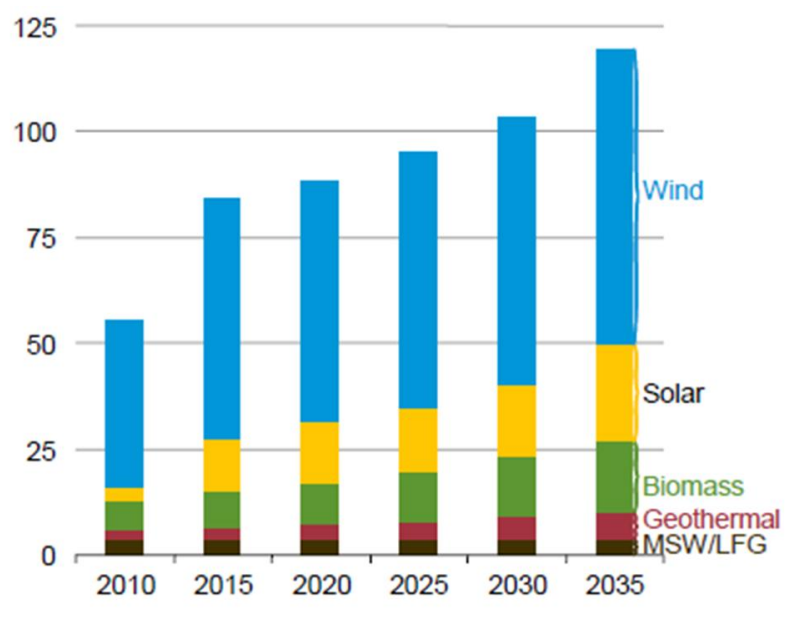

Fig. 1.8 Non-hydropower renewable electricity generation capacities by energy source, including end-use capacity, 2010-2035 (gigawatts) [2]

State Renewable Portfolio Standards (RPS), Federal Renewable Fuel Standards (RFS), and Federal tax incentives have had an influence on the growth of renewables. They are the fastest growing generation source in the US, but their share will still only be 15 percent of the market by 2035. Part of the growth in the renewable sector is projected to be slowed by the availability and low prices of natural gas.

From 2011 to 2035, 60 percent of the total added generation capacity is projected to be from natural gas. This is due to current and future projections of an increase in unconventional natural gas sources which make the price of natural gas relatively cheap, higher efficiency capabilities with combined cycle operation, and low capital costs. Fig. 1.9 shows the projected price of natural gas which will rise at a rate of 2.1 percent from 2010 to 2035 . However, these prices are dependent on many factors, meaning there is a fair amount of uncertainty in them. EIA looks at different scenarios that can affect the natural gas prices and as a result affect the generation source fuel mix as well, for a further in depth analysis [2] is recommended to the reader. 


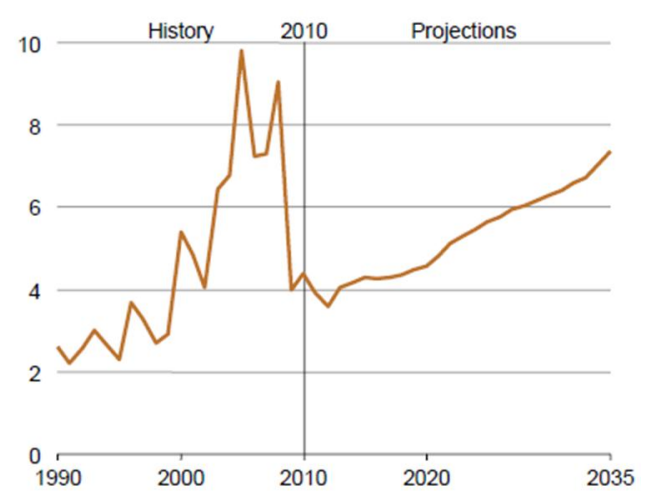

Fig. 1.9 Annual average Henry Hub spot natural gas prices, 1990-2035 (2010 dollars million Btu) [2]

Carbon dioxide emissions in the US are projected to increase at an annual rate of 2 percent from 2010 to 2035 . The rate is slowed down by several different factors such as low economic growth expectations, a switch to a relatively less carbon intensive fuel in natural gas, increased efficiency in different technologies, and an increase in renewable energy generation. Just like the natural gas prices, EIA looks at different scenarios in greenhouse gas (GHG) emissions policies as well since it is a major uncertainty going forward in how the US deals with the rising concern of anthropogenic emissions.

\section{$\underline{\text { Smart Grid }}$}

The Smart Grid is normally not defined by one key aspect but by several important characteristics that will transform the existing grid into a smarter grid. It's the vision that the grid, which is the source of power necessary to run or create other technological advanced products, becomes technologically advanced by today's standards itself. This transformation includes, but not limited to, the following main characteristics described in Table 1.1 from [3]. 
Table 1.1 Smart Grid Characteristics [3]

\begin{tabular}{|c|c|}
\hline Characteristic & Description \\
\hline $\begin{array}{l}\text { 1. Enables } \\
\text { Informed } \\
\text { Participation } \\
\text { by Customers }\end{array}$ & $\begin{array}{l}\text { Consumers become an integral part of the electric power system. They help balance supply } \\
\text { and demand and support reliability by modifying the way they use and purchase electricity. } \\
\text { These modifications come as a result of consumers having choices that motivate different } \\
\text { purchasing patterns and behavior. These choices involve new technologies, new } \\
\text { information about consumers' electricity use, and new forms of electricity pricing and } \\
\text { incentives. }\end{array}$ \\
\hline $\begin{array}{l}\text { 2. Accommodate } \\
\text { s All } \\
\text { Generation \& } \\
\text { Storage } \\
\text { Options }\end{array}$ & $\begin{array}{l}\text { A smart grid accommodates not only large, centralized power plants, but also the growing } \\
\text { array of distributed energy resources (DER). DER integration will increase rapidly all along } \\
\text { the value chain, from suppliers to marketers to customers. Those distributed resources will } \\
\text { be diverse and widespread, including renewables, distributed generation and energy } \\
\text { storage. }\end{array}$ \\
\hline $\begin{array}{l}\text { 3. Enables New } \\
\text { Products, } \\
\text { Services, \& } \\
\text { Markets }\end{array}$ & $\begin{array}{l}\text { Markets that are correctly designed and operated efficiently reveal cost-benefit tradeoffs to } \\
\text { consumers by creating an opportunity for competing services to bid. A smart grid accounts } \\
\text { for all of the fundamental dynamics of the value/cost relationship. Some of the } \\
\text { independent grid variables that must be explicitly managed are energy, capacity, location, } \\
\text { time, rate of change, and quality. Markets can play a major role in the management of } \\
\text { these variables. Regulators, owners/operators, and consumers need the flexibility to modify } \\
\text { the rules of business to suit operating and market conditions. }\end{array}$ \\
\hline $\begin{array}{l}\text { 4. Provides } \\
\text { Power Quality } \\
\text { for the Range } \\
\text { of Needs }\end{array}$ & $\begin{array}{l}\text { Not all commercial enterprises, and certainly not all residential customers, need the same } \\
\text { quality of power. A smart grid supplies varying grades of power and supports variable } \\
\text { pricing accordingly. The cost of premium power quality (PQ) features can be included in the } \\
\text { electricity service contract. Advanced control methods monitor essential components, } \\
\text { enabling rapid diagnosis and precise solutions to PQ events, such as arise from lightning, } \\
\text { switching surges, line faults and harmonic sources. A smart grid also helps buffer the } \\
\text { electricity system from irregularities caused by consumer electronic loads. }\end{array}$ \\
\hline $\begin{array}{l}\text { 5. Optimizes } \\
\text { Asset } \\
\text { Utilization \& } \\
\text { Operating } \\
\text { Efficiency }\end{array}$ & $\begin{array}{l}\text { A smart grid applies the latest technologies to optimize the use of its assets. For example, } \\
\text { optimized capacity can be attainable with dynamic ratings, which allow assets to be used at } \\
\text { greater loads by continuously sensing and rating their capacities. Maintenance efficiency } \\
\text { involves attaining a reliable state of equipment or "optimized condition." This state is } \\
\text { attainable with condition-based maintenance, which signals the need for equipment } \\
\text { maintenance at precisely the right time. System-control devices can be adjusted to reduce } \\
\text { losses and eliminate congestion. Operating efficiency increases when selecting the least- } \\
\text { cost energy-delivery system available through these adjustments of system-control devices. }\end{array}$ \\
\hline $\begin{array}{l}\text { 6. Operates } \\
\text { Resiliently to } \\
\text { Disturbances, } \\
\text { Attacks, \& } \\
\text { Natural } \\
\text { Disasters }\end{array}$ & $\begin{array}{l}\text { Resilience refers to the ability of a system to react to events such that problematic elements } \\
\text { are isolated while the rest of the system is restored to normal operation. These self-healing } \\
\text { actions result in reduced interruption of service to consumers and help service providers } \\
\text { better manage the delivery infrastructure. A smart grid responds resiliently to attacks, } \\
\text { whether the result of natural disasters or organized by others. These threats include } \\
\text { physical attacks and cyber attacks. A smart grid addresses security from the outset, as a } \\
\text { requirement for all the elements, and ensures an integrated and balanced approach across } \\
\text { the system. }\end{array}$ \\
\hline
\end{tabular}

These characteristics of the Smart Grid will help reduce present and future issues

which impact the environment and cause major economic losses due to decreasing

efficiencies, decreasing power quality, and increasing blackouts. EPRI studies have

estimated that the cost due to outages for businesses in the US is between $\$ 104$ billion 
and $\$ 164$ billion a year, in addition to a $\$ 15$ billion to $\$ 24$ billion cost due to low power quality [4]. Rising peak demand requires new investment in generation and transmission capacity which is only made use of for a small fraction of a typical day, therefore decreasing efficiencies. The cost associated with these investments are increasing and the utilities are having a harder time keeping up with the demand which is causing vulnerability to blackouts to become more frequent.

Demand response and real-time pricing applications are part of the solution to mitigate the rising peak demand by allowing utilities to control consumer's smart appliances and changing the behavior of consumer's electricity consumption. In order for demand response and real-time pricing to occur and have a large effect, Smart Grid aspects like two-way communication need to be developed thoroughly. Another factor that will help decrease congestion and a rising peak demand is increased distributed generation (DG) and energy storage (ES). DG will reduce the need for larger centralized capacity investments and also increase efficiencies of power met at the end user by not having to be delivered over long congested transmission lines. ES can help shift the peak demand from utilities as well by buying cheaper generation at low demand and selling it during peak demand. ES will also play an important role in the ability to increase the penetration of intermittent renewable energy sources like wind and solar by smoothing out the power generated into the system. Again, in order for these applications to have a greater impact Smart Grid aspects like distribution automation need to be fully developed. Currently the distribution automation penetration is only $15 \%$ to $20 \%$ developed at the system feeder level [5]. Fig. 1.10 shows the important building blocks 
of the Smart Grid enabling critical technologies that will help create a sustainable energy future.

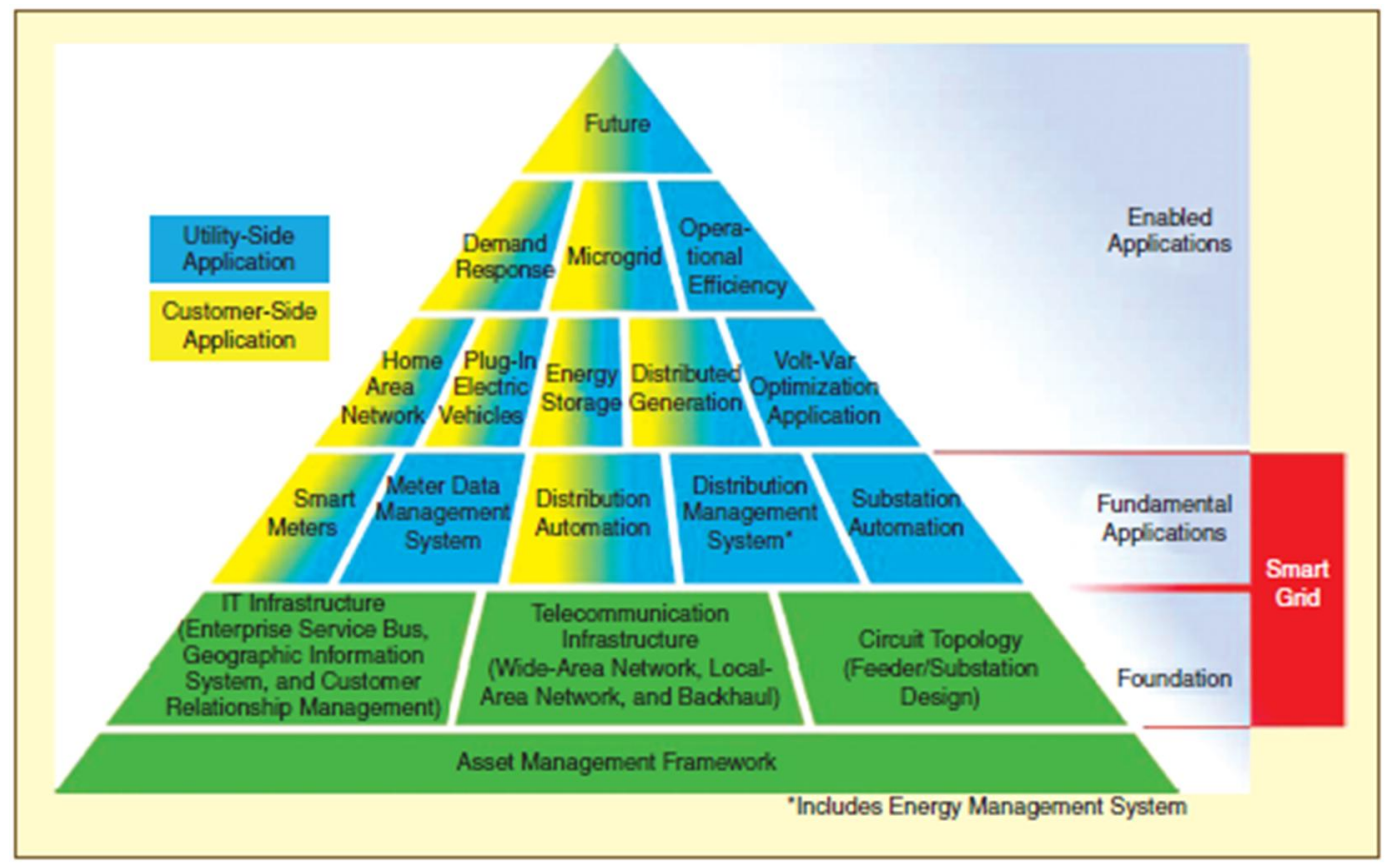

Fig. 1.10 Smart Grid Pyramid [5]

Creating the future grid system is no small task. It will involve efforts from multiple groups across a variety of sectors, long periods of time to smoothly transition into, and a large financial investment. Anywhere between $\$ 338$ billion and $\$ 476$ billion is needed in order to create what is envisioned to be the future grid, but the estimated benefit ranges from $\$ 1,294$ billion to $\$ 2,028$ billion [4]. Grid modernization is a national policy enacted by the Energy Independence and Security Act (EISA) of 2007 [6] and has been driven by the American Reinvestment and Recovery Act of 2009 and other policies such as RPS. 


\section{Microgrid}

The current structure of the electrical system is not fit to control and optimally utilize the promising technologies that will be enabled by the Smart Grid. Increasing use of DG technologies and demand response will create issues with protection, power quality, stability, and reliability due to the current passive distribution network [5], [7]. The use of intermittent sources, such as photovoltaic (PV) and wind energy conversion systems (WECS), will especially be an issue due to their high variability. As mentioned previously, ES will be an important tool to smooth out the variability of the intermittent sources. However, the ability to control DG, ES, and specific loads for demand response is just too overwhelming for the centralized nature of our current system. A concept that will not only allow for the hybridization of these technologies but fully utilize the benefits of them as well is the microgrid (MG). Defined by the Microgrid Exchange Group of the US DOE [8], "A microgrid is a group of interconnected loads and distributed energy resources within clearly defined electrical boundaries that acts as a single controllable entity with respect to the grid. A microgrid can connect and disconnect from the grid to enable it to operate in both grid-connected or island-mode."

Key benefits from the microgrid include increased efficiencies, increased reliability, decreased emissions, and the ability to provide ancillary services to the centralized grid, which are all driven by the main characteristics of a microgrid. In a microgrid, DG sources provide power close to where it is consumed, decreasing the amount of losses through transmission. If the DG sources produce useable waste heat, like fuel cells (FC) and internal combustion engines (ICE), then they can be strategically 
placed near thermal loads to make use of combined heat and power (CHP) practices further increasing efficiency and decreasing emissions. Fig. 1.11 shows a block diagram of a typical microgrid.

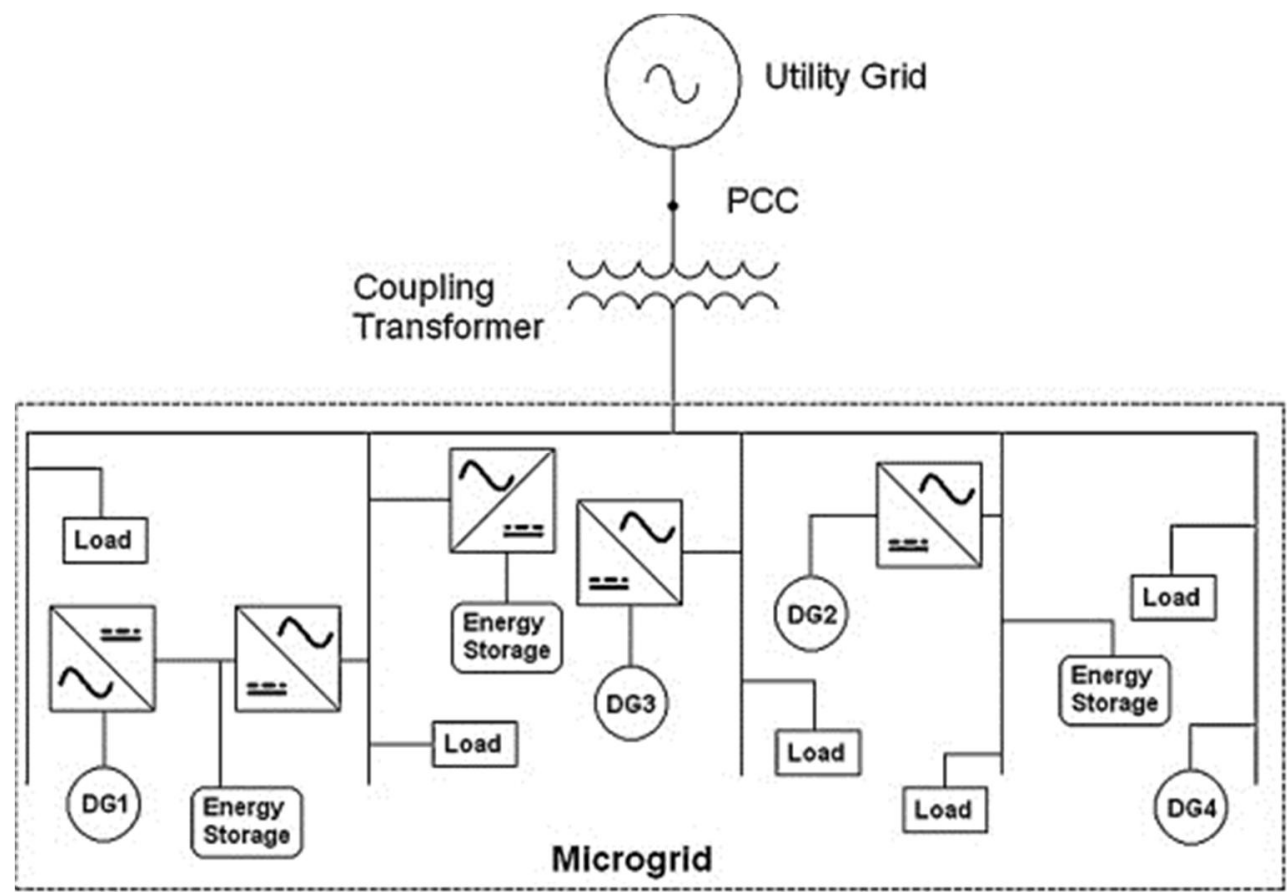

Fig. 1.11 Sample microgrid architecture [9]

One of the most important characteristics of a microgrid is the ability to operate in grid-connected or island-mode. When operating in grid-connected mode the microgrid is stabilized by the main grid. The loads can receive power from the main grid or provide ancillary services to the main grid such as voltage stability or excess power through the point of common coupling (PCC). If a fault or some other type of interruption occurs on the main grid system the microgrid is required to disconnect from the grid within 2 seconds and run in island-mode [10]. In island-mode it is up to the autonomous system to stabilize itself and provide enough power to meet the critical load demand. Once the 
main grid recovers from the disturbance both systems can then become reconnected. The ability to smoothly operate between the two modes can save businesses large sums of money by being able to still provide critical and/or normal services during outages on the main grid. At the residential level, customers would still have the ability to run their critical loads during outages, such as heating or cooling their homes on cold or hot days A major challenge of a microgrid is its design, which ranges from the technologies selected, to its control architecture, and to optimization objectives. Cost, emissions, reliability, and CHP capabilities are just some of the considerations that need to be taken into account when deciding which technologies to be selected and what their capacities will be in the microgrid system. Technology selection and unit sizing has been extensively covered in research to the point where there are software tools to help with this part of the design process, such as the original and commercial versions of $\operatorname{HOMER}^{\circledR}[11],[12]$ and DER-CAM ${ }^{\circledR}[13]$.

Whether the control architecture is centralized, distributed, or a hybrid of the two is another important decision for the designer to choose [14]. A centralized controller has the benefit of basing decisions off of all known information but also suffers from an increased computation time because of this. Another issue with a centralized controller, it is reliant on a single point of control. Meaning if the central controller fails, the entire system can become compromised. On the other hand, a centralized controller requires a less complex communication framework compared to a distributed controller. In distributed control architecture, local controllers of sources and loads communicate with each other in order to decide the overall operating condition. Distributed control is a 
solution to the reliability issue of the centralized control architecture on a single point. Perhaps the best system is a hybrid of the centralized and distributed control architectures which is shown in Fig. 1.12.

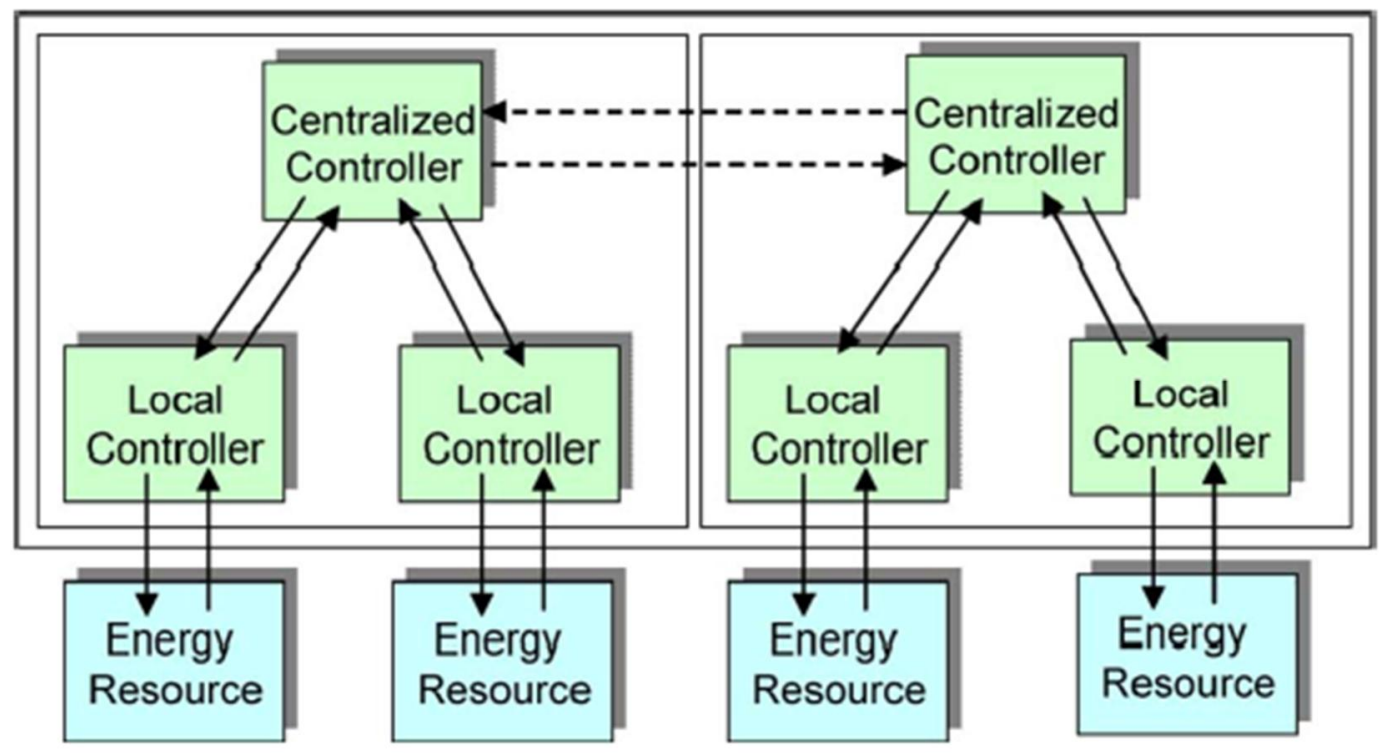

Fig. 1.12 Illustration of a hybrid centralized and distributed control paradigm [14]

In this scenario, groups of sources and loads within the microgrid are controlled centrally, but then the central controllers of the groups use distributed control amongst each other to decide the best operating condition. The hybrid architecture reduces computation time, is not fully reliable on a single point of communication, and is able to use more knowledge among a group of sources and loads to make a decision.

Considering the different optimization objectives is another important design process decision. Not only can multiple objectives be considered in the technology selection and unit sizing portion of the design process, but in the actual operation of the microgrid as well. Objectives such as minimizing cost and emissions, maximizing 
efficiency and power quality are just a few that users typically consider. The optimization process should be continuous and fast enough to satisfy the objectives of the customers optimally.

However, the operation of the microgrid should be consistent from the perspective of the larger grid to which it is connected, which is known as having good citizenship with the grid. Grid citizenship can be described as the way that an interconnected component interacts with the greater power system [15]. Grid citizenship is important for the planning and operation process of the main grid. Microgrids have the ability to be receivers of power one instance and then suppliers the next. This variability can be caused from intermittent sources of DER and also from the nature of the optimization objectives themselves. Therefore, taking into account the consistency of the microgrid's profile is another important part of the design process.

\section{Intelligent Real Time Multi-objective Optimization}

The design of a MG can include varying renewable energy sources, multiple ES technologies, and heating loads making the energy management system (EMS) of the MG very complex. With the addition of multiple objectives and the need to provide optimal energy delivery, the EMS should be run in real-time using a multi-objective optimization algorithm. Simply designing a MG based on yearly data and predetermining an EMS offline is not optimal and limits the options of the user when conditions can continuously change in matter of seconds. 
In [16] several engineering applications are listed using different types of intelligent multi-objective optimization methods including optimal planning of an electrical distribution system [17], power dispatch [18], and economic load dispatch [19]. These techniques have also been studied to use on EMS of factories [20] and optimal dispatch of DER in MG [21]. It was previously shown in [22] that particle swarm optimization (PSO) is a useful technique to perform real-time optimization of an EMS that contained a wind energy conversion system, a microturbine, and a battery. However, the optimization through the use of PSO in the EMS described in [22] was truly a single objective optimization.

\section{Modern Heuristics}

Modern heuristics have become a valuable tool in the effort of solving such a complex optimization problem in a timely manner. While modern heuristics do not guarantee an optimal solution they do provide a solution to complex non-linear problems that other methods cannot solve in a reasonable time frame or at all. These modern heuristics include evolutionary algorithms such as Genetic Algorithms (GA) and swarm based intelligence such as PSO.

In modern heuristics, a user typically selects one of the several different methods starting with the base of the algorithm and modifies it to solve a more specific optimization problem. Optimization problems are formulated as shown in Eq. (1.1).

$$
\begin{aligned}
& \text { minimze or maximize } z=f(x), \quad \text { subject to } \\
& \qquad \begin{array}{c}
g_{i}(x) \geq 0, \quad i \in\{1, \ldots, m\}, \\
h_{j}(x)=0, \quad j \in\{1, \ldots, p\},
\end{array}
\end{aligned}
$$


where $\mathrm{x}$ is a solution vector of the decision variables located in a search space, $\mathrm{X}, \mathrm{z}$ is the fitness function value determined by the objective function, $f(x)$, and $g_{i}$ and $h_{i}$ are the inequality and equality constraints, respectively. An important part of the optimization process is the use of both intensification and diversification throughout the search. Intensification helps find the optimal solution in an area of the search space while diversification makes sure the algorithm isn't trapped in a local optimum so that the global optimum is discovered. A global optimum for a minimization problem is defined as the solution $y \in X$ where $f(y) \leq f(x)$ for all $x \in X$. In order to understand the definition of a local optimum the concept of a neighborhood needs to be known. A neighborhood in an optimization problem describes how similar the solutions are to each other. Each particular solution $\mathrm{x} \in \mathrm{X}$ has a possible neighborhood of solutions $\mathrm{y} \in \mathrm{X}$ that are within some set distance, $\varepsilon$. The distances between solutions, $\mathrm{d}\left(\mathrm{x}_{1}, \mathrm{x}_{2}, \mathrm{x}_{3}, \ldots, \mathrm{x}_{\mathrm{n}}\right)$, can be calculated in many different ways. The Euclidean distance as shown in Eq. (1.2) is one common method.

$d\left(x_{1}, x_{2}, x_{3}, \ldots, x_{n}\right)=\sqrt{\left(x_{1}-y_{1}\right)^{2}+\left(x_{2}-y_{2}\right)^{2}+\left(x_{3}-y_{3}\right)^{2}+\cdots+\left(x_{n}-y_{n}\right)^{2}}$

It is important that the defined neighborhoods present similarities between solutions and that these similarities map well to the fitness landscape as well. With well modeled neighborhoods, local optimums can then be discovered. A local optimum is a solution $\mathrm{x}^{*}$ $\epsilon X$ where $f\left(x^{*}\right) \leq f(x)$ for every $x$ that exists in the neighborhood of $x^{*}, N\left(x^{*}\right)$.

\section{$\underline{\text { Particle Swarm Optimization }}$}

PSO started as an attempt at simulating the flight of a flock of birds and transformed into an optimization tool that started with its original version in [23], and 
progressed to a multi-objective version in [24], [25]. The original version has been improved by many different researchers in the field and has been modified by others to solve their more specific optimization problems. PSO relates to other swarm based intelligence optimization algorithms, such as Ant Colony Optimization (ACO), and evolutionary algorithms, such as GA, where the optimization process starts with an initial population of solutions and moves towards the optimal solution by updating new solution positions based on defined operators that intensify and diversify the search through several iterations until a certain criteria is met.

The original version of PSO starts with a randomly initiated population and updates its positions through a velocity vector that incorporates personal and global best positions. A personal best solution is the solution that represents the best fitness value that the individual particle has experienced. A global best solution is the solution that represents the best fitness value discovered by the collection of particles in the swarm. The following steps outline the original PSO process:

1. Initialize the positions and velocities of each particle in the swarm randomly.

2. Evaluate the fitness function of each particle.

3. Compare each particle's current fitness value with their personal best fitness value. If the current fitness value is better update the personal best fitness value and position, otherwise move to the next step. 
4. Compare each particle's current fitness value with the global best fitness value. If the current fitness value is better update the global best fitness value and position, otherwise move to the next step.

5. Calculate each particle's new position based on the new velocity vectors using Eq. (1.3), (1.4).

$$
\begin{gathered}
V_{i, d}=V_{i, d}+C_{1} * R_{1} *\left(P_{b e s t, i, d}-X_{i, d}\right)+C_{2} * R_{2} *\left(G_{b e s t, d}-X_{i, d}\right) \\
X_{i, d}=X_{i, d}+V_{i, d}
\end{gathered}
$$

The coefficients $\mathrm{C}_{1}$ and $\mathrm{C}_{2}$ are the social learning factors and were originally found to work best with a value of 2 but later work shows a constriction factor changes the values to 1.5 to help with convergence. The coefficients $R_{1}$ and $R_{2}$ are random numbers in the range of 0 to 1 . The velocity vector is also limited to a maximum value which has effects on the diversification and intensification of the search. A larger value allows for diversification while a smaller value intensifies the search.

6. Repeat from step 2 until the ending criterion has been met. The ending criterion is usually when a tolerance value has been met or when the number of generations reaches its max value.

The original version of PSO has been altered numerous times by the same original creators and others as well. One alteration is the use of a local best position instead of a global best. Each particle in the swarm has a defined neighborhood topologically and the local best solution for that one particle is the solution that represents the best fitness value 
within its neighbors. The steps of the original PSO process stay the same except that the global best is replaced with the local best.

Another important change was the addition of an inertia weight factor to the calculation of the velocity vector as shown in Eq. (1.5).

$$
V_{i, d}=w * V_{i, d}+C_{1} * R_{1} *\left(P_{b e s t, i, d}-X_{i, d}\right)+C_{2} * R_{2} *\left(G_{b e s t, d}-X_{i, d}\right)
$$

The weighting factor is another way to implement diversification and intensification in the optimization process. It can be changed throughout the process to control the varying degrees of diversification and intensification and eliminates the use of a maximum velocity vector value. With the maximum velocity vector value eliminated, constrictions on the decision variable ranges are used instead.

\section{$\underline{\text { Multi-objective Optimization }}$}

Multi-objective optimization problems (MOPs) involve a set of objective functions $\left(f_{1}(x), f_{2}(x), \ldots, f_{i}(x)\right)$ that either need to be minimized or maximized. A common way to solve MOPs is to create a single objective optimization function, $\mathrm{F}$, by summing the set of objective functions which are each multiplied by a weighting factor $\alpha_{\mathrm{n}}$ as in Eq. (1.6).

$$
F=\sum_{n=1}^{i} \alpha_{n} * f_{n}(x)
$$

The MOP is now solved like a single objective function and is very useful when the solution $\mathrm{x}$ is able to minimize or maximize all objectives in the set at once. However, this method is not reasonable when objectives will compete and are non-commensurate. 
The weighting factors will dictate the tradeoffs of the objective functions which is not desirable, especially when connections between objective functions are arbitrary.

In the case that a MOP has competing and non-commensurate objectives it is best to create a Pareto front of the viable solutions. A Pareto front is a collection of the nondominated solutions to the optimization problem and displays the true trade-offs between multiple objectives, as shown in Fig. 1.13 [26]. A non-dominated solution is one in which there is not another solution that is at least better in one objective while being just as good or better in the other objectives. Population based optimization techniques work well with this type of multi-objective optimization problem due to the simultaneous generation of multiple solutions.

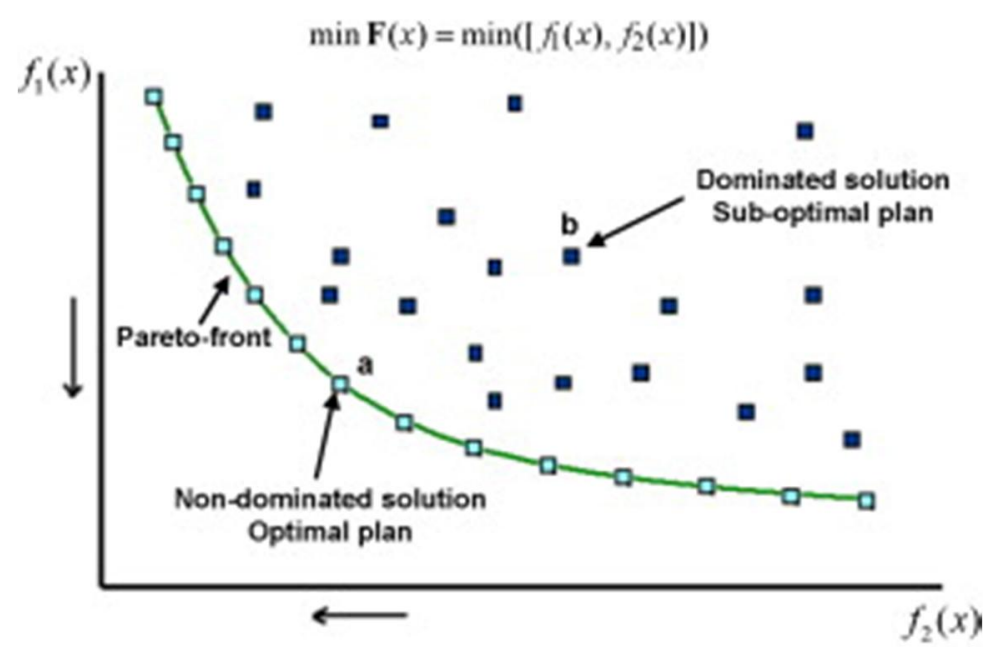

Fig. 1.13. Pareto front example [26].

The goal of multi-objective optimization techniques using Pareto optimality is not only to produce solutions faster but to produce solutions that cover the entire Pareto front uniformly and minimize the distance between solutions as well. 
Multi-objective Particle Swarm Optimization

When using PSO in multi-objective optimization problems, the same equations are used to update the particles as in the traditional case, however, since there is no true global or local optimum they need to be implemented differently. In [24] the neighborhood particles no longer stay fixed through the optimization process but change after each iteration instead. The dynamic neighborhood is determined by calculating the distances between each particle's first objective fitness value in the swarm and selecting the $\mathrm{N}$ closest particles. The local best solution is then selected by choosing the solution that has the best fitness value for the second objective function. The personal best solution is updated only if it dominates the previous personal best.

In [25] the dynamic neighborhood process included an extended memory which speeds up the process by including other possible Pareto optimal solutions other than the just the particles that dominate the current particle. Another modification in [27] is similar in that it uses hypercubes, called repositories, to select the local best solution from. This method improves the distribution of solutions among the Pareto front.

\section{Thesis Organization}

The research presented in this thesis focuses on the optimal energy management of a designed microgrid using a modified MOPSO algorithm. Chapter 2 presents the technology selection and unit sizing of the microgrid and a comparison of two different software programs that were used to aid the process. Chapter 3 presents the energy management of the designed microgrid detailing the optimization problem and 
modifications made to a MOPSO algorithm to produce a Pareto front of solutions to the optimization problem. Simulations were performed on the MATLAB/Simulink platform showing the energy management over a 24-hour period for four different cases. Chapter 4 concludes the thesis with recommendations for future work. 


\section{TECHNOLOGY SELECTION AND UNIT SIZING}

This chapter shows the use of two different publicly available software packages, The Hybrid Optimization Model for Electric Renewables (HOMER) [11] and Distributed Energy Resources Web Optimization Service (WebOpt) [13], [28] developed by National Renewable Energy Laboratory (NREL) and Lawrence Berkley National Laboratory (LBL), respectively. They are used to select and size the proper technologies for a microgrid with practical thermal and electrical loads. Through the design process, it is also desired to show the operation and benefits of each design tool. Real load data from a medium-sized college in San Francisco, CA, which is available through the WebOpt software, is used. This load is included in the California Commercial End-Use Survey (CEUS) [29].

Three different cases are used to justify the final design of the CHP microgrid. Since the two programs have different way of entering inputs and settings, a base case (Case A) was designed to show that these settings were implemented in a similar manner. In this case, the same types of technologies are chosen to be available by both programs. Two other cases are studied; one involves microgrid design with WebOpt alone (Case B) and one with HOMER alone (Case C). These two cases focus on the advantage of technologies that are not available in the other program. Also, within each of the two

cases $(B, C)$ two simulations are carried out, one with the original settings and price data and the other with adjusted settings and price data to justify the changes necessary to incorporate renewable and alternative technologies. 


\section{Brief Description of WebOpt and HOMER}

$\underline{\text { WebOpt }}$

The Distributed Energy Resources Web Optimization Service (WebOpt) is an optimization tool to minimize the cost or emissions for meeting electrical and thermal load demand of a microgrid based on a one-hour time step [13]. WebOpt is based on the Distributed Energy Resources Customer Adoption Model (DER-CAM), a mixed integer linear programing (MILP) tool, implemented on the General Algebraic Modeling System (GAMS) [30]. It is the free non-commercial web-accessible version and nothing needs to be installed on the local system. It is available from LBL. However, it does not contain all the features that the more advanced version, DER-CAM has, e.g. electric vehicle simulation option, stochastic programming, or 5-min time-step optimization, etc. nor does it show the mathematical DER-CAM model [31]. This thesis just focuses on the WebOpt interface and more information on the full DER-CAM version can be found in [13].

WebOpt helps to find the best combination and capacity of the different DER technologies available to meet the desired goals of the user. Constraints involved in the optimization process require that $100 \%$ of each end-use load is met (unless the demand response option is utilized) and the thermodynamics of the system are obeyed. It gives a schedule of operation for the different technologies in the results, as well. Table 2.1 summarizes inputs, outputs, and assumptions of WebOpt. 
Table 2.1 Inputs, Outputs, and Assumptions of WebOpt

\begin{tabular}{lll}
\hline \multicolumn{1}{c}{ Inputs } & \multicolumn{1}{c}{ Outputs } & \multicolumn{1}{c}{ Assumptions } \\
\hline $\begin{array}{l}\text { Load Profiles: space } \\
\text { heat, hot water, gas only, } \\
\text { cooling, and electricity } \\
\text { only. }\end{array}$ & $\begin{array}{l}\text { Optimal combination of } \\
\text { technologies and their } \\
\text { capacities. }\end{array}$ & $\begin{array}{l}\text { Decisions based on direct } \\
\text { economic criteria. }\end{array}$ \\
$\begin{array}{l}\text { Electricity and natural } \\
\text { gas tariffs and rates. }\end{array}$ & $\begin{array}{l}\text { Optimal operation schedule } \\
\text { of the technologies. }\end{array}$ & $\begin{array}{l}\text { Reliability and power quality } \\
\text { benefits are not directly taken } \\
\text { into account }\end{array}$ \\
$\begin{array}{l}\text { Capital and operation } \\
\text { and maintenance }(\mathrm{O} \& \mathrm{M}) \\
\text { technology costs. }\end{array}$ & $\begin{array}{l}\text { Cost data: total annual } \\
\text { energy costs, upfront and } \\
\text { annualized technology cost, }\end{array}$ & $\begin{array}{l}\text { No decrease in efficiency of } \\
\text { equipment over its lifetime. } \\
\text { Also, start-up and other } \\
\text { constraints are not included. }\end{array}$ \\
$\begin{array}{l}\text { Characteristics of } \\
\text { technologies: lifetime, } \\
\text { efficiency, recoverable } \\
\text { heat. }\end{array}$ & $\begin{array}{l}\text { Other: total energy, } \\
\text { emissions, utility electricity } \\
\text { and natural gas consumption, } \\
\text { specific technology }\end{array}$ & $\begin{array}{l}\text { Economies of scale in O\&M } \\
\text { costs for multiple units of the } \\
\text { same technology are not } \\
\text { production. }\end{array}$ \\
\hline
\end{tabular}

WebOpt (and DER-CAM) separates its technologies into two categories, continuous and discrete. Some available technologies are PV, fuel cell + heat exchanger (FC-HX), absorption chillers, batteries, internal combustion engine (ICE), etc. The discrete technologies can only be purchased in increments of the set capacity value, e.g. if the fuel cell capacity is set at $100 \mathrm{~kW}$, then the available capacity values would be 100 , 200, $300 \mathrm{~kW}$, etc. The continuous technologies' capacities can be any size, e.g. 110.5 kW. Table 2.2 summarizes the available technologies in WebOpt. 
Table 2.2 Available Technologies in WebOpt

\begin{tabular}{cc}
\hline \multicolumn{2}{c}{ Technologies Available } \\
\hline Continuous & Discrete \\
Electric Storage & Internal Combustion Engine (ICE) \\
Heat Storage & Gas Turbine (GT) \\
Flow Battery & Microturbine (MT) \\
Absorption Chillers & Fuel Cell (FC) \\
PV & ICE - Heat Exchanger (HX) \\
Solar Thermal & GT - HX \\
Air Source Heat Pump & MT - HX \\
Ground Source Heat Pump & FC - HX \\
\hline
\end{tabular}

Different settings selections and data input are implemented through a series of windows in the main interface of WebOpt. The first window labeled, overview/optimization settings, determines which optimization objective will be used, either cost or $\mathrm{CO}_{2}$ minimization, as well as the investment of DER to be considered in the simulation. The other windows are used to input the load data, utility rates, technology prices and characteristics, demand response parameters, hourly solar radiation data, and $\mathrm{CO}_{2}$ emissions from the conventional generators on the grid side.

Once the simulation has completed, the results are shown in the last window of the WebOpt program. The results contain optimal technology and capacity selection, annualized cost data, total fuel consumption, utility electricity and utility natural gas consumption, and $\mathrm{CO}_{2}$ emissions data. The results also show area plots of how all the different load profiles are met for the weekdays, weekends, and peak profiles for each month. 


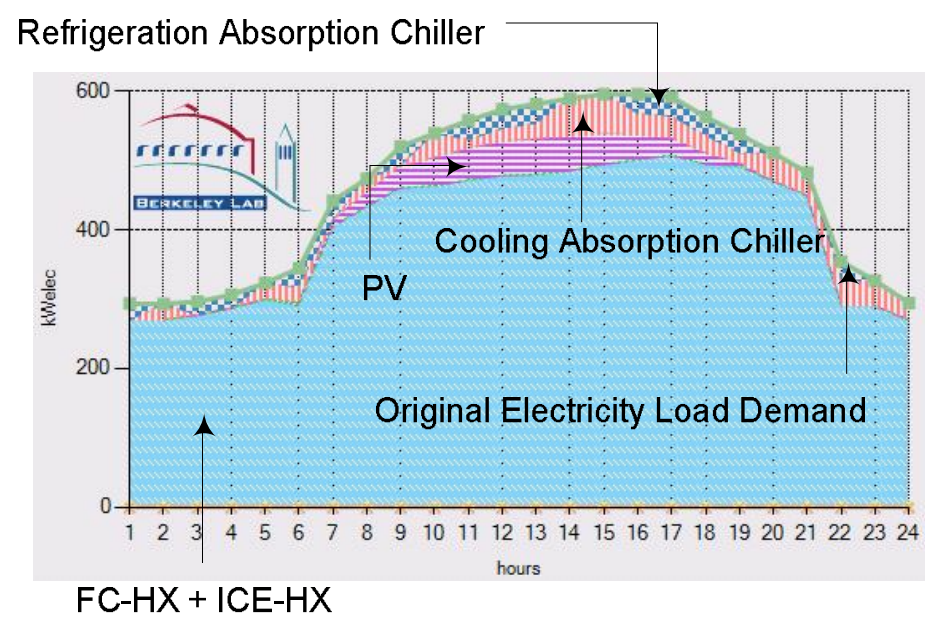

Fig. 2.1 WebOpt area plot example of a typical electrical load demand in summer, met by the different generation sources in a 24 hour period

Fig. 2.1 is an example of the WebOpt results area plot, where a demand profile and the operation period of the different available technologies are shown. This example shows the addition of the absorption chillers offsets some of the original electrical load demand by providing the necessary cooling through the generated waste heat.

\section{$\underline{\text { HOMER }}$}

The Hybrid Optimization Model for Electric Renewables (HOMER) software was originally developed at the National Renewable Energy Laboratory (NREL) and now a commercial version (which has been made available to the authors) has been developed by HOMER Energy, LCC. The results in this paper are solely from the free public version of HOMER, so that a fair comparison is made between this version and WebOpt. The HOMER energy modelling software is a tool for designing and analysing hybrid power systems, which can contain a variety of technologies. For either grid-tied or islanded-mode, HOMER helps determine how intermittent resources, such as wind and 
solar, can be optimally integrated into microgrids. The economic feasibility of a hybrid energy system and optimization of the system design are the ultimate goals in HOMER. It will help to mitigate the financial risk of a hybrid power system at the design process [11].

The model requires inputs such as technology options, component costs, and resource availability. The inputs are used to simulate different system configurations, and create a list of feasible configurations sorted by net present cost (NPC). HOMER is an hourly simulation model; it models system components, available energy resources, and loads on an hourly basis for one year. Energy flows and costs are assumed to be constant over any given hour. The user can enter in hourly data but HOMER can also synthesize hourly load resource data from monthly averages as well. Table 2.3 summarizes inputs, outputs, and assumptions of HOMER.

Table 2.3 Inputs, Outputs, and Assumptions of HOMER

\begin{tabular}{|c|c|c|}
\hline Inputs & Outputs & Assumptions \\
\hline $\begin{array}{l}\text { Load profiles: electrical and } \\
\text { thermal }\end{array}$ & $\begin{array}{l}\text { Optimal combination of } \\
\text { technologies and } \\
\text { capacities. }\end{array}$ & $\begin{array}{l}\text { Decisions based on } \\
\text { economic }\end{array}$ \\
\hline $\begin{array}{l}\text { Component quantities: } \\
\mathrm{kW} \text { ratings, thermal ratings, } \\
\text { and fuel ratings }\end{array}$ & $\begin{array}{l}\text { Sensitivity analysis, } \\
\text { thermal output, and fuel } \\
\text { consumption }\end{array}$ & $\begin{array}{l}\text { Energy flow is constant } \\
\text { over each hour of the } \\
\text { year }\end{array}$ \\
\hline $\begin{array}{l}\text { Component costs: cost per } \mathrm{kW} \text {, } \\
\text { replacement cost, } \\
\text { and operation } \\
\text { and maintenance cost }\end{array}$ & Net present cost analysis & $\begin{array}{l}\text { Analysis done over a } \\
\text { year }\end{array}$ \\
\hline $\begin{array}{l}\text { Characteristics of technologies: } \\
\text { lifetime, efficiency, recoverable } \\
\text { heat }\end{array}$ & $\begin{array}{l}\text { Effect of net present cost } \\
\text { calculation }\end{array}$ & - \\
\hline $\begin{array}{l}\text { Energy resources: solar, } \\
\text { diesel, natural gas, wind, } \\
\text { hydro }\end{array}$ & - & - \\
\hline
\end{tabular}


Technologies available in HOMER are PV, wind turbine generator, batteries, hydrogen storage, and generic generators. The generator technology could be an ICE, FC, microturbine, gas turbine, or another type of generator depending on its generator settings, i.e. the fuel source, efficiency, lifetime, etc. [11]. All of these technologies can be connected through a DC bus with a DC/AC converter or directly to an AC bus. Also, the considered capacities of the technologies are selected by the user. At first, the user enters a discrete range of technology capacities. After HOMER simulates all of the possible system configurations, it displays a list of feasible systems, sorted by lifecycle cost. At the top of the list is the least cost system [32]. Using a simple direct search method the user can find the near optimal scenario by narrowing the previously considered discrete range of capacities based on the previous simulation results. Table 2.4 summarizes the available technologies in HOMER.

Table 2.4 Available Technologies in HOMER

\begin{tabular}{c}
\hline Available Technologies \\
\hline PV \\
Wind Turbine \\
Hydro \\
Converter \\
Electrolyzer \\
Hydrogen Tank \\
Reformer \\
Battery \\
Generator \\
\hline
\end{tabular}

HOMER produces summary graphs and tables for each possible configuration displaying the system's cost summary, technology hourly output power, fuel consumption, etc. It also has the ability to export the raw hourly data so the results can 
be analysed by the user as needed. Fig. 2.2 is a sample area plot produced by the user in HOMER, where several technologies including ICE-HX, storage battery, PV, and FC-HX are used to supply the demand. The operation period of the different technologies are shown in the figure. When the PV power is greater than the load demand, the electrolyzer is run to produce hydrogen which is stored for later use by the FC.

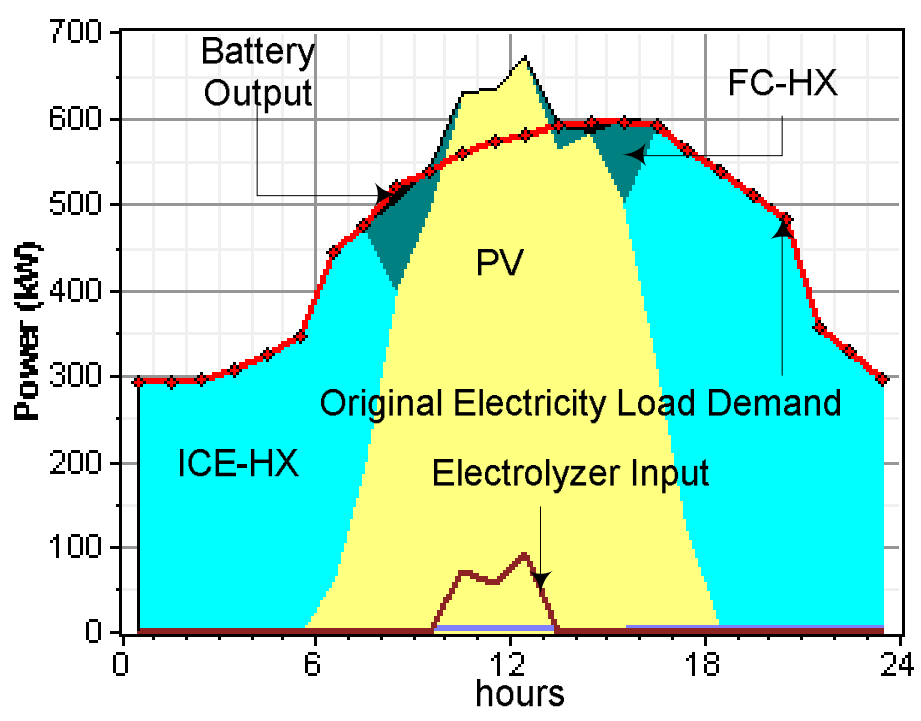

Fig. 2.2 Example of an area plot of the electrical load demand being met by the different generation sources over a 24 hour period from HOMER.

\section{$\underline{\text { Simulation Setup and Results }}$}

Different simulation cases were setup to compare the performance and show the unique qualities between the two software packages for designing a microgrid. Fig. 2.3 shows the load demand profile for a typical summer day of a medium-sized college in San Francisco, CA, which has been used in the two programs for technology selection. 


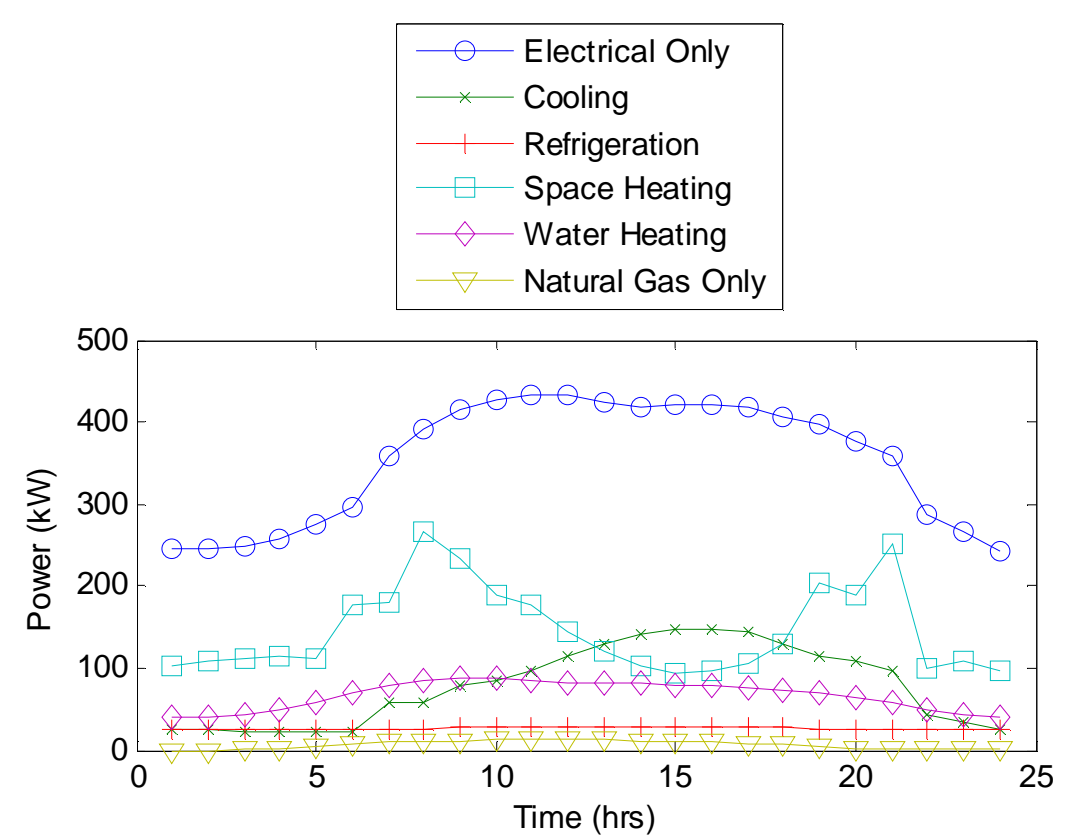

Fig. 2.3 Sample load demand profile for a typical summer day of a medium-sized college in San Francisco, CA.

The electrical only load consists of lighting, appliance, and other demands that can only be met by electricity. The cooling and refrigeration loads can be met by either electricity or generated waste heat through the use of absorption chillers. Space and hot water heating are met by either generated waste heat or natural gas. The natural gas only load is mainly demand from cooking. For WebOpt, each of these loads are input separately, but in HOMER the cooling and refrigeration loads were added to the electricity load since they can only be met through electricity and not generated waste heat. The space and water heating loads were combined along with the natural gas only load to create one thermal load in the system as well. The selected technologies, their capital and maintenance costs, lifetime, and efficiencies are given for each case. The 
results for each case contain the capacity size of each technology, total annualized cost, annual consumption and cost of fuel.

\section{Case A: Base Case}

This case was designed to show the inputs for the loads, prices, and other settings were implemented similarly for both programs. PV, battery, FC-HX, and ICE-HX are the selected technologies to be considered since the technologies needed to be available by both programs. Table 2.5 shows their capital cost, O\&M cost, efficiency, and lifetime inputs used for both application programs [33]-[35].

Table 2.5 Case A: WebOpt \& HOMER Technology Input Descriptions

\begin{tabular}{|c|c|c|c|c|}
\hline $\begin{array}{l}\text { Tech. } \\
\text { Selection }\end{array}$ & $\begin{array}{l}\text { Capital Cost } \\
(\$ / \mathrm{kW} \\
\$ / \mathrm{kWh} \text { for } \\
\text { Battery) }\end{array}$ & $\begin{array}{l}\text { Annual O\&M } \\
\text { Cost } \\
(\$ / \mathrm{kW}, \$ / \mathrm{kWh} \\
\text { for Battery, FC, } \\
\text { ICE) }\end{array}$ & $\begin{array}{l}{ }^{\mathrm{d}} \text { Elec. Eff. (\%)/ CHP } \\
\text { Eff. }(\%) / \text { Recov. Heat } \\
(\mathrm{kW} / \mathrm{kW})\end{array}$ & $\begin{array}{l}{ }^{\mathrm{e}} \text { Lifetime } \\
\text { (Years/ } \\
\text { Hours of } \\
\text { Use) }\end{array}$ \\
\hline $\mathrm{PV}^{\mathrm{a}}$ & 5000 & 18.00 & & 20 \\
\hline Battery $^{b}$ & 139 & 9.26 & 85 & 6 \\
\hline $\mathrm{FC}-\mathrm{HX}^{\mathrm{c}}$ & 4500 & 0.03 & $40 / 70 / 1.0$ & $10 / 160,000$ \\
\hline ICE-HX ${ }^{\mathrm{c}}$ & 1200 & 0.01 & $40 / 75 / 1.25$ & $20 / 40,000$ \\
\hline \multicolumn{5}{|c|}{$\begin{array}{l}{ }^{\mathrm{a}} \mathrm{PV} \text { data was obtained from NREL [33], }{ }^{\mathrm{b}} \text { Battery data was obtained from DOE [34], } \\
{ }^{\mathrm{c}} \mathrm{FC}-\mathrm{HX} \text { and ICE-HX data was obtained from [35]. }{ }^{\mathrm{d}} \text { In HOMER, CHP efficiency is a } \\
\text { percent and in WebOpt it is recoverable heat in kW per electrical output in kW. } \\
\text { e }{ }^{\mathrm{L}} \mathrm{kifetime} \text { in WebOpt is in years for FC-HX and ICE-HX, whereas in HOMER it is in } \\
\text { hours of use. }\end{array}$} \\
\hline
\end{tabular}

Two issues with WebOpt, no islanded mode of operation and the consideration of all the natural gas-based DER technologies at once, needed to be resolved. This was done by setting the utility electricity rates and the unwanted DER technologies' prices to the highest possible input value to deter the program from purchasing electricity from the 
utility and selecting the undesirable technologies. Since WebOpt only considers natural gas as a fuel source and its unit price is set in $\$ / \mathrm{kWh}$, HOMER is also set to only consider natural gas as the fuel source and the unit price is converted from $\$ / \mathrm{kWh}$ to $\$ / \mathrm{m}^{3}$ to be applicable in HOMER. The natural gas rates used are $0.04 \$ / \mathrm{kWh}$ and $0.395 \$ / \mathrm{m}^{3}$, for WebOpt and HOMER, respectively. This natural gas rate is grabbed from the WebOpt software. The project lifetime is set to 25 years.

As noticed from Table 2.6, similar results are obtained from both programs in Case A. The results show that the ICE-HX is the main technology selected to meet the load demands for both WebOpt and HOMER, where the proposed capacities are $650 \mathrm{~kW}$ and $625 \mathrm{~kW}$, respectively. It can be noticed from the results that $0.1 \mathrm{~kW}$ of PV generation is recommended by WebOpt, while it is zero in the case of HOMER. The 0.1 $\mathrm{kW}$ difference is negligible compared to the total generation capacity of the hybrid system. Since there is a small investment in PV, this could be one reason why there is a small discrepancy in invested battery capacity between the two programs as well. Also, similar total annualized cost, total fuel consumption, and total fuel cost are shown. The results between the two programs do not show any glaring differences, justifying the inputs and settings were implemented in a similar manner. 
Table 2.6 Case A: WebOpt \& HOMER Results

\begin{tabular}{lll}
\hline & WebOpt & HOMER \\
\hline Tech. Selection & \multicolumn{2}{l}{ Size $(\mathrm{kW}, \mathrm{kWh}$ for Battery) } \\
PV & 0.1 & 0.0 \\
Battery & 19.3 & 8.64 \\
FC- HX & 0.0 & 0.0 \\
ICE-HX & 650 & 625 \\
\hline Total Ann. Cost (\$/yr) & 484,664 & 518,578 \\
Total Fuel Con. $(\mathrm{kWh} / \mathrm{yr})$ & $9,464,385$ & $9,832,548$ \\
Fuel Cost $(\$ / \mathrm{yr})$ & 378,575 & 393,302 \\
\hline
\end{tabular}

\section{Case B: WebOpt Only}

This case only involved WebOpt as the program for the microgrid design. The same settings are used as in Case A, plus the addition of the cooling and refrigeration absorption chillers. The absorption chillers improve the efficiency of the system through use of waste heat to serve the cooling and refrigeration loads, instead of increasing electrical generation with the use of more fuel. Two scenarios are performed, one with normal prices as in Case A, and another with adjusted prices and settings so that the optimal design included all the technologies considered. Table 2.7 shows the setting details of both scenarios. Results of the technologies and capacities selected by WebOpt for both scenarios are given in Table 2.8. 
Table 2.7 Case B: WebOpt Technology Input Descriptions

\begin{tabular}{|c|c|c|c|c|c|}
\hline & $\begin{array}{l}\text { Tech. } \\
\text { Selection }\end{array}$ & $\begin{array}{l}\text { Capital Cost } \\
\text { (\$/kW, } \\
\$ / k W h \text { for } \\
\text { Battery) }\end{array}$ & $\begin{array}{l}\text { Annual O\&M Cost } \\
\text { (\$/kW, \$/kWh for } \\
\text { Battery, FC, ICE) }\end{array}$ & $\begin{array}{l}\text { Elec. Eff. (\%)/ } \\
\text { Recov. Heat } \\
(\mathrm{kW} / \mathrm{kW})\end{array}$ & $\begin{array}{l}\text { Lifetime } \\
\text { (Years) }\end{array}$ \\
\hline \multirow{6}{*}{ 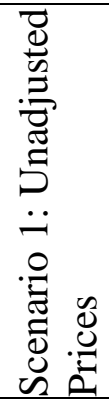 } & PV & 5000 & 18.0 & & 20 \\
\hline & Battery & 139 & 9.26 & 85 & 6 \\
\hline & FC-HX & 4500 & 0.03 & $40 / 1.0$ & 10 \\
\hline & $\begin{array}{l}\text { Abs. Chil. } \\
\text { Refrig. }{ }^{f}\end{array}$ & 831 & 0.00 & & 20 \\
\hline & $\begin{array}{l}\text { Abs. Chil. } \\
\text { Cooling }\end{array}$ & 831 & 0.00 & & 20 \\
\hline & ICE-HX & 1200 & 0.01 & $40 / 1.25$ & 20 \\
\hline \multirow{6}{*}{ 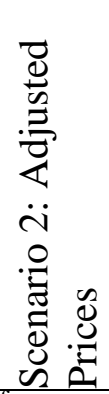 } & PV & 2750 & 18.0 & & 20 \\
\hline & Battery & 75 & 2.40 & 85 & 10 \\
\hline & FC-HX & 1200 & 0.02 & $40 / 1.0$ & 10 \\
\hline & $\begin{array}{l}\text { Abs. Chil. } \\
\text { Refrig. }\end{array}$ & 831 & 0.00 & & 20 \\
\hline & $\begin{array}{l}\text { Abs. Chil. } \\
\text { Cooling }\end{array}$ & 831 & 0.00 & & 20 \\
\hline & ICE-HX & 1200 & 0.02 & $35 / 1.25$ & 20 \\
\hline
\end{tabular}

${ }^{\mathrm{f}}$ Abosrption chiller data was obtained from SMUD [36].

Table 2.8 Case B: WebOpt Only Results

\begin{tabular}{lll}
\hline & $\begin{array}{l}\text { Scenario 1: } \\
\text { Unadjusted Prices }\end{array}$ & $\begin{array}{l}\text { Scenario 2: } \\
\text { Adjusted Prices }\end{array}$ \\
\hline Technologies Considered & \multicolumn{2}{c}{ Size $(\mathrm{kW}, \mathrm{kWh}$ for Battery) } \\
PV & 0.0 & 39.6 \\
Battery & 0.0 & 41.7 \\
FC-HX & 0.0 & 280 \\
Absorption Chiller Ref. & 27.2 & 27.2 \\
Absorption Chiller Cooling & 82.2 & 68.0 \\
ICE-HX & 580 & 300 \\
Util. Elec. Con. $(\mathrm{kWh} / \mathrm{a})^{\mathrm{g}}$ & 145 & 109 \\
\hline Total Annualized Cost $(\$ / \mathrm{yr})$ & 475,061 & 553,170 \\
Total Fuel Con. $(\mathrm{kWh} / \mathrm{yr})$ & $8,930,624$ & $9,453,594$ \\
Fuel Cost $(\$ / \mathrm{yr})$ & 357,225 & 378,144 \\
\hline
\end{tabular}

${ }^{g}$ Since WebOpt cannot limit the microgrid to islanded mode there can still be a little amount of utility electricity consumption even though the rates are maxed out, due to the constraint of the load being met $100 \%$. 
Case B (the WebOpt only simulations) shows major changes to the price of technologies are needed in order to incorporate the desired technologies. For Scenario 1, as in Case A, the major generation source is the ICE-HX which is rated at $580 \mathrm{~kW}$. However, compared to WebOpt in Case A, the capacity is reduced by $70 \mathrm{~kW}$ because of the added absorption chillers which is offsetting parts of the electrical load used for refrigeration and cooling. The absorption chillers are rated at $27.2 \mathrm{~kW}$ (for refrigeration) and $82.2 \mathrm{~kW}$ (for cooling). None of the other technologies were selected; which is due to the high cost of PV and FC-HX.

In order to have the FC-HX and PV as competitive technologies, their prices were reduced in Scenario 2. The price of the FC-HX is reduced to that of the ICE-HX, along with a decrease in efficiency for the ICE-HX. Also, the PV and battery capital costs are reduced to $55 \%$ and $54 \%$, respectively, of their original prices. The battery O\&M cost was also reduced, along with an increase in its lifetime. With the new prices and settings, WebOpt selected a good combination of the FC-HX and ICE-HX, $280 \mathrm{~kW}$ and $300 \mathrm{~kW}$, respectively. Also, the recommended capacities of the PV and batteries are practical at $39.6 \mathrm{~kW}$ and $41.7 \mathrm{kWh}$, respectively.

These adjustments, which resulted in the selection of additional technologies, had an effect on the cooling absorption chiller capacity, reducing it to $83 \%$ of its recommended capacity in Scenario 1. The refrigeration absorption chiller capacity remained the same. However, even though the results from Scenario 2 present a desirable combination of different technologies, it is achieved with significant price reduction of renewable technologies. 


\section{Case C: HOMER Only}

Case $\mathrm{C}$ only deals with HOMER as the tool for the microgrid design. As in Case B, two scenarios are carried out to show the required modifications in prices and settings to create a microgrid that included all of the desired technologies. In Scenario 3 the same settings are used as in Case A, with the added technologies, an electrolyzer and a hydrogen tank, to incorporate another option for energy storage.

Scenario 4 includes a minimum renewable fraction setting of $20 \%$ so that the technology price data does not need to be changed drastically, as it was in Case B with WebOpt. This setting simply means that the final design will include at least $20 \%$ renewable generation regardless of the renewable technology price. Table 2.9 shows the settings of the scenarios.

Table 2.9 Case C: HOMER Technology Input Descriptions

\begin{tabular}{|c|c|c|c|c|c|}
\hline & $\begin{array}{l}\text { Tech } \\
\text { Selection }\end{array}$ & $\begin{array}{l}\text { Capital Cost } \\
\text { (\$/kW, \$/kWh for } \\
\text { Battery, \$/kg for } \\
\mathrm{H}_{2} \text { Tank) }\end{array}$ & $\begin{array}{l}\text { Annual O\&M Cost } \\
\text { (\$/kW or } \$ / k W h \text { for } \\
\text { Battery, FC, ICE) }\end{array}$ & $\begin{array}{l}\text { Elec. } \\
\text { Eff./ } \\
\text { CHP Eff. } \\
(\%)\end{array}$ & $\begin{array}{l}\text { Lifetime } \\
\text { (Years, Hours } \\
\text { of Use) }\end{array}$ \\
\hline \multirow{6}{*}{ 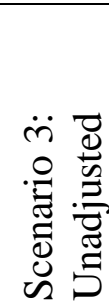 } & PV & 5000 & 18.0 & & 20 \\
\hline & Battery & 139 & 9.26 & 85 & 6 \\
\hline & FC-HX & 4500 & 0.03 & $40 / 70$ & 40,000 \\
\hline & ICE-HX & 1200 & 0.01 & $35 / 75$ & 160,000 \\
\hline & Elect. $^{\mathrm{h}}$ & 1000 & 0.00 & 80 & 15 \\
\hline & $\mathrm{H}_{2}$ Tank $^{\mathrm{i}}$ & 650 & 0.00 & & 25 \\
\hline \multirow{6}{*}{ 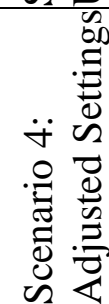 } & $\mathrm{PV}$ & 5000 & 18.0 & & 20 \\
\hline & Battery & 278 & 9.26 & 85 & 6 \\
\hline & FC-HX & 4500 & 0.03 & $40 / 70$ & 40,000 \\
\hline & ICE-HX & 1200 & 0.01 & $35 / 75$ & 160,000 \\
\hline & Elect. & 1000 & 0.00 & 80 & 15 \\
\hline & $\mathrm{H}_{2}$ Tank & 650 & 0.00 & & 25 \\
\hline
\end{tabular}

The electrolyzer data is from [37], ${ }^{\mathrm{i}}$ and the hydrogen tank data from [38]. 
In Scenario 4, the battery price is the only technology price adjusted and it is $100 \%$ more than the original price. This is done to limit the amount of capacity purchased so that hydrogen storage was invested in as well. Table 2.10 displays the results of both scenarios.

Table 2.10 Case C: HOMER Only Results

\begin{tabular}{lll}
\hline & $\begin{array}{l}\text { Scenario 3: } \\
\text { Unadjusted Settings }\end{array}$ & $\begin{array}{c}\text { Scenario 4: } \\
\text { Adjusted Settings }\end{array}$ \\
\hline Tech Selection & Size $(\mathrm{kW}, \mathrm{kWh}$ for & Battery, kg for $\mathrm{H}_{2}$ Tank $)$ \\
PV & 0.0 & 700 \\
Battery & 8.64 & 43.2 \\
FC-HX & 0.0 & 100 \\
ICE-HX & 625 & 600 \\
Electrolyzer & 0.0 & 100 \\
Hydrogen Tank & 0.0 & 50 \\
\hline Total Annualized Cost $(\$ / y r)$ & 518,578 & 773,148 \\
Total Fuel Con. (kWh/yr) & $9,832,548$ & $7,504,883$ \\
Fuel Cost (\$/yr) & 393,302 & 300,196 \\
\hline
\end{tabular}

Case C (where only HOMER was used) shows, as in Case B, that changes needed to be made in order to create a microgrid that incorporates the desired renewable technologies. In Scenario 3, with just the addition of the desired technologies, the exact same results are obtained as in the HOMER simulation in Case A (Tables 2.10, 2.6). The results of Scenario 4 show a significant increase in the PV capacity, from zero to $700 \mathrm{~kW}$. The proposed hydrogen storage system in the structure includes a $50 \mathrm{~kg} \mathrm{H} 2$ tank, $100 \mathrm{~kW}$ electrolyzer, and $100 \mathrm{~kW}$ FC-HX. The battery capacity also increased even though the price was increased by $100 \%$; this is because of the large investment in PV. Including the renewable fraction constraint in the simulation limited the required price changes, and 
as a result of the major investment in the renewable technologies, the cost of the whole system is increased in Scenario 4 compared to all the other scenarios.

\section{Discussion}

Through the comparison of the results obtained from the two software packages, it is noted that WebOpt is found valuable for its use with CHP strategies and HOMER is valuable for its additional setting options, like the minimum renewable fraction and islanded operation. WebOpt's ability to enter in electrical, heating, and cooling loads separately and the included availability of absorption chillers enhances the use of CHP applications. The results show that adding the consideration of the absorption chiller technologies alone decreases the total annualized cost and fuel consumption of the system. WebOpt is also able to find the true optimal technology selection and size for the system's settings, without relying upon the user. Unfortunately, at the present time major changes in the pricing of the technology is required in order to increase the amount of renewable generation. Also for WebOpt, utility rates and some technology costs need to be maxed in order to deter the program from considering them.

HOMER's inclusion of a minimum renewable energy fraction setting allows for a larger investment in renewable technologies without drastically decreasing the price of those technologies. HOMER has the ability to consider an islanded microgrid and include CHP strategies, but for heating loads only. It can also consider each technology individually, whereas WebOpt does not have this feature, but it is included in its upgraded version, DER-CAM. HOMER, while providing the least cost system out of all 
the different considered configurations, it is a simulation tool which relies upon the user to find the near-optimal system configuration. Since it only takes specific capacities (not a continuous capacity range) entered by the user, there could be a more optimal capacity that is not being considered.

\section{$\underline{\text { Simulink Model of Final Microgrid Design }}$}

The final microgrid design chosen to perform real-time energy management on was Scenario for in Case C. The sizing and technologies selected are summarized in Table 2.10. The heating load is supplied by a boiler that uses natural gas. This design was selected due to the good mix of renewable technologies and energy storage while being able to keep the realistic pricing of the technologies. A block diagram of the microgrid is shown in Fig. 2.4.

This microgrid design was modeled in Matlab/Simulink where the real-time energy management process is to be simulated. The modeling in [39] of the FC, PV, electrolyzer, hydrogen storage system, and proper power electronics was obtained and used in this research. The sizing of each system was adjusted to the results of the final microgrid design. Modeling of the heat exchanger for the FC system was done by using the system designed in [40]. The modeling of the ICE and battery was done by using the diesel generator system and battery, respectively, in the SimPower Systems Toolbox of Matlab. The waste heat produced by the ICE was a simple calculation using the heat to electrical power ratio. Due to long simulation times because of the power electronic systems in the model, the PV power was simulated beforehand, since the PV power was 
going to be used the same in every simulation. The PV power data was saved and then implemented as a negative load on the system.

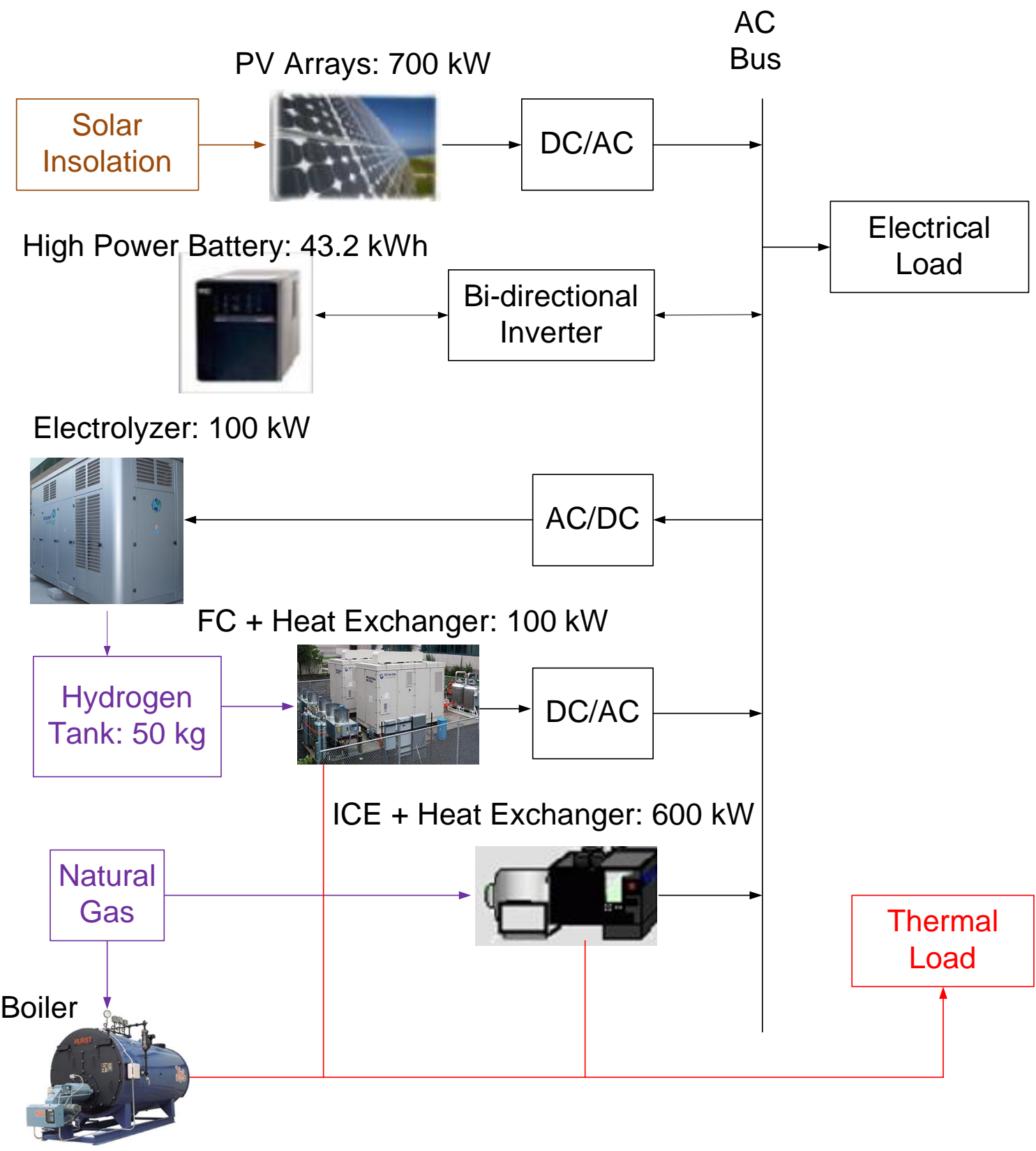

Fig. 2.4 Block diagram of the designed AC-coupled microgrid. The microgrid meets electrical demand through PV, FC, ICE, and Battery sources. The thermal load is met through waste heat from the FC and ICE and the heat generated by the boiler. 


\section{ENERGY MANAGEMENT OF MICROGRID}

\section{Formulation of Optimization Problem}

The multi-objective energy management problem of the designed MG, shown in Fig 2.4 with given technology sizes, contains two non-commensurate competing objectives, cost and emissions. These objectives are subject to four decision variables, the power operating points of each energy source in the MG. Each decision variable has a constraint depending on the state of operation. This section details the two objective functions and the constraints of the energy management system.

\section{Cost Objective Function}

The cost objective function depends on the cost of five different energy sources as show in Eq. (3.1)

$$
\text { Cost }=C_{E}+C_{F C}+C_{B a t t}+C_{I C E}+C_{B}
$$

where $\mathrm{C}_{\mathrm{E}}, \mathrm{C}_{\mathrm{FC}}, \mathrm{C}_{\mathrm{Batt}}, \mathrm{C}_{\mathrm{ICE}}$, and $\mathrm{C}_{\mathrm{B}}$ are the total cost per optimization time step of the electrolyzer, fuel cell, battery, internal combustion engine, and boiler, respectively. The cost of the PV is not included in the optimization problem because the PV power profile is the same for each case evaluated, and in each case the PV power is used whenever it is available.

The cost of each energy source is calculated based on a combination of lifetime cost, operations and maintenance cost, and fuel cost as shown in Eq. (3.2)-(3.6).

$$
\begin{aligned}
& C_{E}=\left(C_{L T, E}+C_{O \& M, E} * P_{E}\right) * t_{o n, E} \\
& C_{F C}=\left(C_{L T, F C}+C_{O \& M, F C} * P_{F C}+C_{f u e l, F C}\right) * t_{o n, F C}
\end{aligned}
$$




$$
\begin{aligned}
& C_{\text {Batt }}=C_{b f} *\left(C_{L T, B a t t}+C_{O \& M, B a t t}\right) * P_{\text {Batt }} * t_{\text {on,Batt }} \\
& C_{I C E}=\left(C_{L T, I C E}+\left(C_{O \& M, I C E}+C_{f u e l, I C E}\right) * P_{I C E}\right) * t_{\text {on }, I C E} \\
& C_{B}=C_{f u e l, B} * Q_{B} * t_{\text {on, },}
\end{aligned}
$$

where $C_{L T}$ is the lifetime cost, $C_{O \& M}$ is the operations and maintenance cost, $C_{\text {fuel }}$ is the fuel cost, $\mathrm{P}$ is the operating power of the energy source, $\mathrm{Q}_{\mathrm{B}}$ is the heat generated by the boiler, $\mathrm{C}_{\mathrm{bf}}$ is an arbitrary cost factor depending on the battery state of charge, and $\mathrm{t}_{\mathrm{on}}$ is the duration of the optimization time step for when the energy source is being used. The lifetime cost is calculated the same for the electrolyzer, FC, and ICE as shown in Eq. (3.7), and the battery lifetime is calculated as in Eq. (3.8).

$$
\begin{gathered}
C_{L T, i}=\frac{C_{\text {capital }} * \text { Capacity Size }}{L T} \\
C_{L T, B a t t}=\frac{C_{\text {Capital }} * \# \text { of Units }}{T P}
\end{gathered}
$$

where LT is the lifetime, $\mathrm{C}_{\text {Capital }}$ is the capital cost, and TP is the throughput (the total amount of energy the battery can provide in its life time in $\mathrm{kWh}$ ).

The fuel cost for the ICE and the boiler are based on their consumption of natural gas and calculated as show in Eq. (3.9) but the fuel used for the FC is hydrogen and its consumption is based on the operating current, $\mathrm{I}_{\mathrm{FC}}$, as in Eq. (3.10).

$$
\begin{aligned}
& C_{f u e l, i}=F C R * \text { Fuel Price } \\
& C_{f u e l, F C}=\frac{I_{F C} * N_{c} * N_{s} * M_{H_{2}} * H_{2} \text { Price }}{2 * F C * F U}
\end{aligned}
$$

where FCR is the fuel consumption ratio in $\mathrm{m}^{3} / \mathrm{s} / \mathrm{W}, \mathrm{N}_{\mathrm{c}}$ is the number of cells in the FC stack, $\mathrm{N}_{\mathrm{s}}$ is the number of FC stacks, $\mathrm{M}_{\mathrm{H} 2}$ is the molar mass of hydrogen, $\mathrm{FC}$ is Faraday's constant, and FU is the fuel utilization ratio. The fuel cell current is taken from the 
power vs. current curve, shown in Fig. 3.1, using the lookup function in Matlab. The curve was produced using the same FC modeled for the simulations by using a ramp power load from zero up to its rated power of $100 \mathrm{~kW}$ and recording the FC current at the same time.

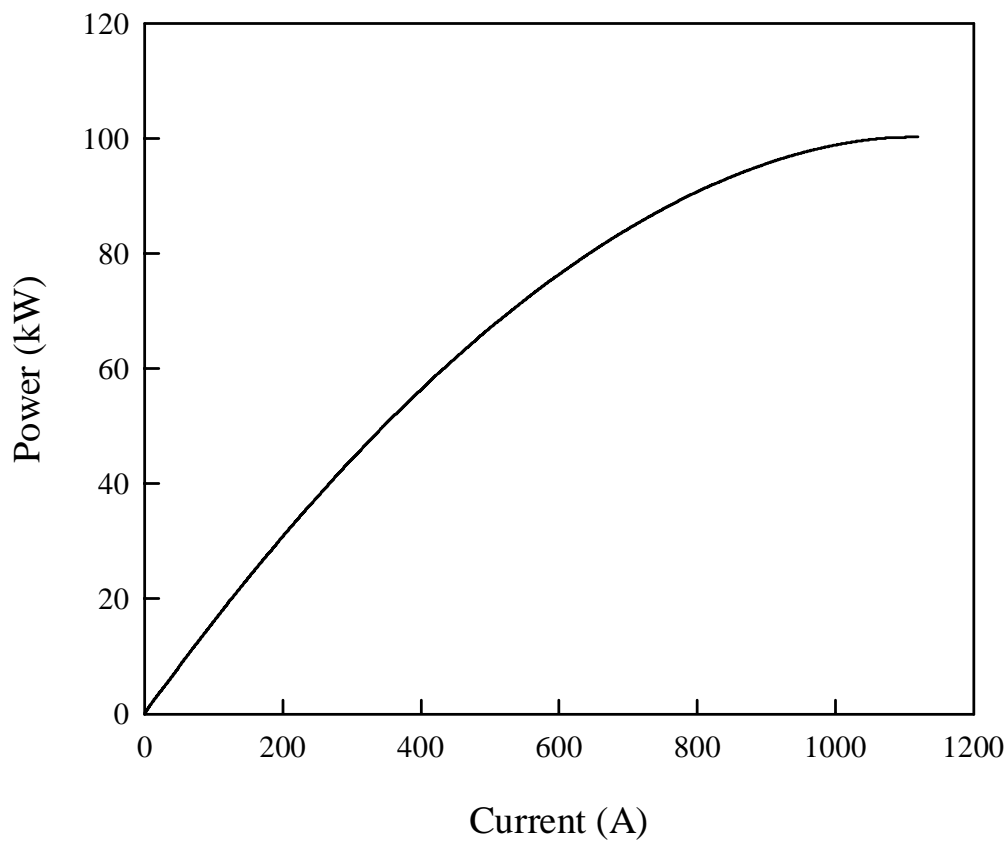

Fig. 3.1 Fuel cell power versus load current characteristic.

The battery cost also has an arbitrary cost factor assigned to it based on its current state of charge in order to reflect its cost characteristics closer to its true behavior. The goal is to reflect higher costs when the battery is in a low state of charge since it negatively affects the battery life when a battery sits at a low state of charge or is discharged further at a low state of charge [41]. Three different scenarios have a cost factor defined over the state of charge operating range of the battery, $30 \%-100 \%$. The 
first scenario is when power is being demanded and the battery is chosen to discharge.

Eq. (3.11) shows how the cost factor is defined for this scenario and Fig. 3.2 (a) shows a plot of Eq. (3.11) over the state of charge operating range.

$$
C_{b f}=1+\exp \left(\left(\frac{25}{S o C}-1\right) * 7\right)
$$

The plot shows the battery cost is increased when it is demanded to discharge at a low state of charge. The next scenario is when power is being demanded and the battery is chosen to charge. Eq. (3.12) shows how the cost factor is defined for this scenario and Fig. 3.2 (b) shows a plot of Eq. (3.12) over the state of charge operating range.

$$
C_{b f}=-\frac{\exp \left(\left(\frac{25}{S o C}-1\right) * 7\right)}{5}
$$

The plot shows for this scenario that the cost factor is negative and increases in magnitude for when the battery is in a lower state of charge. This is done to allow for the scenario when other generation sources are chosen to produce more power than what is being demanded in order to charge the battery. When the battery is in a lower state of charge there is a larger benefit to charging the battery in this scenario. The last scenario is when power is available and the battery is chosen to charge. Eq. (3.13) shows how the cost factor is defined for this scenario and Fig. 3.2 (b) shows a plot of Eq. (3.13), except that the data is plotted in reverse order, over the state of charge operating range.

$$
C_{b f}=\frac{\exp \left(\left(\frac{25}{S o C}-1\right) * 7\right)}{15}
$$


The plot again shows the cost is reduced to charge the battery when it is in a lower state of charge to the point where it is chosen to charge rather than produce hydrogen through the electrolyzer which is normally cheaper to do. All three Eqs. (3.11) - (3.13) were determined experimentally to reflect the characteristics described above. The lookup function in Matlab is used again to select the cost factor from the generated data.

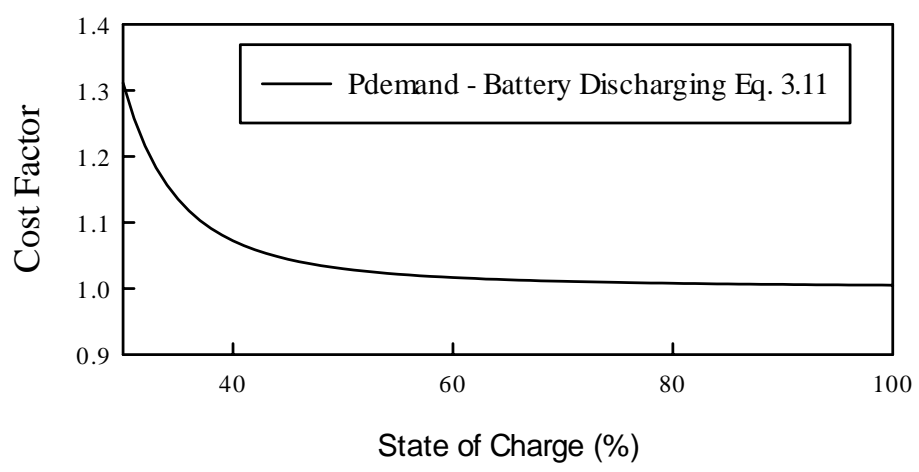

(a)

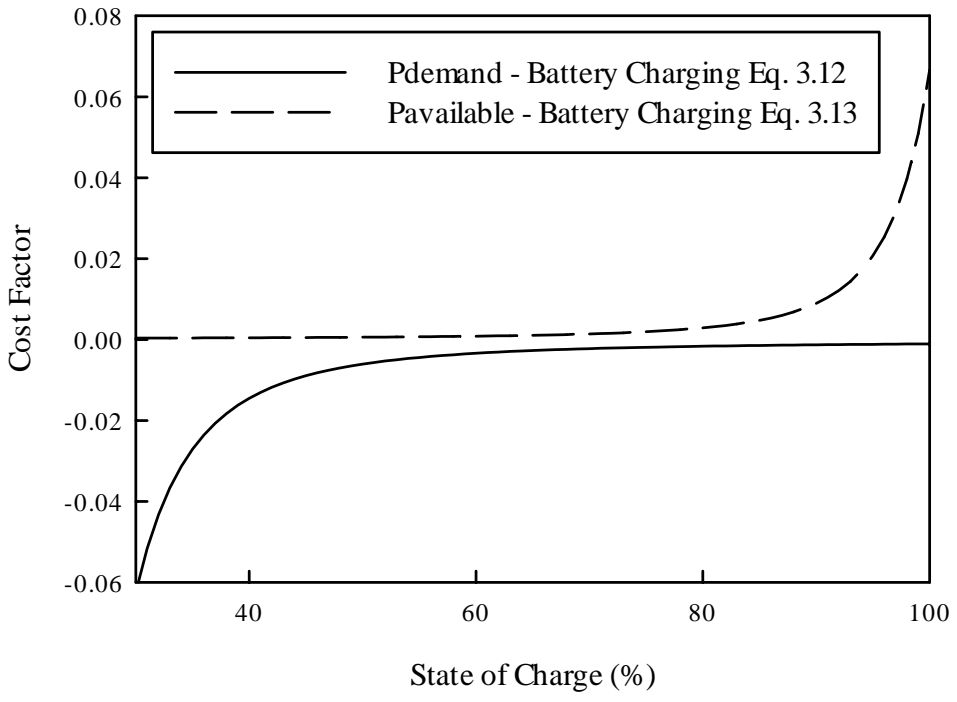

(b)

Fig. 3.2 Cost factor vs. battery state of charge for three different scenarios: battery discharging during power demand (a), battery charging during power demand and power available (b). 
Emissions Objective Function

Emissions is the second objective function to be minimized in the energy management optimization problem. The emissions are produced from the natural gas used to fuel the ICE and the boiler as shown in Eq. (3.14).

$$
\text { Emissions }=E_{I C E} * P_{I C E} * t_{\text {on }, I C E}+E_{B} * Q_{B} * t_{\text {on }, B}
$$

where $\mathrm{E}_{\mathrm{ICE}}$ and $\mathrm{E}_{\mathrm{B}}$ are the $\mathrm{CO}_{2}$ producing rates calculated as in Eq. (3.15).

$$
E_{i}=F C R * \rho_{n g} * C C * M W R
$$

where $\rho_{\mathrm{ng}}$ is the density of natural gas in $\mathrm{kg} / \mathrm{m}^{3}, \mathrm{CC}$ is natural gas' percent carbon content, and MWR is the molecular weight ratio of $\mathrm{CO}_{2}$. The heat generated by the boiler, $\mathrm{Q}_{\mathrm{B}}$, is the excess heat that needs to be generated after waste heat from the ICE, $\mathrm{Q}_{\mathrm{ICE}}$, and FC, $\mathrm{Q}_{\mathrm{FC}}$, is recuperated as shown in Eq. (3.16).

$$
Q_{B}=Q_{\text {load }}-Q_{I C E}-Q_{F C}
$$

where $\mathrm{Q}_{\text {load }}$ is the heating load of the previously designed microgrid. The recoverable heat of the ICE and FC are calculated as in Eq. (3.17) and Eq. (3.18), respectively.

$$
\begin{aligned}
Q_{I C E} & =\left(F C R * \rho_{n g} * L H V-1\right) * P_{I C E} * \% R H \\
Q_{F C} & =R H R * P_{F C}
\end{aligned}
$$

where LHV is the lower heating value of the fuel, $45 \mathrm{MJ} / \mathrm{kg}, \% \mathrm{RH}$ is the percentage of recoverable heat, and RHR is the recoverable heat ratio.

\section{$\underline{\text { Constraints }}$}

The energy management optimization problem contains one equality constraint and two to four inequality constraints depending on the operating state of the system. During power demand, $\mathrm{P}_{\text {demand, }}$, the equality constraint ensures the sum of the power 
generated/consumed from the different sources equals the amount of power that is needed after the PV is used to supply power to the load, as shown in Eq. (3.19). When the PV is producing more power than what is needed by the load then power is available, $\mathrm{P}_{\mathrm{ava}}$, and the equality constraint ensures the power consumed by the electrolyzer, battery, or dump load, $\mathrm{P}_{\text {dump }}$, is equal to it, as shown in Eq. (3.20).

$$
\begin{aligned}
& P_{\text {demand }}=P_{\text {load }}-P_{p v}=P_{I C E}+P_{F C} \\
& P_{a v a}=P_{p v}-P_{\text {load }}=P_{E}+P_{B a t t}
\end{aligned}
$$

Fig. 3.3 shows the profile of the load power and PV power to display when power is demanded, $0-5.6$ hours and $13.7-24$ hours, and when power is available, $5.6-13.7$ hours.

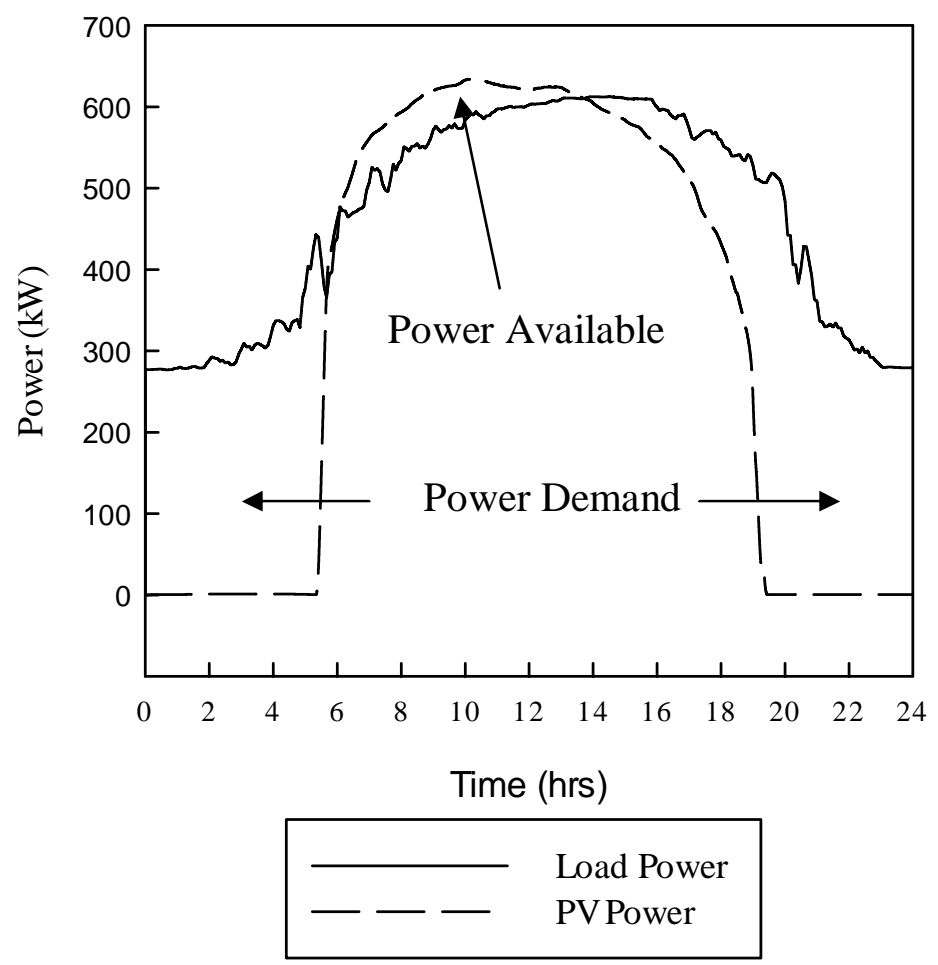

Fig. 3.3. Load demand and PV power profiles displaying when power is demanded from additional generation sources and when power is available to storage loads. 
The inequality constraints are simple operating ranges allowed for each energy source, shown generally in Eq. (3.21), where the minimum and maximum values for each state are given in Table 3.1.

$$
P_{\text {min }} \leq P_{o p} \leq P_{\text {max }}
$$

Table 3.1 Minimum and Maximum Values of Operating Ranges

\begin{tabular}{|c|c|c|c|}
\hline State & Variable & Min. $(\mathrm{kW})$ & Max. (kW \\
\hline \multirow{3}{*}{$\begin{array}{l}\text { Pdemand } \\
30<\mathrm{B}_{\mathrm{SoC}}<100 \\
\mathrm{H}_{2, \mathrm{SoC}}>20\end{array}$} & $\mathrm{P}_{\mathrm{ICE}}$ & 0 & 600 \\
\hline & $\mathrm{P}_{\mathrm{FC}}$ & 0 & 100 \\
\hline & $P_{\text {Batt }}$ & -10 & 10 \\
\hline \multirow{3}{*}{$\begin{array}{l}\text { Pdemand } \\
\mathrm{B}_{\mathrm{SoC}}=100 \\
\mathrm{H}_{2, \mathrm{SoC}}>20\end{array}$} & $\mathrm{P}_{\mathrm{ICE}}$ & 0 & 600 \\
\hline & $\mathrm{P}_{\mathrm{FC}}$ & 0 & 100 \\
\hline & $P_{\text {Batt }}$ & 0 & 10 \\
\hline \multirow{3}{*}{$\begin{array}{l}\text { Pdemand } \\
\mathrm{B}_{\mathrm{SoC}}<=30 \\
\mathrm{H}_{2, \mathrm{SoC}}>20\end{array}$} & $\mathrm{P}_{\text {ICE }}$ & 0 & 600 \\
\hline & $\mathrm{P}_{\mathrm{FC}}$ & 0 & 100 \\
\hline & $P_{\text {Batt }}$ & -10 & 0 \\
\hline \multirow{2}{*}{$\begin{array}{l}\text { Pdemand } \\
30<\mathrm{B}_{\mathrm{SoC}}<100 \\
\mathrm{H}_{2, \mathrm{SoC}}<20\end{array}$} & $P_{\text {ICE }}$ & 0 & 600 \\
\hline & $\mathrm{P}_{\text {Batt }}$ & -10 & 10 \\
\hline \multirow{2}{*}{$\begin{array}{l}\text { Pdemand } \\
\mathrm{B}_{\mathrm{SoC}}=100 \\
\mathrm{H}_{2, \mathrm{SoC}}<20\end{array}$} & $\mathrm{P}_{\text {ICE }}$ & 0 & 600 \\
\hline & $\mathrm{P}_{\text {Batt }}$ & 0 & 10 \\
\hline \multirow{2}{*}{$\begin{array}{l}\text { Pdemand } \\
\mathrm{B}_{\mathrm{SoC}}<=30 \\
\mathrm{H}_{2, \mathrm{SoC}}<20 \\
\end{array}$} & $\mathrm{P}_{\mathrm{ICE}}$ & 0 & 600 \\
\hline & $\mathrm{P}_{\text {Batt }}$ & -10 & 0 \\
\hline \multirow{2}{*}{$\begin{array}{l}\text { Pava } \\
\mathrm{B}_{\text {SoC }}<100 \\
\mathrm{H}_{2, \mathrm{SoC}}<100\end{array}$} & $\mathrm{P}_{\mathrm{E}}$ & 0 & 100 \\
\hline & $\mathrm{P}_{\text {Batt }}$ & 0 & 10 \\
\hline
\end{tabular}

Note, when either the battery or hydrogen tank or both are fully charged during the time of available power, the excess power will automatically be consumed by the device that isn't fully charged, i.e., the battery or electrolyzer or by the dump load, if both 
the battery and the hydrogen tanks are fully charged. Therefore, no optimization run is needed during the above states.

\section{Intelligent Optimization Algorithms}

Two intelligent optimization techniques were used to confirm the optimization results and compare which method worked best. A modified multi-objective PSO algorithm was developed to solve the energy management problem and the multiobjective GA in the Matlab toolbox was used to confirm the results.

\section{Particle Swarm Optimization}

The MOPSO algorithm used in this thesis has similar attributes to that in [25] but is tailored to solve and handle the constraints of the energy management optimization problem described earlier. Besides the modifications to handle the constraints, the modified algorithm also chooses its personal and neighborhood bests differently. Instead of just updating the personal best when it is dominated by the new solution the personal best is also updated if the new solution is only not dominated by the old personal best. This means the personal best factor allows for more diversity in finding new solutions and doesn't exclude solutions that could potentially help find more optimal results which helps speed the simulation. The neighborhood best selection is similar in that it uses an extended selection of solutions but differs in how the neighbors and best solution are selected. The neighborhood is calculated as in Eq. (3.22) in the solution space where any solution within the maximum neighbor distance, MaxD, is in the neighborhood.

$$
\sqrt{\left(x_{1}-y_{1}\right)^{2}+\left(x_{2}-y_{2}\right)^{2}+\left(x_{3}-y_{3}\right)^{2}+\cdots+\left(x_{n}-y_{n}\right)^{2}} \leq \operatorname{MaxD}
$$


In [25] the neighbors are chosen by the ten closest first objective values to the solution that the neighbors are being determined for. The best neighbor solution in the modified MOPSO algorithm used in this thesis is then selected at random whereas in [25] the best neighbor is then selected by whichever solution produces the best value for the second objective function. By determining the neighborhood based on the solution space and selecting the best one by random selection, none of the objective functions are favored in the selection process and a more diverse Pareto front can be produced. Another modification is the use of a global best at times instead of only a neighborhood best in order to create more diversity. Fig 3.4 shows a flow chart of the algorithm used.

The first step is to load the proper constants, decision variable ranges, and decision variable orders for the determined state. The reason for multiple decision variable orders is to eliminate bias in the way the particle positions are contained to satisfy the constraints and to create a more balanced Pareto front. The first decision variable order is then selected and the process begins with the random initialization of particle positions, the calculation of their respective cost and emissions values, and the creation of the first memory and local swarms. The same process is then repeated for a max number of generations, 50, except that the updated positions are calculated based on Eq. (3.23) or Eq. (3.24) depending on what the status of the generation value is.

$$
\begin{gathered}
V_{i, d}=w * V_{i, d}+C_{1} * R_{1} *\left(P_{b e s t, i, d}-X_{i, d}\right)+C_{2} * R_{2} *\left(G_{b e s t, d}-X_{i, d}\right) \\
V_{i, d}=w * V_{i, d}+C_{1} * R_{1} *\left(P_{b e s t, i, d}-X_{i, d}\right)+C_{2} * R_{2} *\left(N_{b e s t, d}-X_{i, d}\right)
\end{gathered}
$$

Eq. (3.24) is used most often except for the last $10 \%$ of generations where Eq. (3.23) is used. 


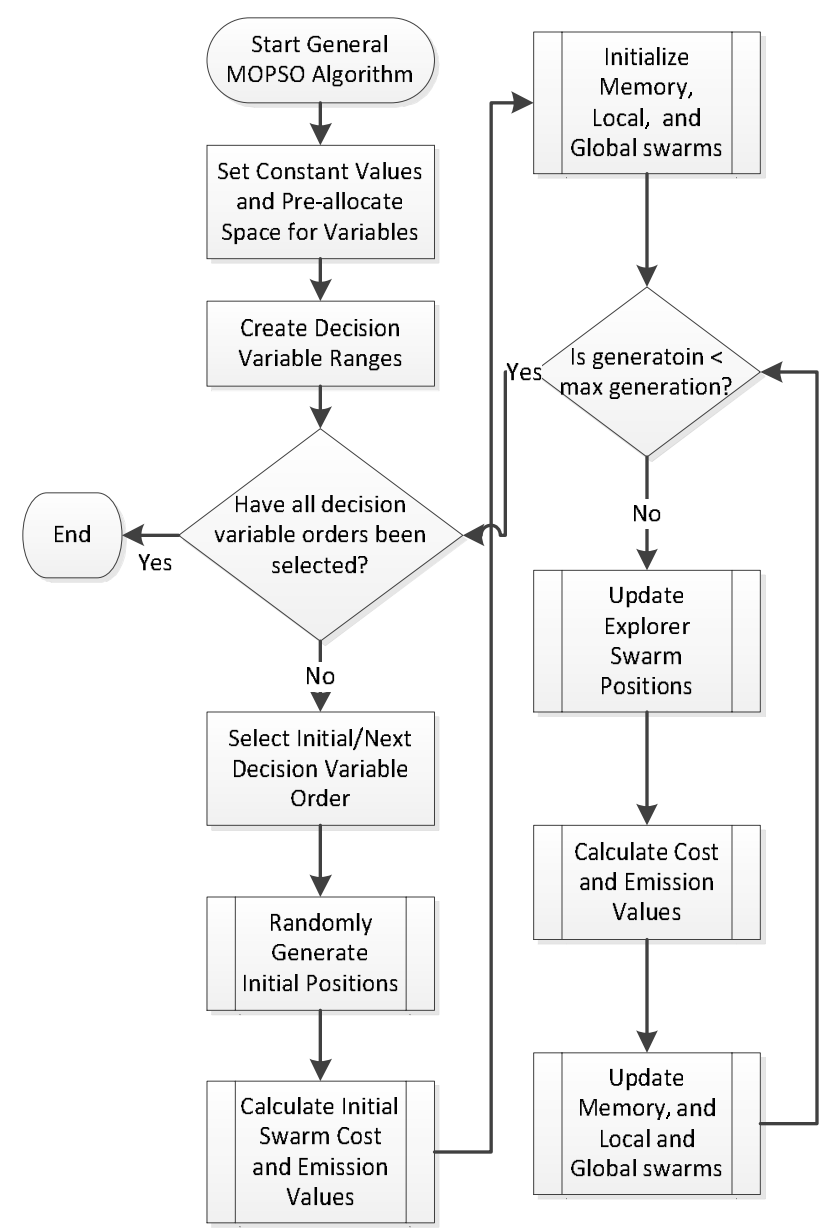

Fig. 3.4 Flow diagram showing the general process of the multi-objective PSO algrotihm. Once the state of the system is determined the process starts.

The MOPSO algorithm starts after the state of the system has been determined.

Once the generation value has reached the max generation value the algorithm moves onto the next decision variable order. All swarm positions are erased and the process starts over again with the new decision variable order. Once all decision variable orders have been selected the MOPSO algorithm is complete.

As the entire process was being carried out all swarm positions were being stored in a separate vector. After the end of the MOPSO algorithm this vector is then screened to delete all common solutions and then all dominated solutions to create the Pareto front. 
Then based on the decision making of the user a solution is selected and the operating points of the sources are updated.

In order to satisfy the equality and inequality constraints of the optimization problem, the particle positions were contained as shown in Fig. 3.5 during the updating process of the particle positions.

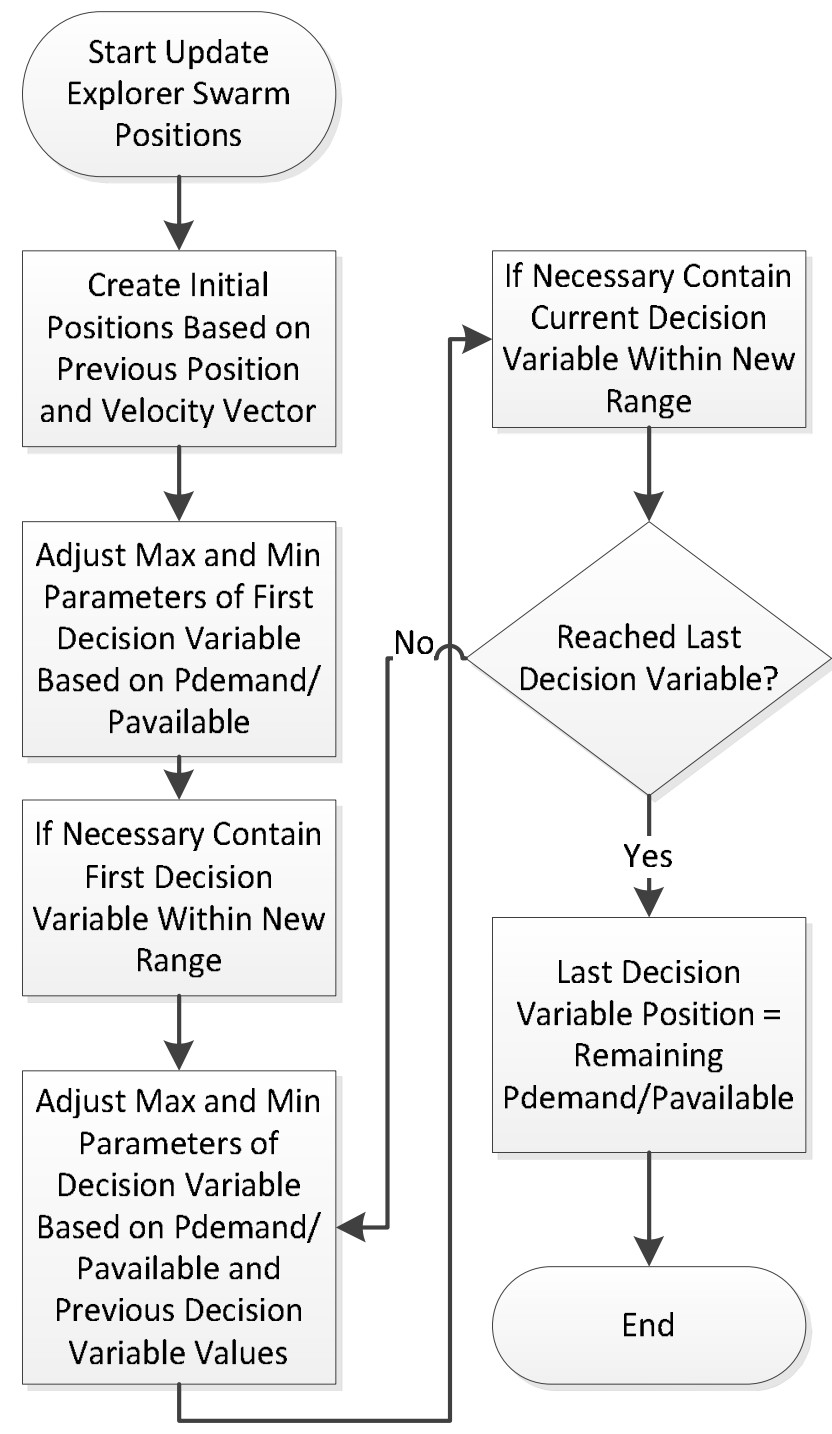

Fig. 3.5 Flow diagram of the containment of particle positions in order to satisfy the equality and inequality constraints of the optimization problem. 
After the positions are calculated, the maximum and minimum values of the first decision variable in the set order are changed based on the available or demanded power. This essentially changes the allowed solution space of the one variable. If the position of the particle is outside the new solution space it is placed on the bound that it exceeds. The next decision variable is selected and its maximum and minimum values are then changed based on the available or demanded power and any other previous variable positions. It is then contained if needed and the process repeats until the last variable is selected. The last variable's position is calculated so that the equality constraint is satisfied.

\section{Genetic Algorithm}

GA is another powerful optimization tool that has been around since its development in the 1960s [42]. Like PSO it was inspired by a process in nature, the evolutionist theory of natural selection. In GA the solution is called a chromosome which is made of genes or the decision variables. Again, the process starts with a randomization of the solutions to create an initial population. GA creates new solutions through the use of two operators, crossover and mutation. Crossover involves the reproduction between two parent chromosomes to create offspring. With the selection of the better solutions the algorithm converges towards the optimal solution after several generations. The mutation operator is used to create small changes in the solutions to create diversity and escape local optima. 
Multi-objective GA has been extensively covered as well and has been considered useful for multi-objective optimization problems for the same reasons as PSO. In this paper a multi-objective GA optimization tool was used in Matlab to compare the multiobjective PSO results to [43]. A short description is given here of the options that were chosen for the multi-objective GA function. The crossover function used was @ crossoverheuristic with a crossover fraction of .8. The mutation function used was @ mutationadaptfeasible to ensure feasible solutions. The number of generations was set to 25 with two different cases for population size, 150 and 250. The Pareto fraction was set to the max of 1 .

\section{$\underline{\text { Simulation Results }}$}

Four energy management simulation cases were run; one no optimization case and three optimization cases using the MOPSO algorithm. One optimization case chose the cheapest solution on the Pareto front, another case chose the solution that produced the least amount of emissions, and the last one chose a solution with an emissions value in the middle representing a trade-off between emissions and cost. In each case it is necessary to match the load demand curve, as shown in Fig. 3.3, with the available power generation and storage sources.

This section first compares the Pareto front results of one of the energy management states, showing why the MOPSO algorithm was chosen to run the energy management simulations. Then an analysis of each of the energy management cases is given. 


\section{Pareto Front Comparison}

As discussed previously in the introduction, the Pareto front represents a collection of optimal non-dominated solutions to the multi-objective optimization problem. Fig. 3.6 shows the comparison of Pareto front results between the multiobjective GA algorithm and the MOPSO algorithm for two different simulation states.

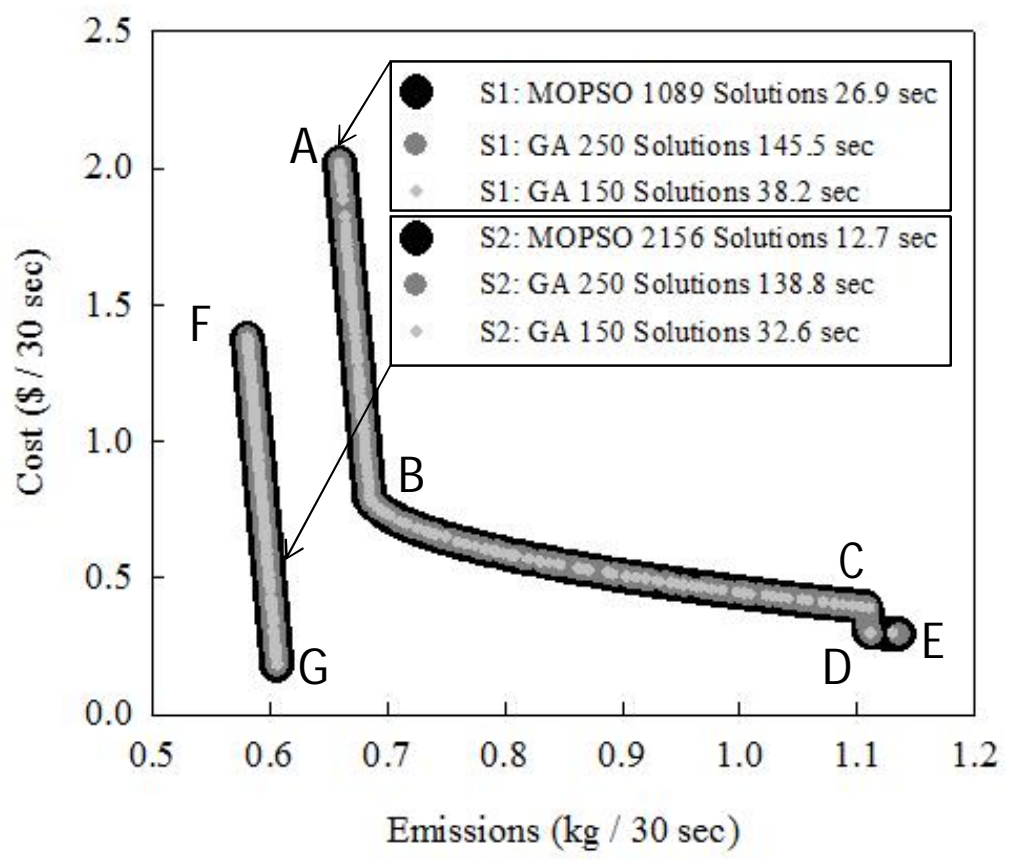

Fig. 3.6 Comparison of Pareto fronts for the different optimization algorithms and for two different operating states.

For the first simulation state the power demand was set equal to $250 \mathrm{~kW}$, the battery state of charge was set to $50 \%$, and the hydrogen tank was set to $50 \%$ as well. Similarity in the shape of the Pareto front between the two different algorithms confirms the modified MOPSO algorithm is able to find the Pareto optimal solutions over the 30 second optimization interval (which does not guarantee optimal results over the 24 hour 
energy management simulations). However, there are major differences in the results between the two different optimization methods. The modified MOPSO algorithm proved to be faster than the GA case with 150 solutions and over five times faster than the GA case with 250 solutions while also producing 1089 solutions.

The Pareto front shape and values change for each of the different states, which can be seen by the second Pareto front in Fig. 3.6 where the power demand was set to 50 $\mathrm{kW}$, battery state of charge to $100 \%$, and the hydrogen tank was set to $20 \%$. For this state there are only two decision variables to optimize, the ICE and the battery due to the hydrogen tank level being too low to use the FC. Again, the MOPSO algorithm proved to be faster and produce a denser Pareto front than the other GA optimization cases, this holds true for each simulation state of this optimization problem. Therefore, the MOPSO algorithm was chosen to run the energy management simulations. Table 3.2 shows the different operating points for the letters A - G in Fig. 3.6 where the Pareto front begins, ends, and any major shift in the shape.

Table 3.2 Operating Points for Letters A - G in Fig. 3.6

\begin{tabular}{|c|c|c|c|}
\hline Point & Battery $(\mathrm{kW})$ & FC $(\mathrm{kW})$ & ICE $(\mathrm{kW})$ \\
\hline S1: $\mathrm{A}$ & 10 & 100 & 140 \\
\hline S1: $\mathrm{B}$ & 0 & 100 & 150 \\
\hline S1: C & 1 & 0 & 249 \\
\hline S1: D & 0 & 0 & 250 \\
\hline S1: $\mathrm{E}$ & -10 & 0 & 260 \\
\hline S2: $\mathrm{F}$ & 10 & 0 & 40 \\
\hline S2: G & 0 & 0 & 50 \\
\hline
\end{tabular}




\section{Twenty-Four Hour Energy Management Simulation}

Each case starts out with the battery state of charge at $50 \%$ and the hydrogen tank at approximately $48 \%$. Each state also uses all of the PV power that is available and updates the operating points of its sources every 30 seconds after the optimization is complete. The ICE power output is allowed to freely change after its new operating point has been set in order to ensure the equality constraint is met due to fluctuations in load and PV power over the 30 second interval. Figs. 3.7-3.10 show the power from loads and sources in each of the energy management simulation cases and also the state of charge for the battery and hydrogen tank.

The first case presented, in Fig. 3.7, is the case that doesn't include the modified MOPSO algorithm, i.e., no optimization was used. In this case the FC and battery were set to operate at their max operating points until their state of charges dropped to $20 \%$ and $30 \%$, respectively. The ICE would then pick up the rest of the load that needed power to be met. During the period of available power, $5.6-13.7$ hour range, the battery was given priority to charge first and then when there was excess available power above what the battery can handle or if the battery was fully charged the electrolyzer was used to produce hydrogen. The no optimization case was chosen to run this way to reflect the intended use of the renewable and energy storage technologies since they were greatly invested in in the design process. 

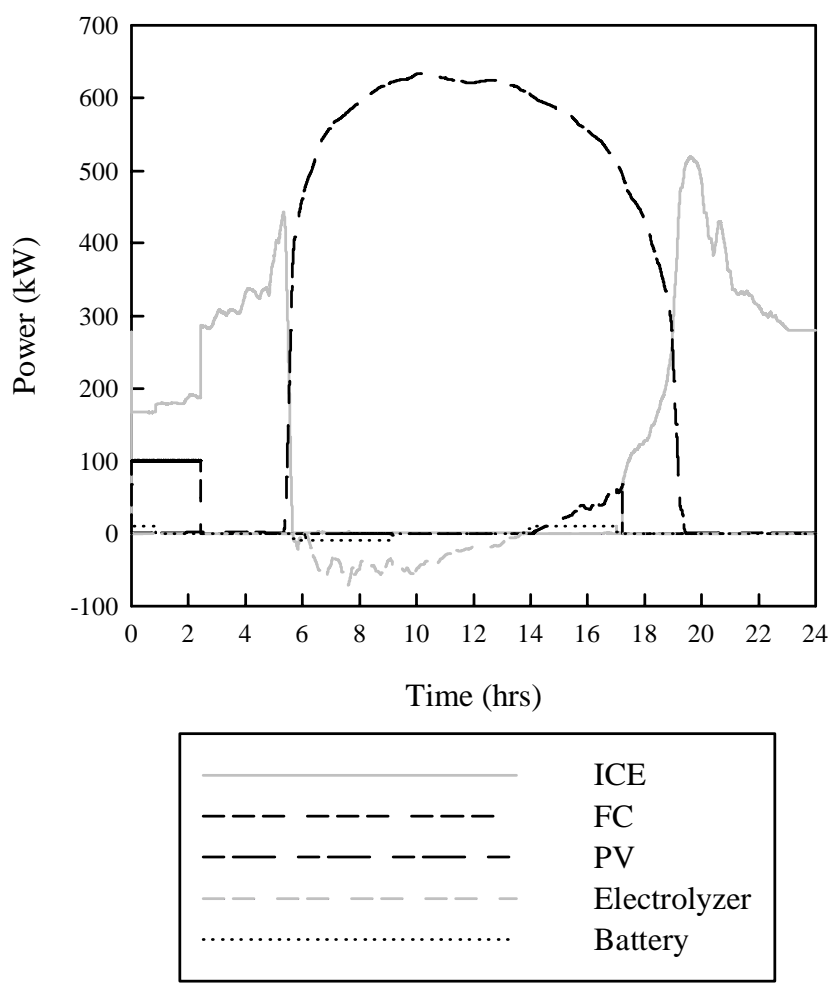

(a)

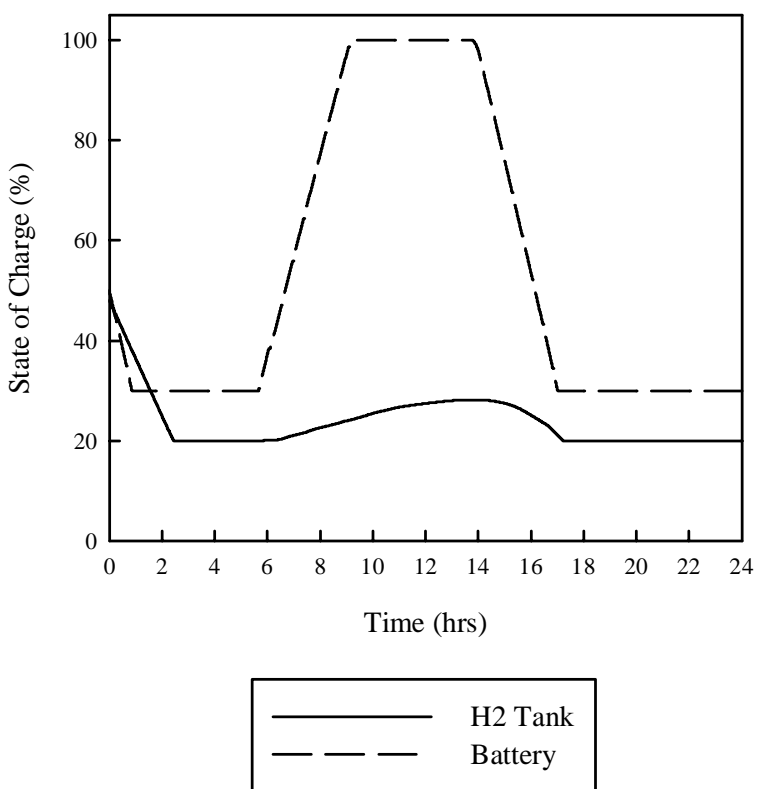

(b)

Fig. 3.7 No optimization energy management case. The top figure displays the power supplied by the different energy sources and the power consumed by the energy storage devices. The bottom figure displays the state of charge of both the hydrogen tank and battery. 
In the first optimization case, Fig. 3.8, the solution that was the cheapest was selected from the Pareto front for any state that it was in. The figure shows during the time of power demand, $0-5.6$ and $13.7-24$ hour ranges, the ICE was the only source producing energy. During the period when power was available due to excess PV power the battery was charged and the electrolyzer was used to produce hydrogen. However, unlike the no optimization case the battery never reaches full charge. At the beginning of the period when power is available the battery is charging and the electrolyzer is producing hydrogen. This is due to the low cost factor that lowers the cost of the battery when it has a low state of charge and because of excess available power still that can be consumed by the electrolyzer. Once the battery reaches about $70 \%$ state of charge, it stops charging due to the battery cost increasing back towards its normal cost. At this point, the cost still remains low enough that charging the battery would be a cheaper option than running the electrolyzer if the battery could consume all of the available power. However, the available power is much greater than the battery capacity and the electrolyzer still needs to be used. Since the cost function of operating the electrolyzer has a constant value for whenever it is on, i.e., the lifetime cost of the electrolyzer, it is only the O\&M cost that is compared to the entire cost of using the battery for the amount of available power up to the battery capacity. This O\&M cost is cheaper than the battery cost and therefore only the electrolyzer is chosen to run at this point. Once the power available reduces to below the capacity of the battery it is then cheaper to operate the battery than the electrolyzer. 

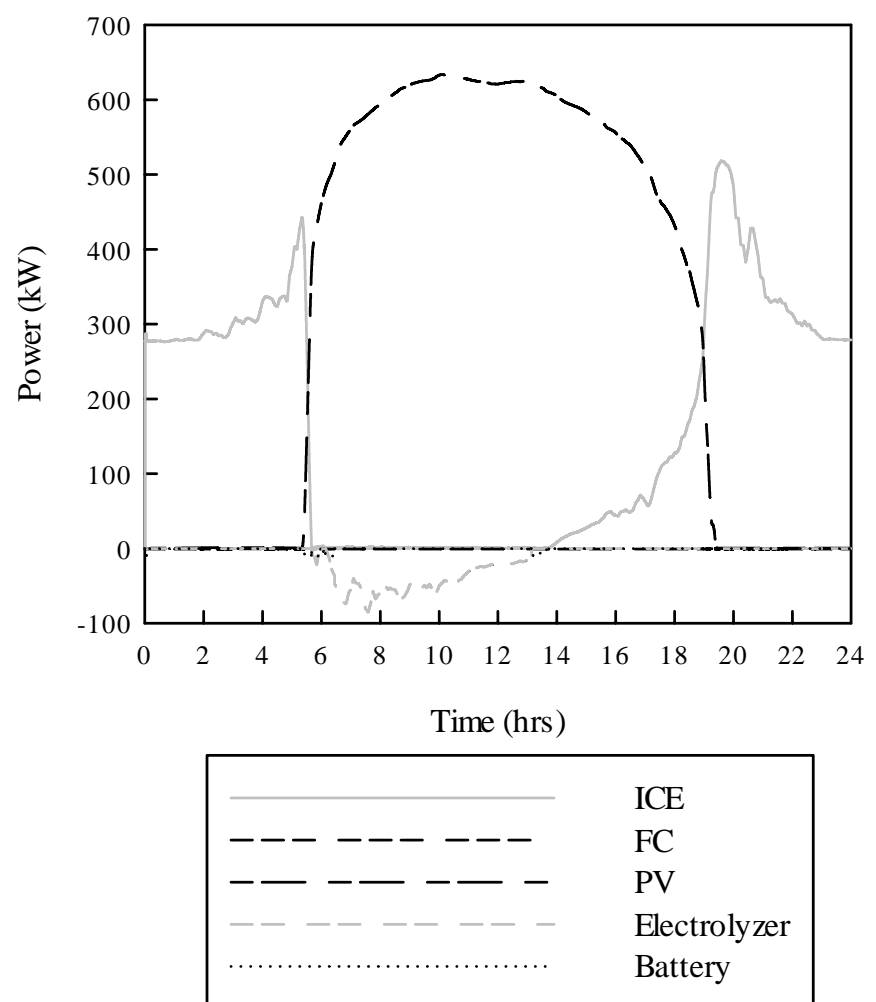

(a)

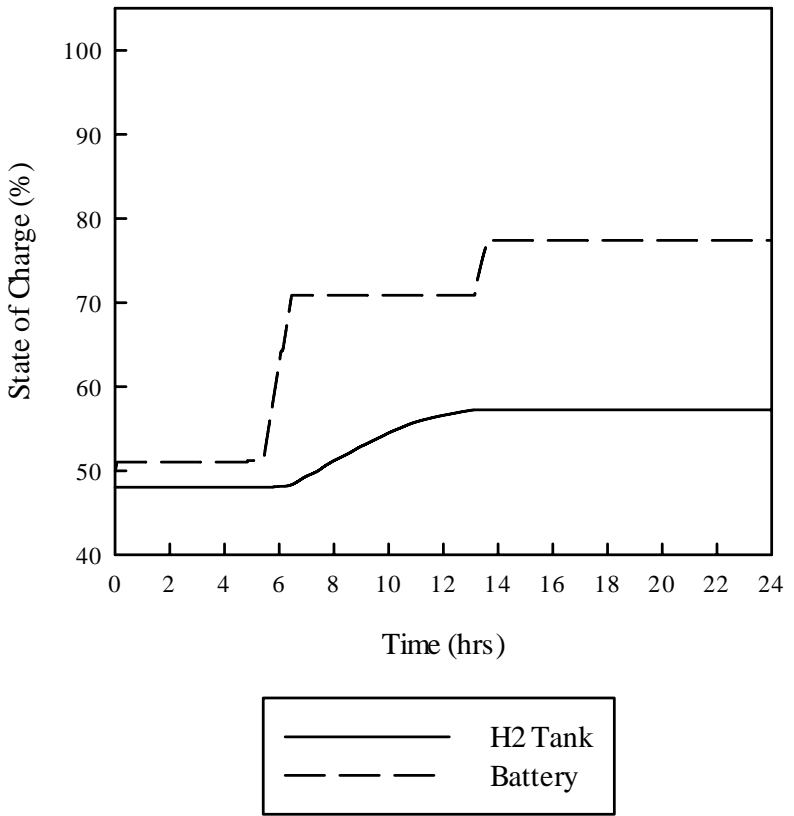

(b)

Fig. 3.8 Cheapest Case. The top figure displays the power supplied by the different energy sources and the power consumed by the energy storage devices. The bottom figure displays the state of charge of both the hydrogen tank and battery. 
The second optimization case, Fig. 3.9, chose the solution that would produce the least amount of emissions over the optimization time step of 30 seconds. The FC and battery were used at the beginning of the simulation just like the no optimization case. During the time PV power is available the same process occurs as during the first optimization case (Fig. 3.8). The battery was discharged more previously to power being available which is why it charges longer until it reaches around $70 \%$ again. Once the simulation changes back to power being demanded, at approximately the 13.7 hour mark, and since the power demand is less than the capacity of the FC while the battery is not fully charged, the FC is chosen to operate above the demanded power to charge the battery. This is due to the emissions that are reduced by the useable waste heat from the fuel cell instead of operating the boiler. The hydrogen tank eventually runs out of hydrogen and the ICE and battery are used again.

The third optimization case, a trade-off condition shown in Fig. 3.10, chose the solution that would produce the middle amount of emissions over each 30 second interval. The same characteristics as the previous two optimization cases can be seen during the time of available power. During the time of power demand the FC is used at about half of its rated capacity even though there is enough power demand for it to operate at full capacity. This is due to the trade-off of allowing increased emissions for a lower operating cost of the microgrid over the 30 second interval. The battery isn't used to provide power until the hydrogen in the tank has reached its lower limit of $20 \%$. 

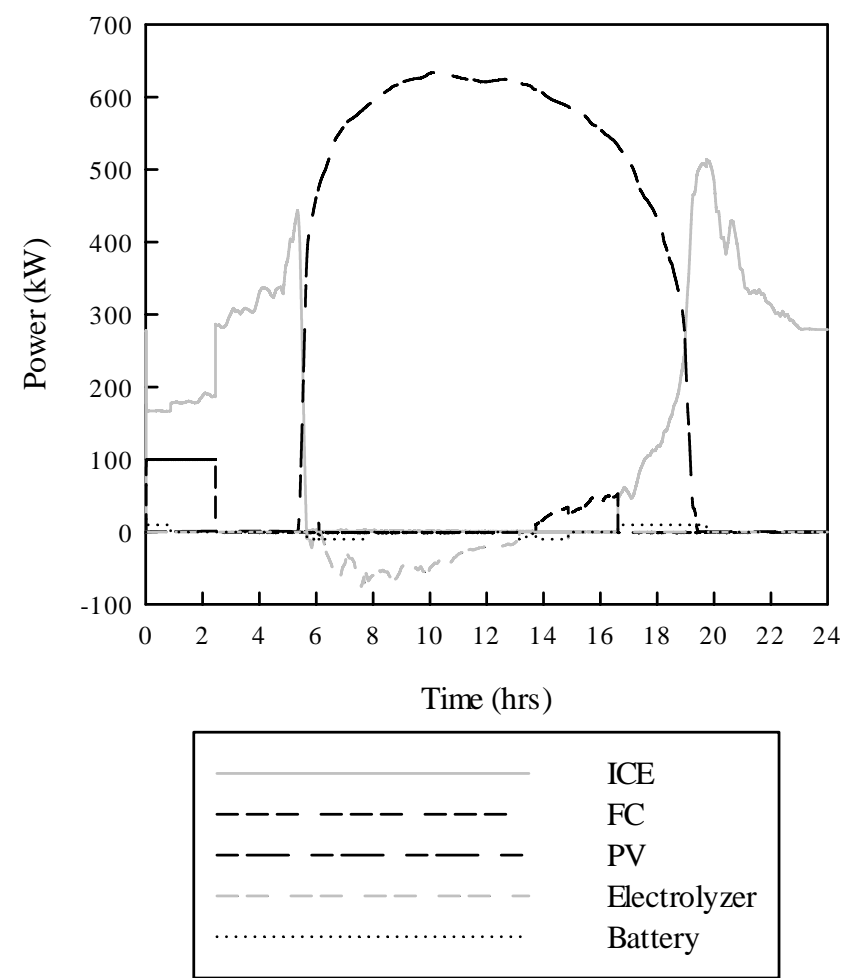

(a)

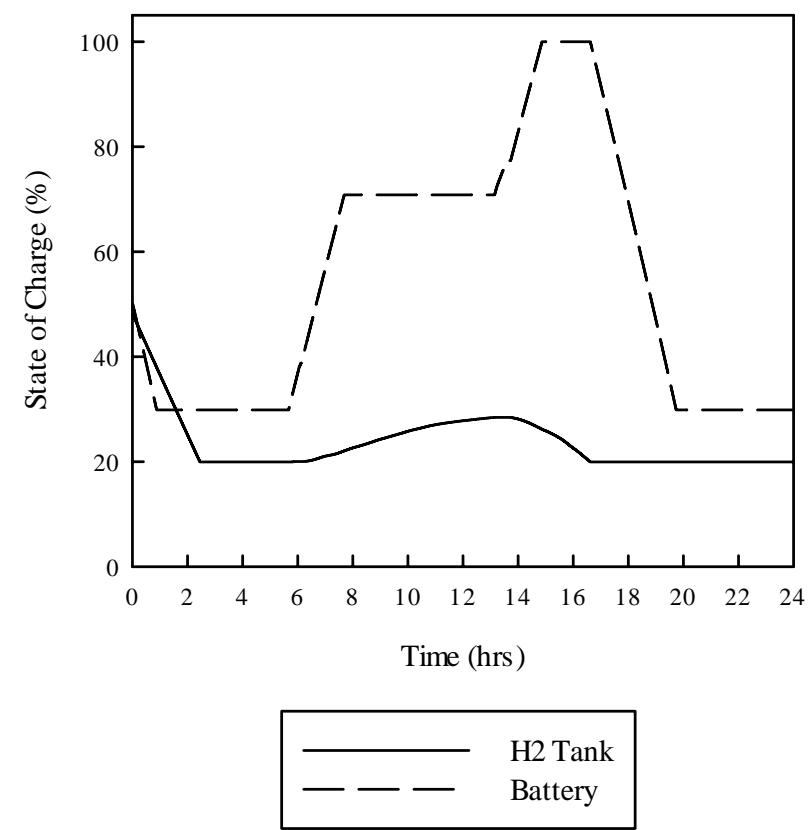

(b)

Fig. 3.9 Least Emissions Case. The top figure displays the power supplied by the different energy sources and the power consumed by the energy storage devices. The bottom figure displays the state of charge of both the hydrogen tank and battery. 
66
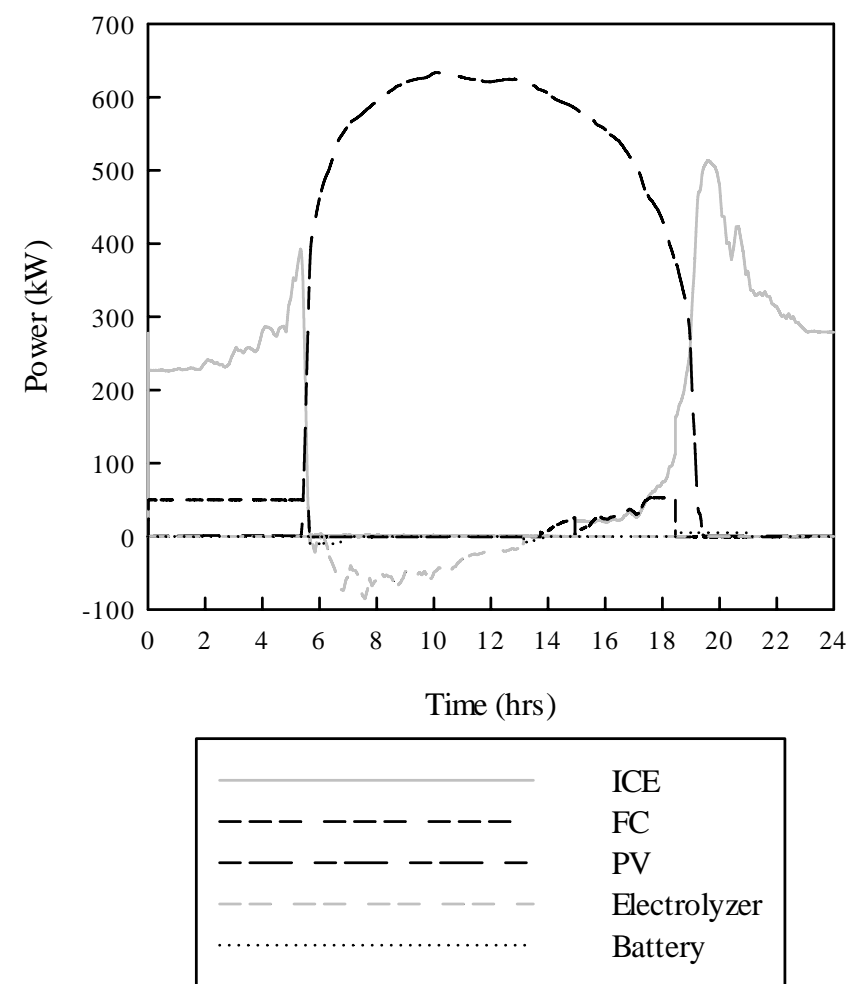

(a)

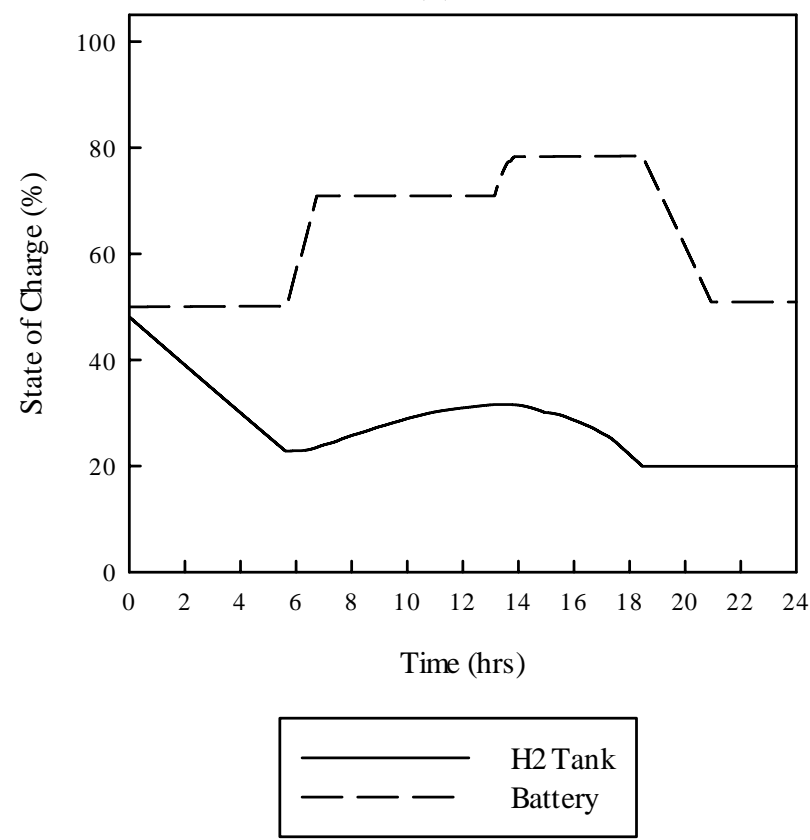

(b)

Fig. 3.10 Middle Emissions Case. The top figure displays the power supplied by the different energy sources and the power consumed by the energy storage devices. The bottom figure displays the state of charge of both the hydrogen tank and battery. 
Each simulation case then had its total cost and emissions calculated over the full 24 hour simulation period which are shown in Table 3.3 using the equations that described the optimization problem previously in this chapter.

Table 3.3 Total Cost and Emissions Values over the 24 Hour Period

\begin{tabular}{|l|l|l|}
\hline Run & Total Cost $(\$)$ & Total Emissions $(\mathrm{kg})$ \\
\hline Least Cost & 781 & 2857 \\
\hline Middle Emissions & 1245 & 2650 \\
\hline Least Emissions & 1767 & 2680 \\
\hline No Opt. & 1771 & 2679 \\
\hline
\end{tabular}

The optimization case that selected the cheapest solution over the 30 second interval was indeed the cheapest through the entire 24 hour simulation and also produced the most amounts of emissions. However, the least emissions case, which chose the operating conditions that would produce the least amount of emissions over each 30 second optimization interval individually, did not produce the least emissions over the 24 hour period. The least amount of emissions was produced with the middle emissions optimization case, which chose the operating conditions that would produce the middle amount of emissions over each 30 second optimization interval individually, and also did it at a lower cost than the least emissions case. The reason for this is, in both the "middle" and "least" emission cases, the hydrogen is completely used up by the end of the simulation and the "middle" emissions case uses the hydrogen more efficiently by operating the FC in the middle of its capacity range. With the "least" emissions case the FC is operating at its highest capacity for most of the simulation which is less efficient due to the polarization losses [44]. If there was no limit to the use of hydrogen over the 
24 hour simulation then the least emissions case would indeed produce the least amount of emissions compared to the middle emissions case.

The no optimization case, chosen to use the FC and battery whenever available, is the most expensive and produces just slightly less emissions than the "least" emissions case. Fewer emissions are produced due to the charging process (of the battery or the operation of the electrolyzer) when power is available. In the no optimization case the battery is fully charged as soon as possible whereas in the "least" emissions case the electrolyzer is chosen after the battery reaches $70 \%$ state of charge due to lower costs since at that instant emissions don't change whether the battery or electrolyzer is used. Since the energy storage efficiency of charging/discharging the battery is higher than the electrolyzer/FC cycle the no optimization case makes use of the available power more efficiently, therefore producing fewer emissions than the "least" emissions case. Choosing the cheapest option to store energy in the "least" emissions case is also the reason why it costs less than the no optimization case. 


\section{CONCLUSION AND FUTURE WORK}

Technologies were optimally selected and sized for a medium-sized college in San Francisco containing electrical and thermal loads. Two software packages (WebOpt and HOMER) developed by the US national laboratories LBL and NREL, respectively, were used to perform the optimal sizing and technology selection. Three cases were used to justify the adjustments made to create a microgrid that incorporates different renewable/alternative generation sources including energy storage and CHP. The final microgrid structure, Scenario 4 with optimization through HOMER, contained PV, FCHX, ICE-HX, batteries, and hydrogen storage technologies. A comparison of the operation and benefits of WebOpt and HOMER was also accomplished through the design process.

Real-time energy management of the final microgrid design was then simulated using a modified MOPSO algorithm to optimize the complex problem. A description and comparison of the modified MOPSO algorithm to a multi-objective GA optimization tool in Matlab was also reported. The faster simulation time and denser Pareto front showed the MOPSO algorithm to be superior and was therefore used in the 24 hour energy management simulations. The results of the energy management simulations show the differences in which a user can operate the microgrid in real-time compared to a predetermined energy management plan. The results also show the intended optimization goal of least emissions, which was done every 30 seconds, did not hold true over the 24 hour period. Therefore, it could potentially be beneficial to add forecasting techniques, e.g, load forecasting and/or PV forecasting, to the optimization algorithm to improve the 
optimization over a 24 hour period. For example, if the algorithm could be given information that the hydrogen tank will most likely be empty by the end of the day and not refilled anytime soon then it could be beneficial to lower the operating point of the FC to make use of the hydrogen more efficiently.

Multi-objective optimization in the technology selection and unit sizing could potentially improve results as well. The microgrid design done in this thesis used a minimum renewable fraction limit to provide incentive to invest in technologies that would reduce emissions. If a multi-objective technology selection and unit sizing tool was used, it would provide a clearer picture of the options available to the user. The design options would range from producing the approximate least amount of emissions through a year to the design that would approximately cost the least. Each design could provide a range of emissions and a range of costs for the year depending on how the microgrid would be operated, i.e., a least cost or least emissions scenario. This would provide better technology selection and unit sizing for a real-time multi-objective optimization process. 
REFERENCES CITED 
[1] U.S. Energy Information Administration. International Energy Outlook 2011. [Online]. Available:

http://www.eia.gov/forecasts/ieo/pdf/0484(2011).pdf

[2] U.S. Energy Information Administration. Annual Energy Outlook 2012 with Projections to 2035. [Online]. Available:

http://www.eia.gov/forecasts/aeo/pdf/0383(2012).pdf

[3] U.S. Department of Energy. 2010 Smart Grid System Report. [Online]. Available: http://energy.gov/sites/prod/files/2010 Smart Grid System Report.pdf

[4] Electric Power Research Institute. Estimating the Costs and Benefits of the Smart Grid. [Online]. Available:

http://www.rmi.org/Content/Files/EstimatingCostsSmartGRid.pdf

[5] H. Farhangi, "The path of the smart grid," IEEE Power Energy Mag., vol. 8, no. 1, pp. 18-28, Jan.-Feb. 2010.

[6] U.S. Department of Energy. Smart Grid Investment Grant Program. July 2012 [Online]. Available:

http://www.smartgrid.gov/sites/default/files/doc/files/sgig-progress-report-finalsubmitted-07-16-12.pdf

[7] U.S. Department of Energy. The Smart Grid: An Introduction. [Online] Available: http://energy.gov/sites/prod/files/oeprod/DocumentsandMedia/DOE_SG_Book_S ingle_Pages.pdf

[8] Microgrid Exchange Group, DOE Microgrid Workshop Report, August 2011 [Online]. Available:

http://energy.gov/sites/prod/files/Microgrid\%20Workshop\%20Report\%20August \%202011.pdf

[9] Taha Selim Ustun, Cagil Ozansoy, Aladin Zayegh, Recent developments in microgrids and example cases around the world-A review, Renewable and Sustainable Energy Reviews, Volume 15, Issue 8, October 2011, Pages 40304041.

[10] EEE Standard for Interconnecting Distributed Resources with Electric Power Systems, IEEE Std. 1547-2003, 2003.

[11] HOMER, National Renewable Energy Laboratory [Online]. Available: http://www.analysis.nrel.gov/homer/

[12] HOMER Energy [Online]. Available: https://www.homerenergy.com/ 
[13] DER-CAM—Distributed energy resources customer adoption model, Lawrence Berkeley National Laboratory [Online]. Available: http://www.der.lbl.gov/der-cam

[14] M. H. Nehrir, C. Wang, K. Strunz, H. Aki, R. Ramakumar, J. Bing, Z. Miao, and Z. Salameh, "A review of hybrid renewable/alternative energy systems for electric power generation: Configurations, control, and applications," IEEE Trans. Sust. Energy, vol. 2, no. 4, pp. 392-403, Oct. 2011.

[15] C. M. Colson and M. H. Nehrir, "A review of challenges to real-time power management of microgrids," presented at the 2009 IEEE Power Energy Soc. Gen. Meet., Calgary, AB, Canada, PESGM2009-001250.

[16] C.A. Coello Coello, D.A. Van Veldhuizen, and G.B. Lamont, Evolutionary Algorithms for Solving Multi-Objective Problems. Kluwer Academic Publishers, New York, ISBN 0-3064-6762-3, May 2002.

[17] I. J. Ramirez Rosado and J. L. Bernal Agustin. Reliability and Cost Optimization for Distribution Networks Expansion Using an Evolutionary Algorithm. IEEE Transactions on Power Systems, 16(1):111-118, February 2001.

[18] E. Tsoi, K. P. Wong, and C. C. Fung. Hybrid GA/SA Algorithms for Evaluating Trade-off Between Economic Cost and Environmental Impact in Generation Dispatch. In D. B. Fogel, editor, Proceedings of the Second IEEE Conference on Evolutionary Computation (ICEC'95), pages 132-137, Piscataway, New Jersey, 1995. IEEE Press.

[19] B. Zhao and Y. j. Cao. Multiple objective particle swarm optimization technique for economic load dispatch. Journal of Zhejiang University SCIENCE,6A(5):420427, 2005.

[20] G. Corso , M. L. Di Silvestre, M. G. Ippolito, E. Riva Sanseverino, G. Zizzo, "Multi-objective long term optimal dispatch of distributed energy resources in micro-grids" Universities Power Engineering Conference 2010, Cardiff UK.

[21] S. Kitamura, K. Mori, S. Shindo, Y. Izui, and Y. Ozaki, "Multiobjective energy management system using modified MOPSO," in Proc. IEEE Int. Conf. Syst., Man, Cybern., Hyogo, Japan, 2005, pp. 3497-3503.

[22] S. A. Pourmousavi, M. H. Nehrir, C. M. Colson, and C. Wang, "Real-time energy management of a stand-alone hybrid wind-microturbine energy system using particle swarm optimization," IEEE Trans. Sustain. Energy, vol. 1, no. 3, pp. 193-201, Oct. 2010. 
[23] Hu. Xiaohui and Eberhart, Russell C, "Multiobjective optimization using dynamic neighborhood particle swam optimization," Proceedings of the IEEE Congress on Evolutionary Computation (CEC 2002), Honolulu, Hawaii USA, 2002.

[24] A. Alarcon-Rodriguez, G. Ault, S. Galloway, "Multi-objective planning of distributed energy resources: A review of the state-of-the-art," Renewable and Sustainable Energy Reviews, Volume 14, Issue 5, June 2010, Pages 1353-1366.

[25] Hu, X., Eberhart, R. C., and Shi, Y, "Particle swarm with extended memory for multiobjective optimization," Proceedings of the IEEE Swarm Intelligence Symposium 2003 (SIS 2003), Indianapolis, Indiana, USA. pp. 193-197, 2003.

[26] J. Kennedy and R. C. Eberhart, "Particle swarm optimization," in Proc. IEEE Int. Conf. Neural Networks, 1995, pp. 39-43.

[27] Coello Coello, Carlos A. and Lechuga. Maximino Salazar, "MOPS0 a proposal for multiple objective particle swam optimization," Proceedings of the IEEE Congress on Evolutionary Computation (CEC 2002), Honolulu, Hawaii USA. 2002.

[28] C. Marnay, G. Venkataramanan, M. Stadler, A. S. Siddiqui, R. Firestone, and B. Chandran, "Optimal Technology Selection and Operation of CommercialBuilding Microgrids," IEEE Trans. Power Systems, vol. 23, no. 3, pp. 975-982, Aug. 2008.

[29] Lawrence Berkeley National Laboratory, "The carbon dioxide abatement potential of California's mid-sized commercial buildings," January, 2010.

[30] GAMS Development Corporation [Online]. Available: http://www.gams.com/

[31] Stadler Michael, Chris Marnay, Maximilian Kloess, Gonçalo Cardoso, Gonçalo Mendes, Afzal Siddiqui, Ratnesh Sharma, Olivier Megel, Judy Lai, "Optimal Planning and Operation of Smart Grids with Electric Vehicle Interconnection," Journal of Energy Engineering, American Society of Civil Engineers (ASCE), Special Issue: Challenges and opportunities in the 21st century energy infrastructure, Volume 138, Issue 2, June 2012.

[32] National Renewable Energy Laboratory, "Innovation for our energy future." [Online]. Available: https://analysis.nrel.gov/homer/includes/downloads/HOMERBrochure_English.p df 
[33] Energy technology cost and performance data, Energy analysis, National Renewable Energy Laboratory [Online]. Available: http://www.nrel.gov/analysis/tech_cost_dg.html

[34] EPRI-DOE handbook of energy storage for transmission and distribution applications, Dec. 2003.

[35] Gas-fired distributed energy resource technology characterizations, National Renewable Energy Laboratory, Nov. 2003.

[36] Compare - Installed costs - Chillers, Sacramento Municipal Utility District [Online]. Available:

http://smud.apogee.net/comsuite/content/ces/?utilid=smud\&id=1084

[37] National Research Council, The Hydrogen Economy: Opportunities, Costs, Barriers, and $R \& D$ Needs. Washington, DC: The National Academies Press, 2004, pp. 98.

[38] ORNL Researchers Design Low-Cost Hydrogen Storage Systems for Stationary Applications, Oak Ridge National Laboratory [Online]. Available:

http://www.ornl.gov/sci/eere/PDFs/Cost-fffective_storage_final2.pdf

[39] M. H. Nehrir and C. Wang, Modeling and Control of Fuel Cells, Hoboken, NJ: Wiley-IEEE Press, 2009.

[40] C. M. Colson and M. H. Nehrir, "Evaluating the Benefits of a Hybrid Solid Oxide Fuel Cell Combined Head \& Power Plant for Energy Sustainability and Emissions Avoidance," IEEE Trans. Energy Convers., vol. 26, no. 1, pp. 140-148, March 2011.

[41] C.M. Colson, "Towards real-time power management of microgrids for power system integration: a decentralized multi-agent based approach," Ph.D.

Dissertation, Montana State University, 2012, [Online]. Available: http://search.proquest.com/docview/1267824465.

[42] A. Konak, D.W. Coit, A.E. Smith, "Multi-objective optimization using genetic algorithms: a tutorial," Reliability Engineering and System Safety, 91 (2006), pp. 992-1007.

[43] Global Optimization Toolbox: Multiobjective Genetic Algorithm Solver, Mathworks [Online]. Available:

http://www.mathworks.com/products/global-optimization/description5.html 
[44] Huayang Zhu, Robert J. Kee, Thermodynamics of SOFC efficiency and fuel utilization as functions of fuel mixtures and operating conditions, Journal of Power Sources, Volume 161, Issue 2, 27 October 2006, Pages 957-964. 
APPENDICES 
$\underline{\text { APPENDIX A }}$

MATLAB/SIMULINK MICROGRID MODELS 


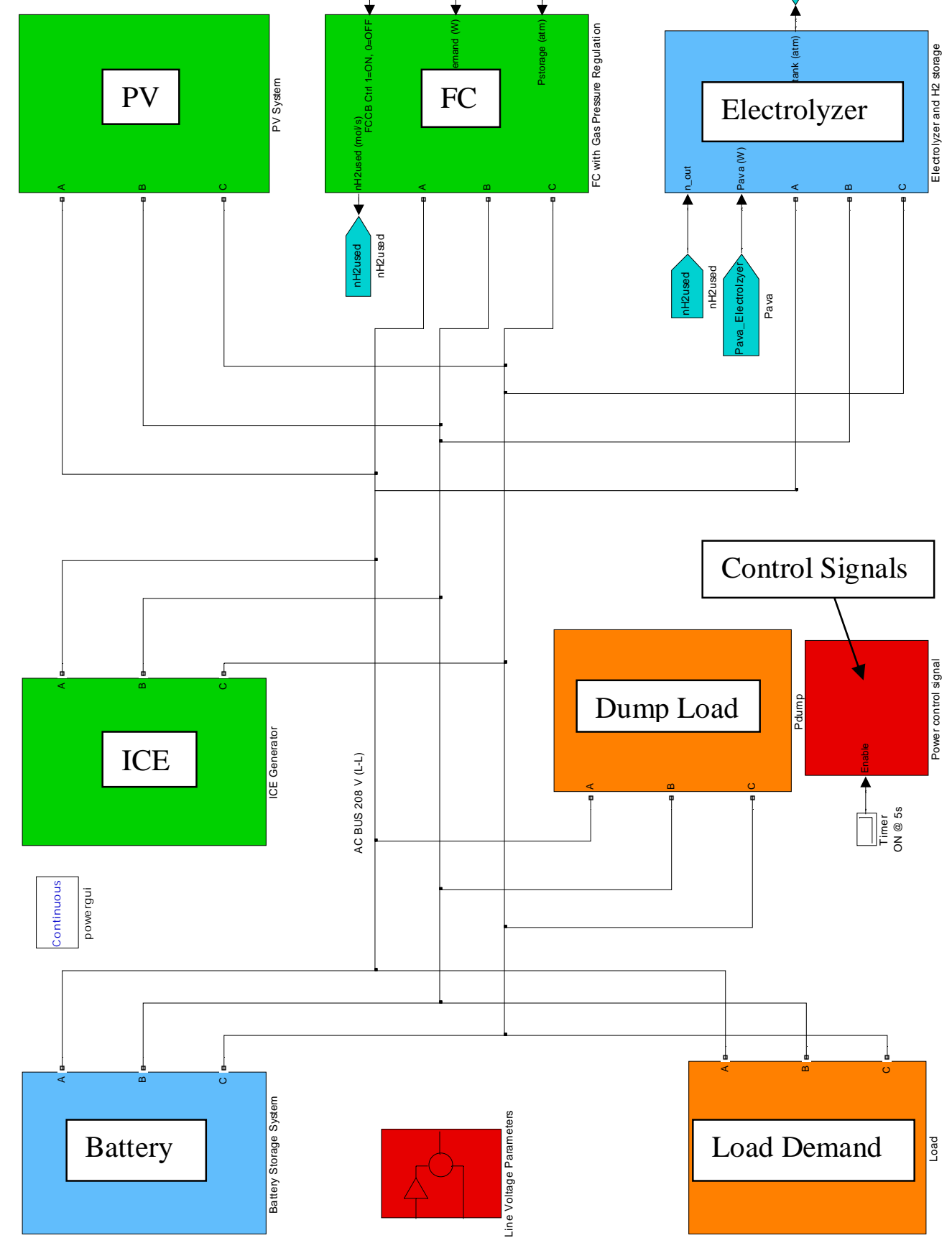

Fig. A.1 Top layer of MATLAB/Simulink Models. Sources and loads are connected to a common AC bus. 


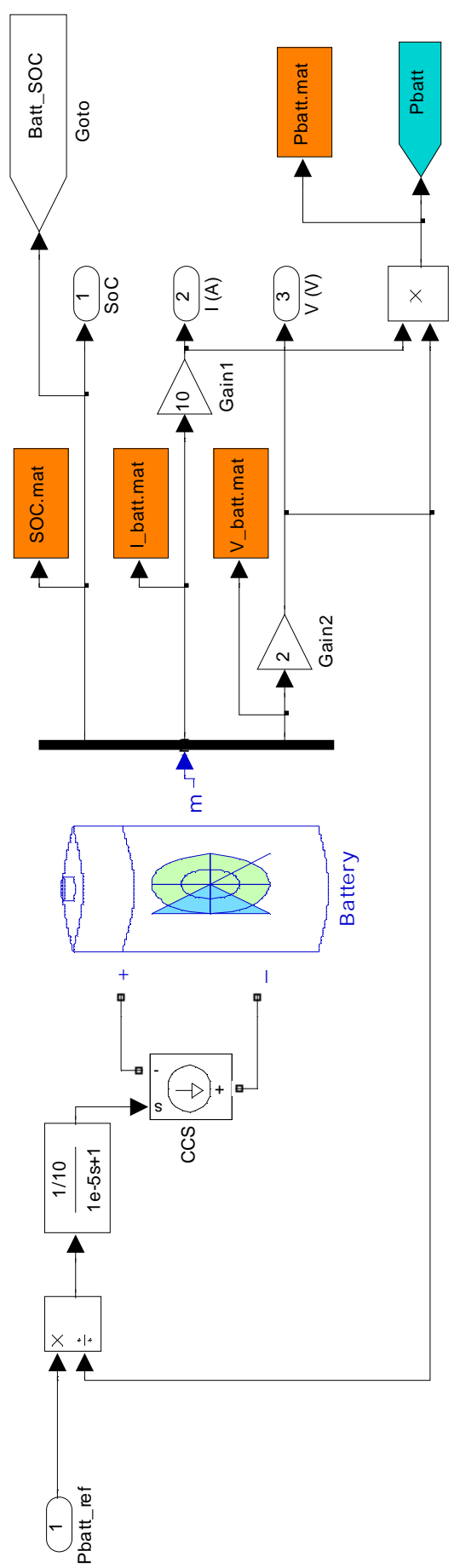

Fig. A.2 Battery Model 


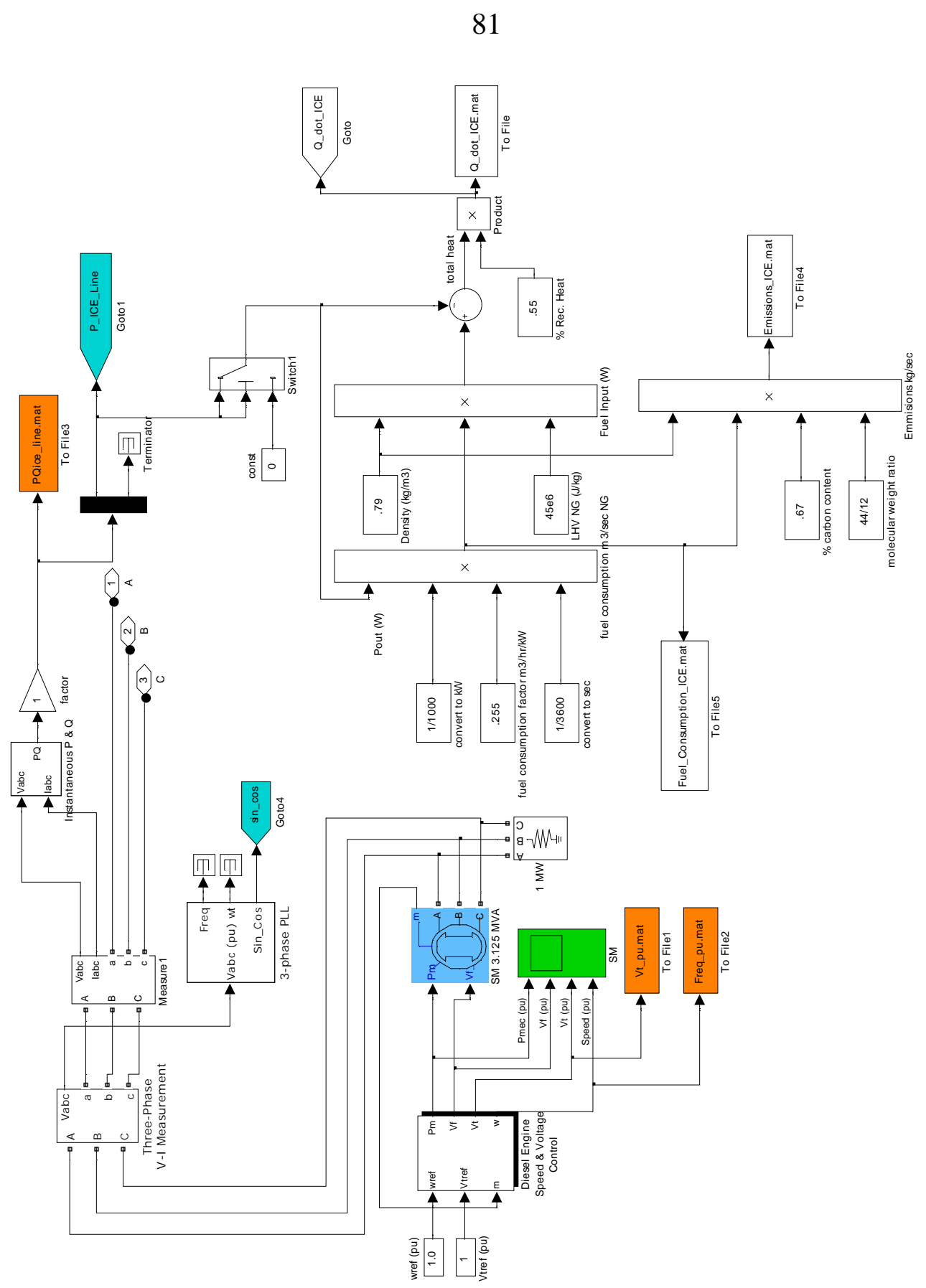

Fig. A.3 ICE model 


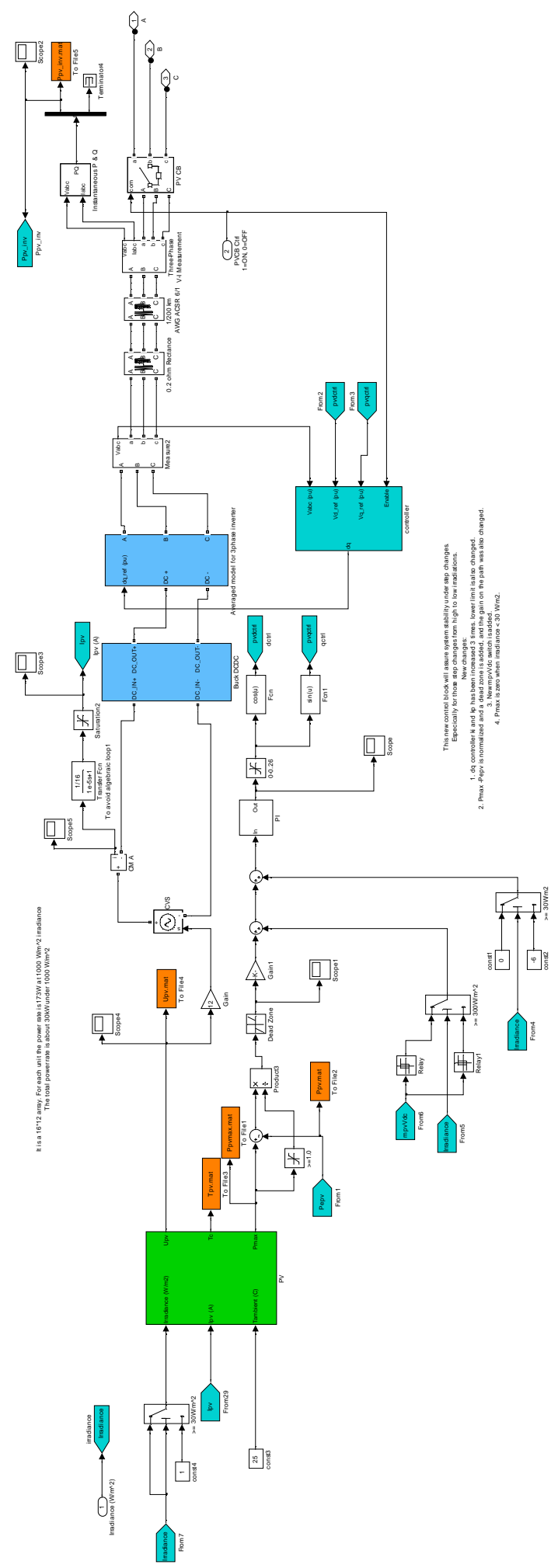

Fig. A.4 PV model 


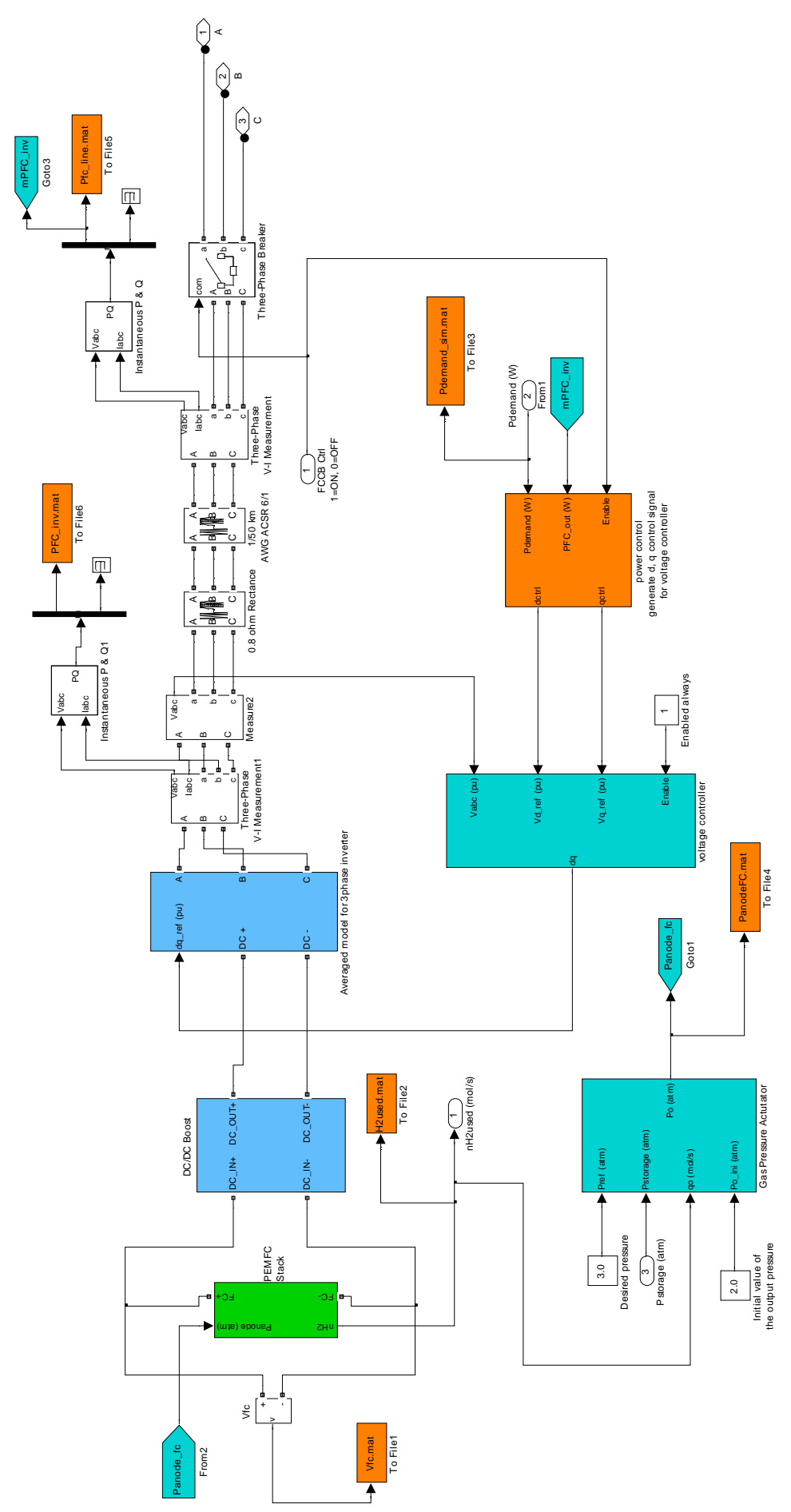

Fig. A.5 FC model 


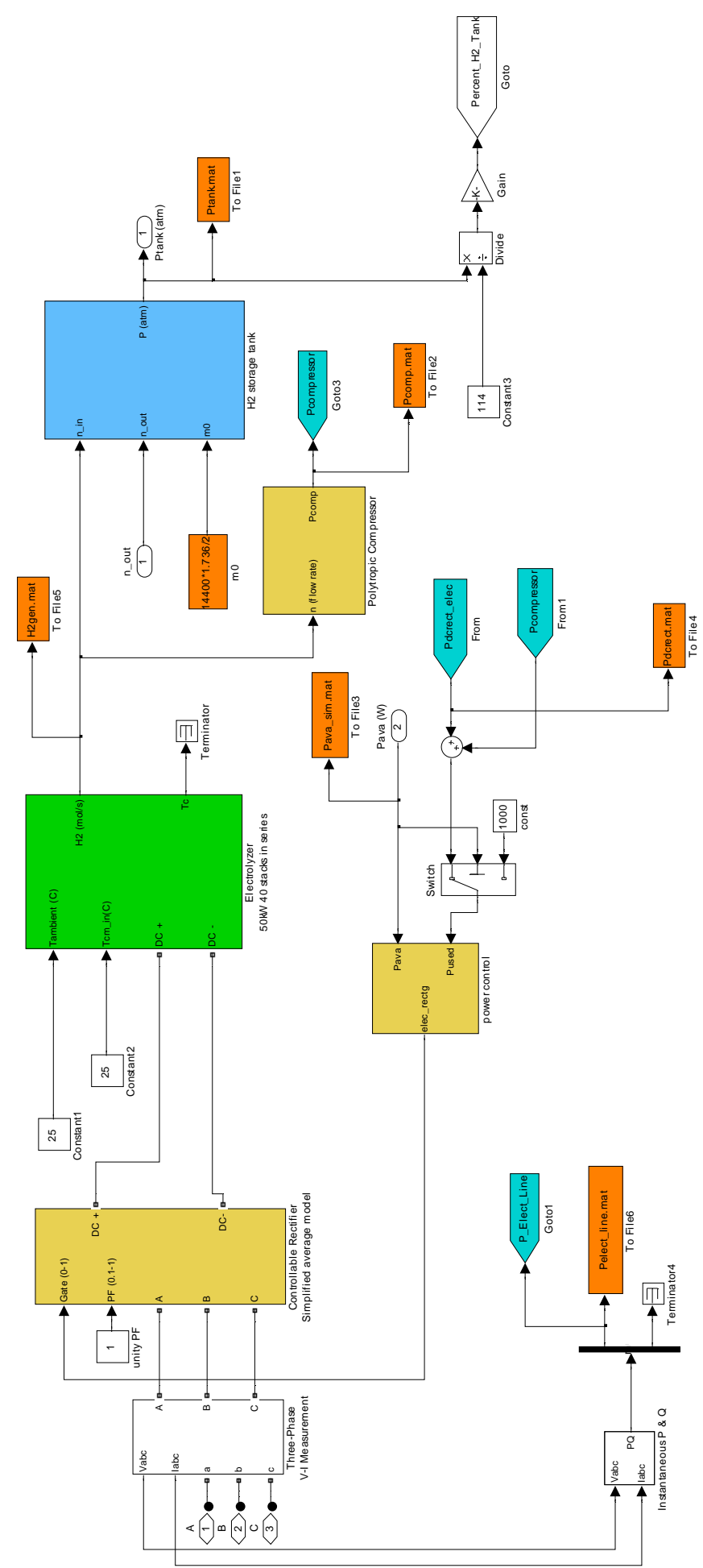

Fig. A.6 Electrolyzer and H2 storage model 


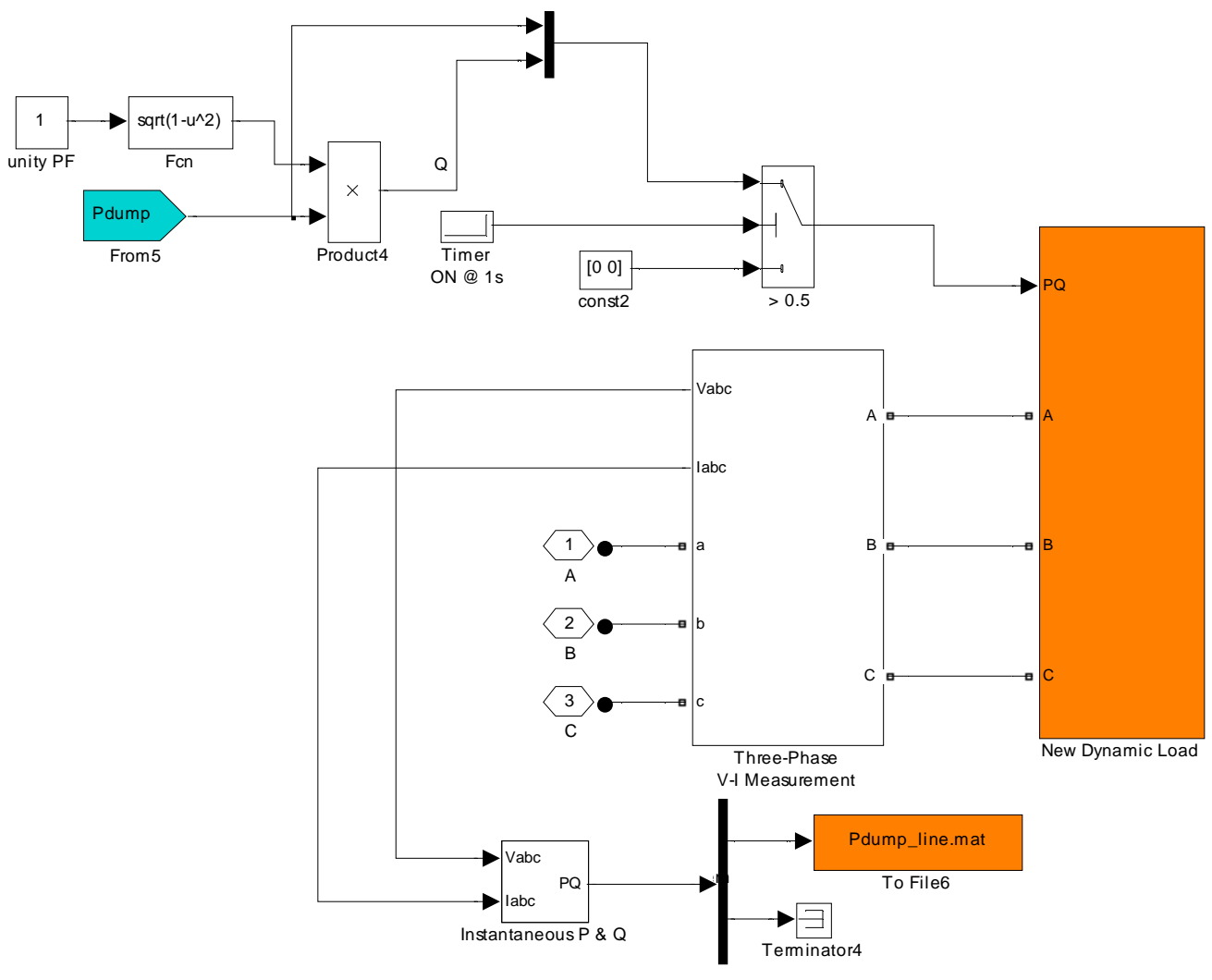

Fig. A.7 Dump load model 


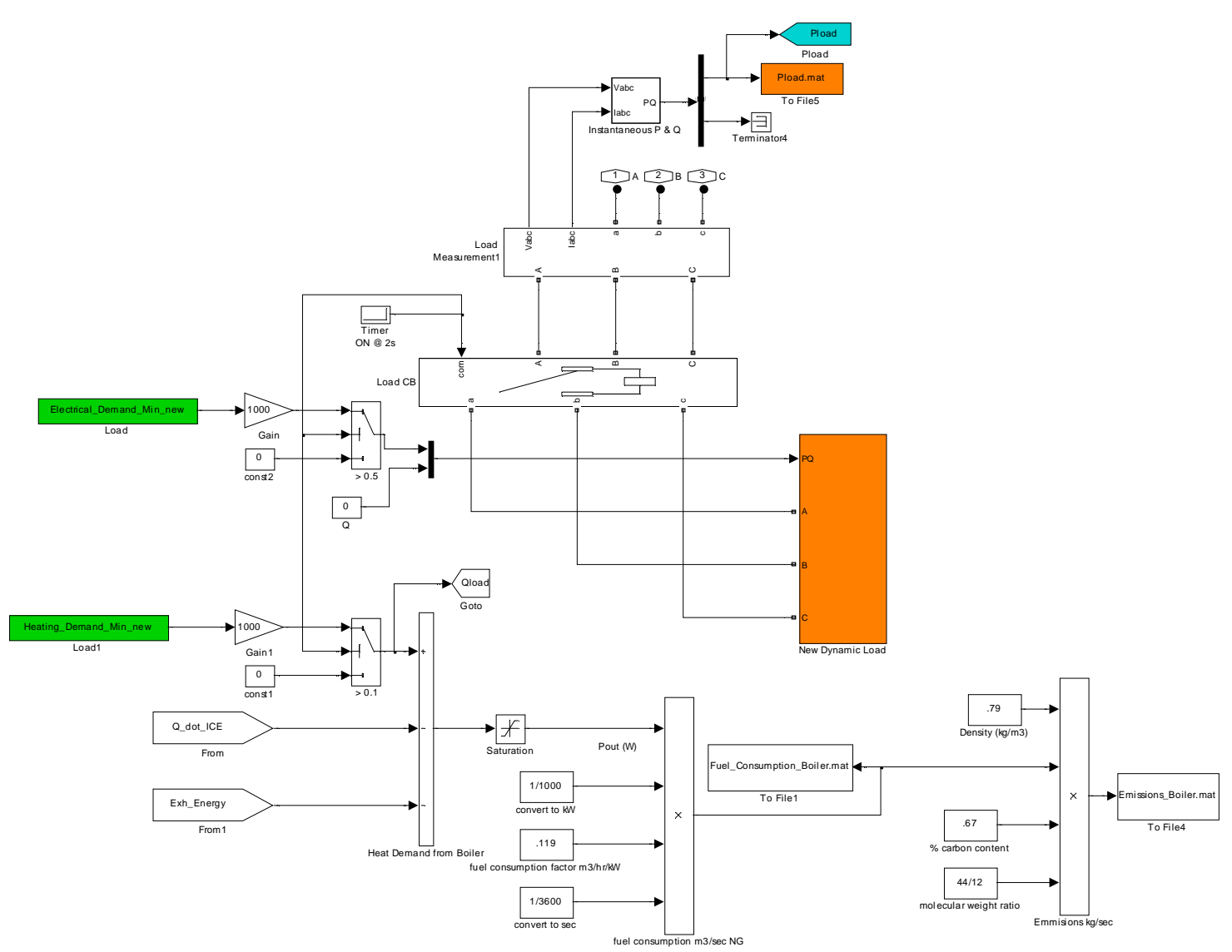

Fig. A.8 Electrical and heating load models 


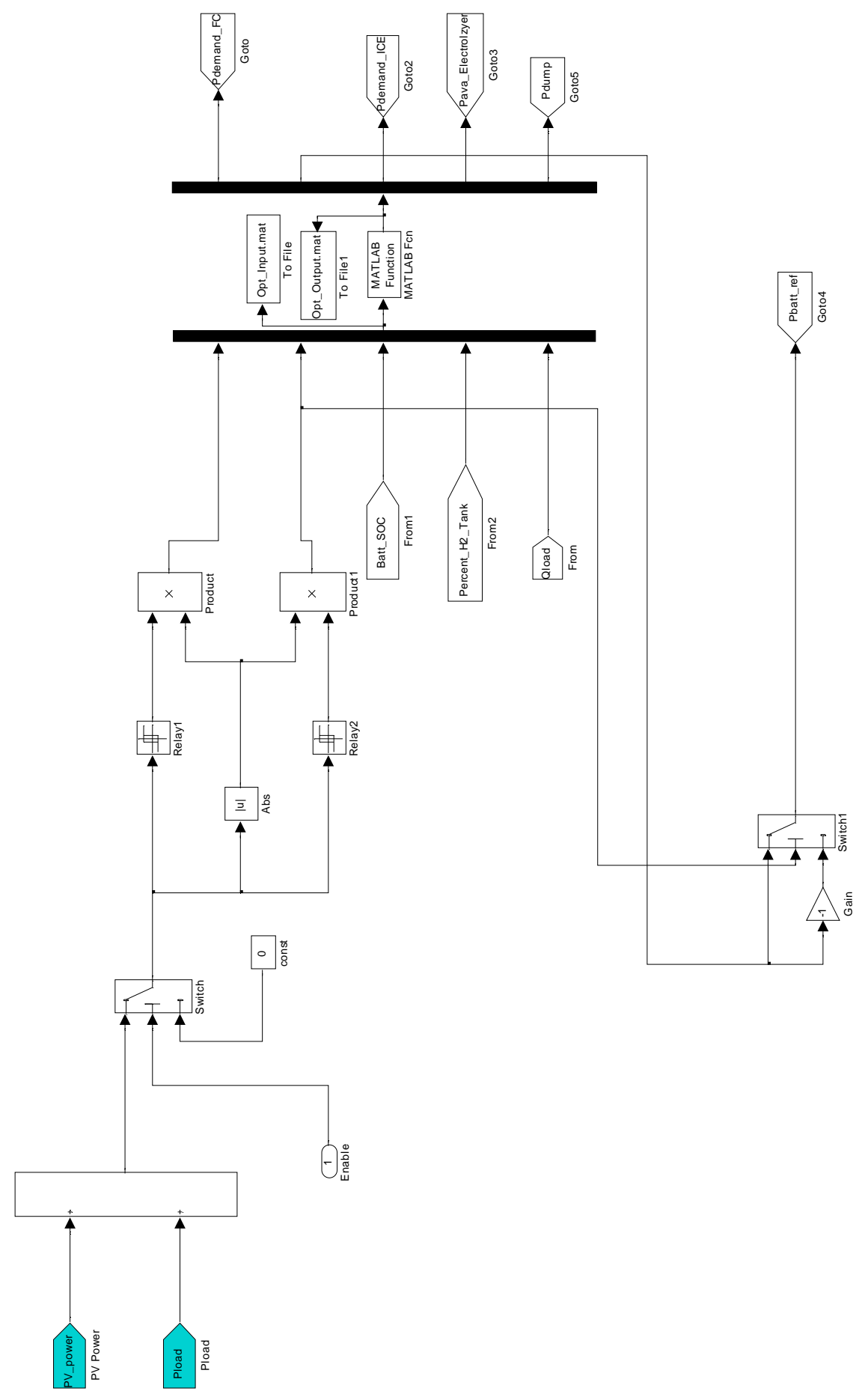

Fig. A.9 Power control signals model with modified MOPSO algorithm call function 
APPENDIX B

ENERGY MANAGEMENT AND MODIFIED MOPSO ALGORITHM FUNCTION 1 


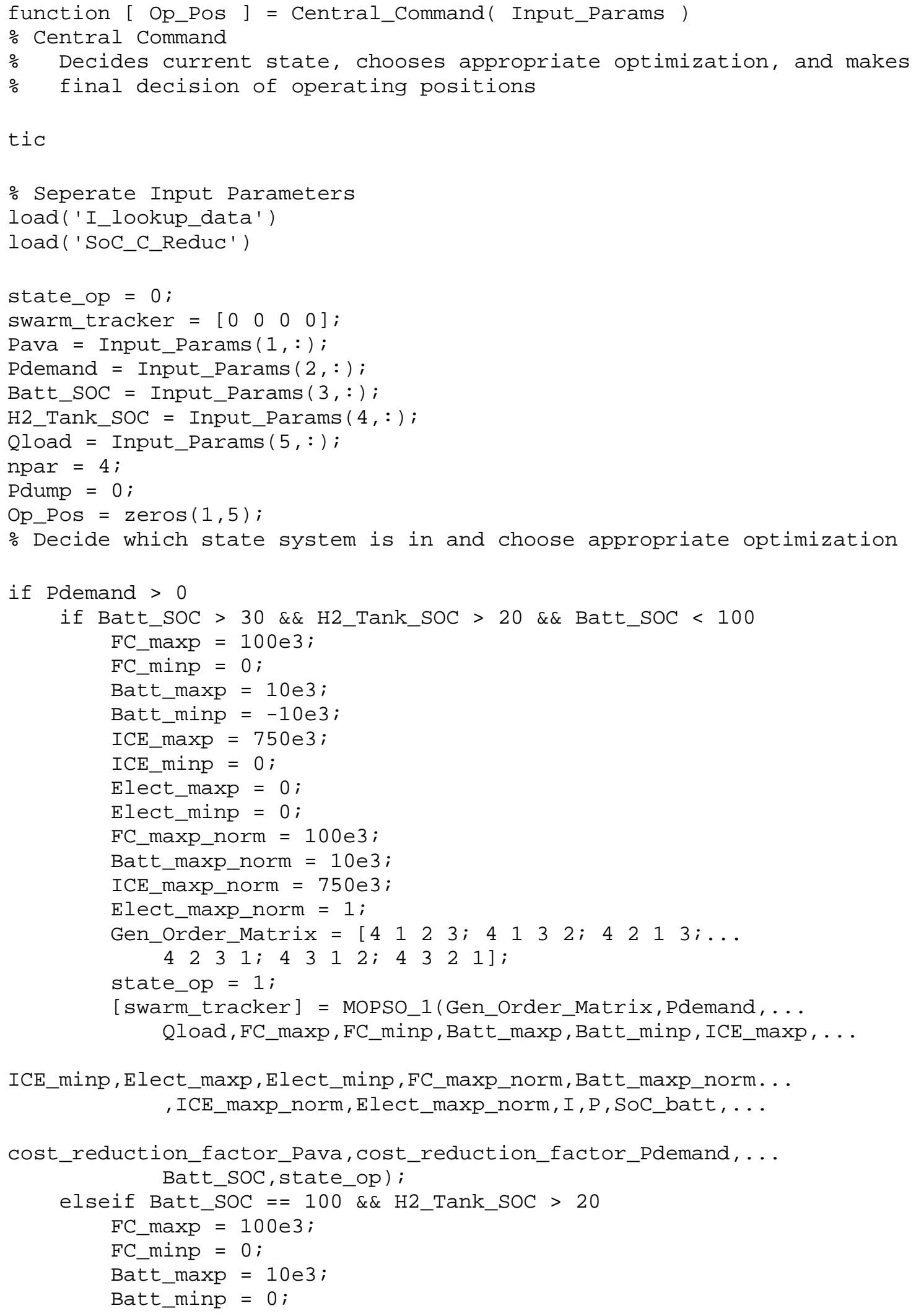




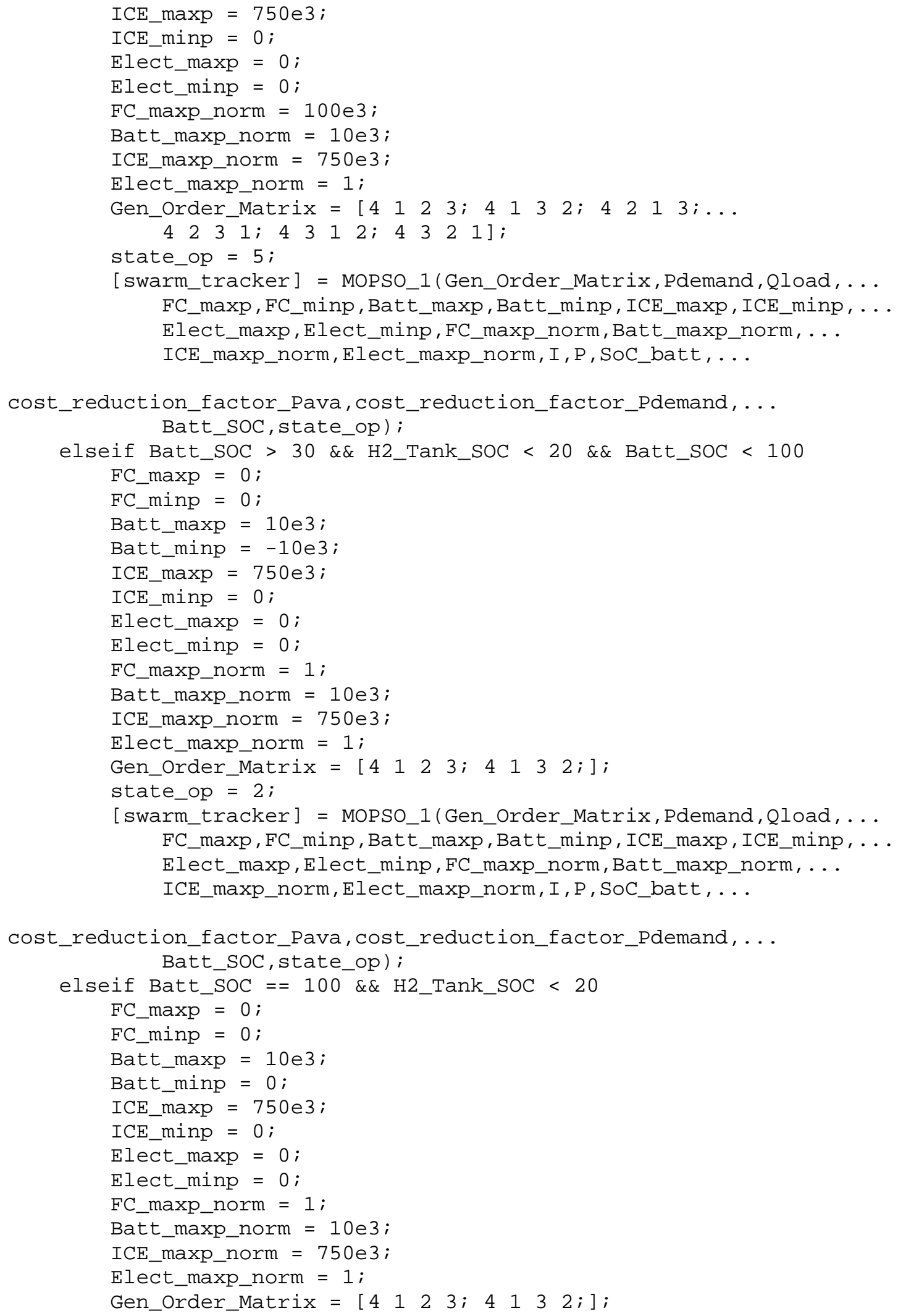




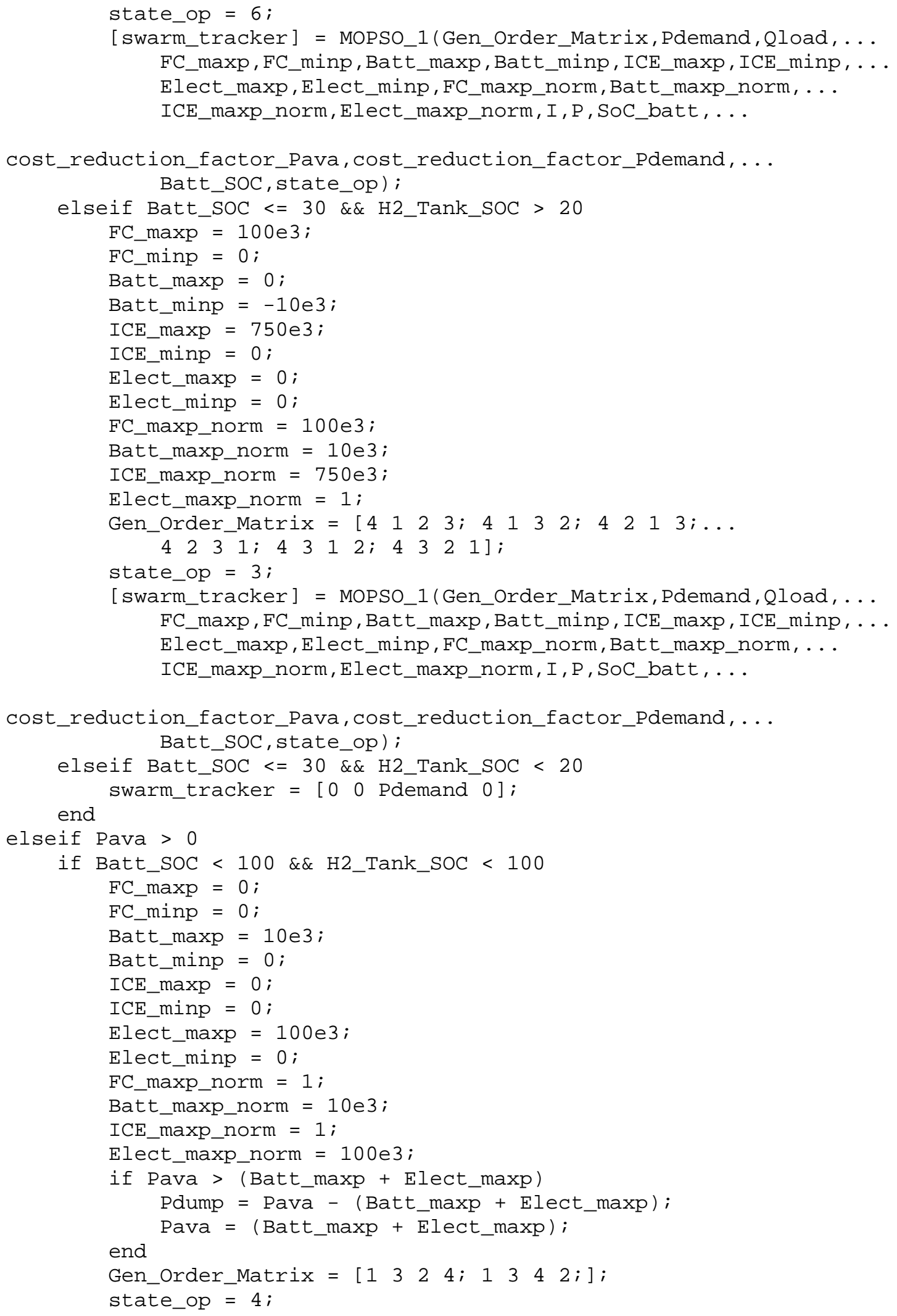




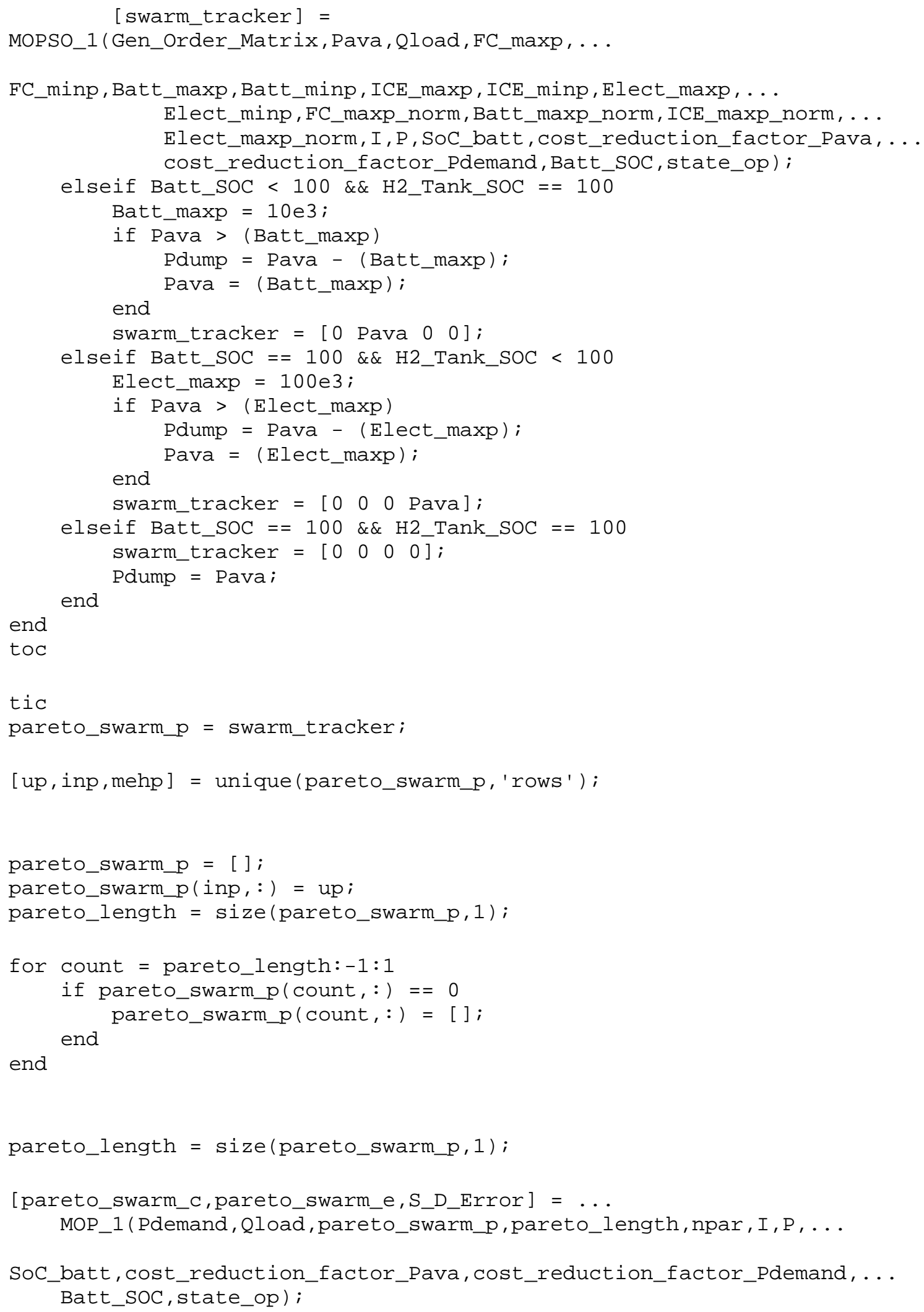




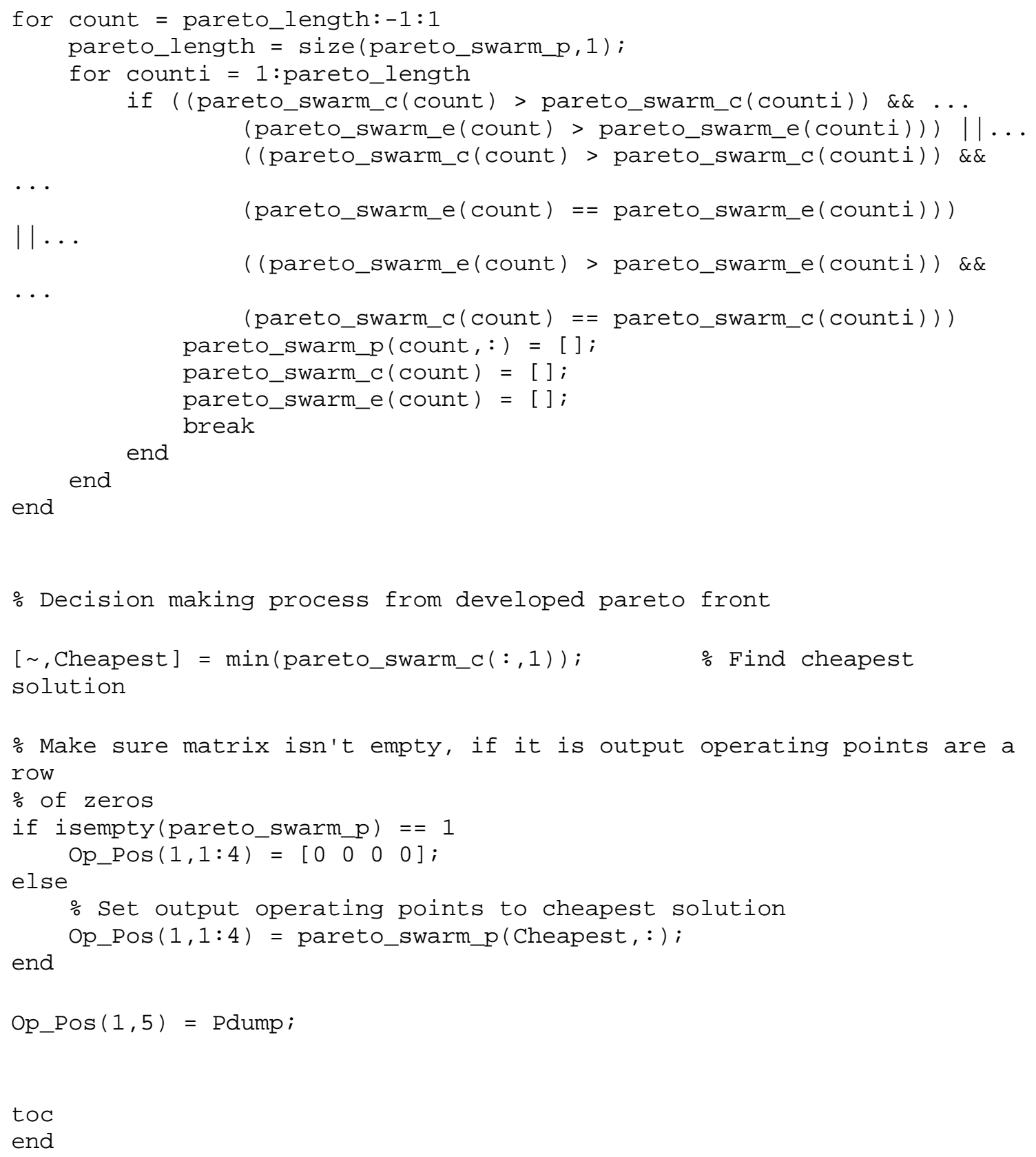


$\underline{\text { APPENDIX C }}$

ENERGY MANAGEMENT AND MODIFIED MOPSO ALGORITHM FUNCTION 2 


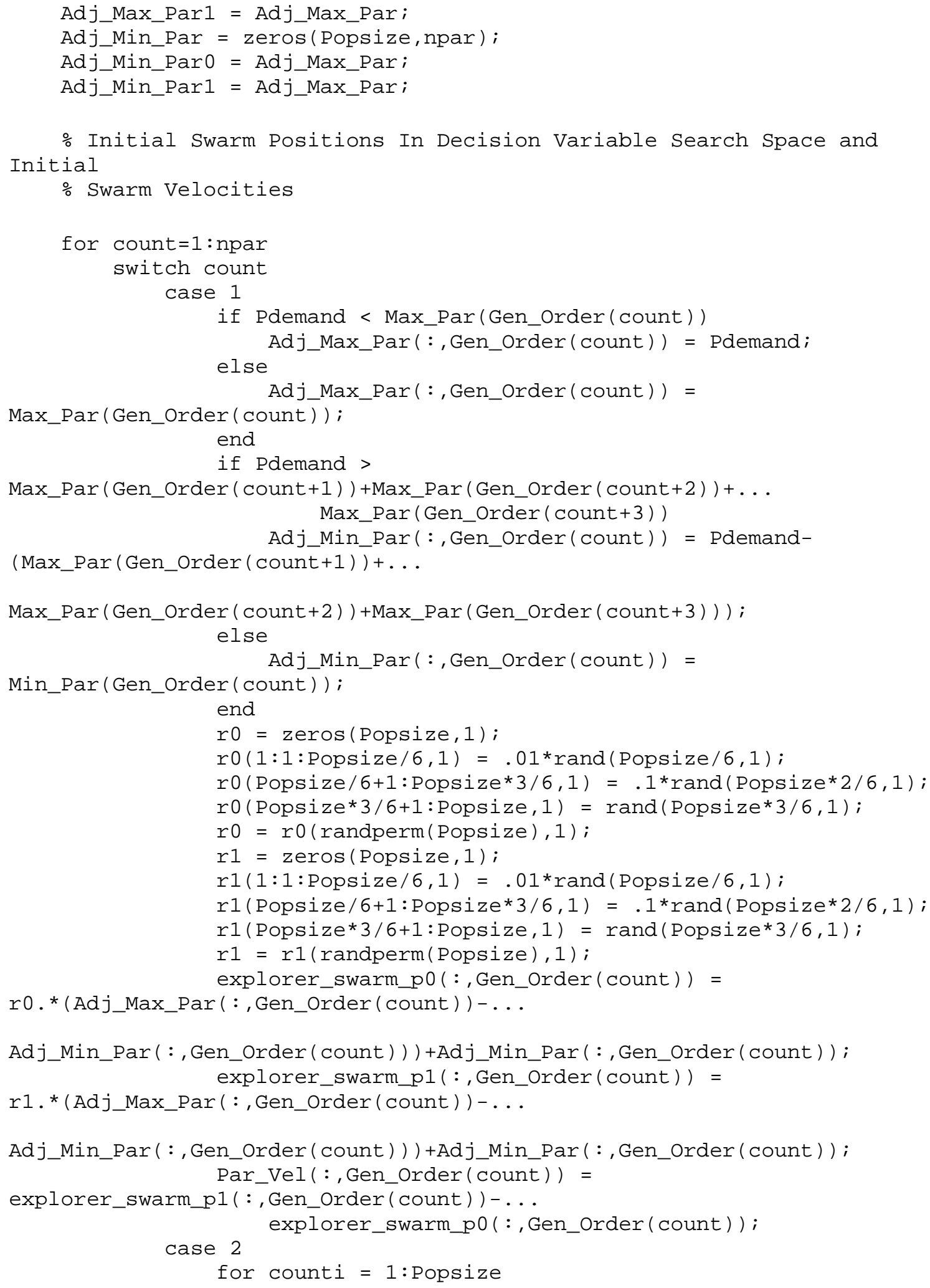




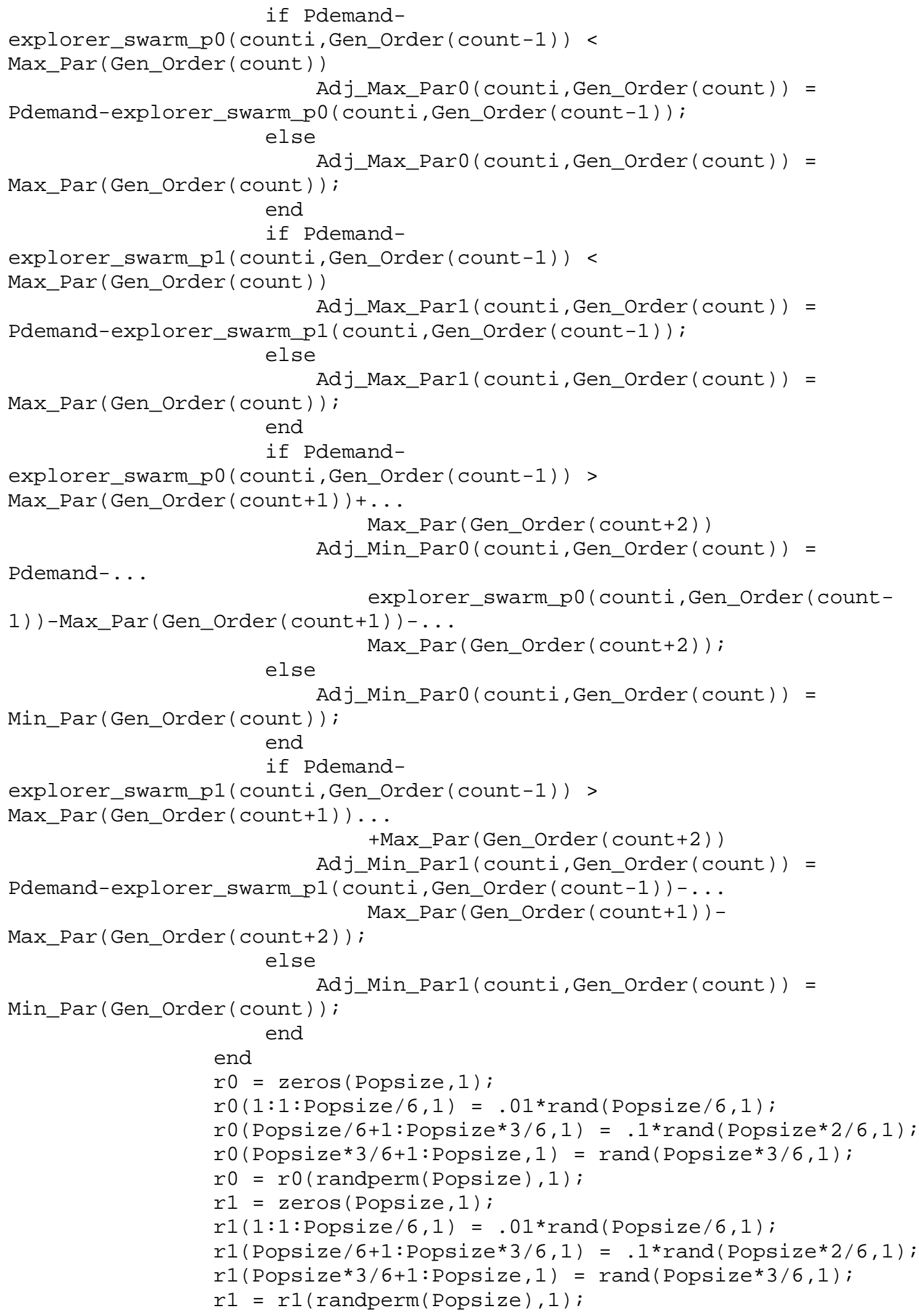




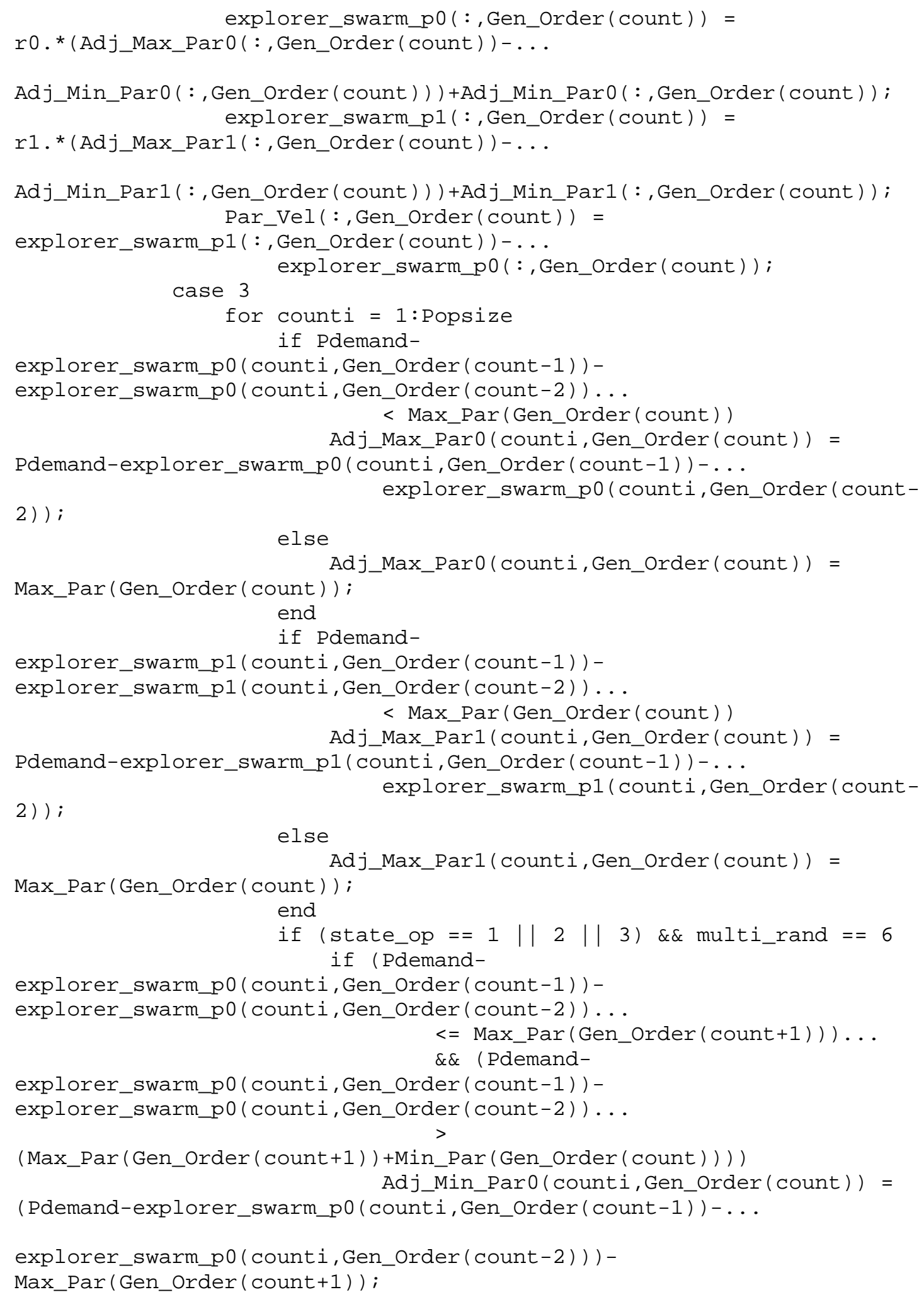


elseif Pdemand-

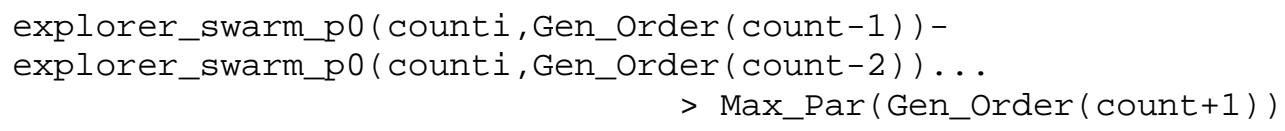


if Pdemand-

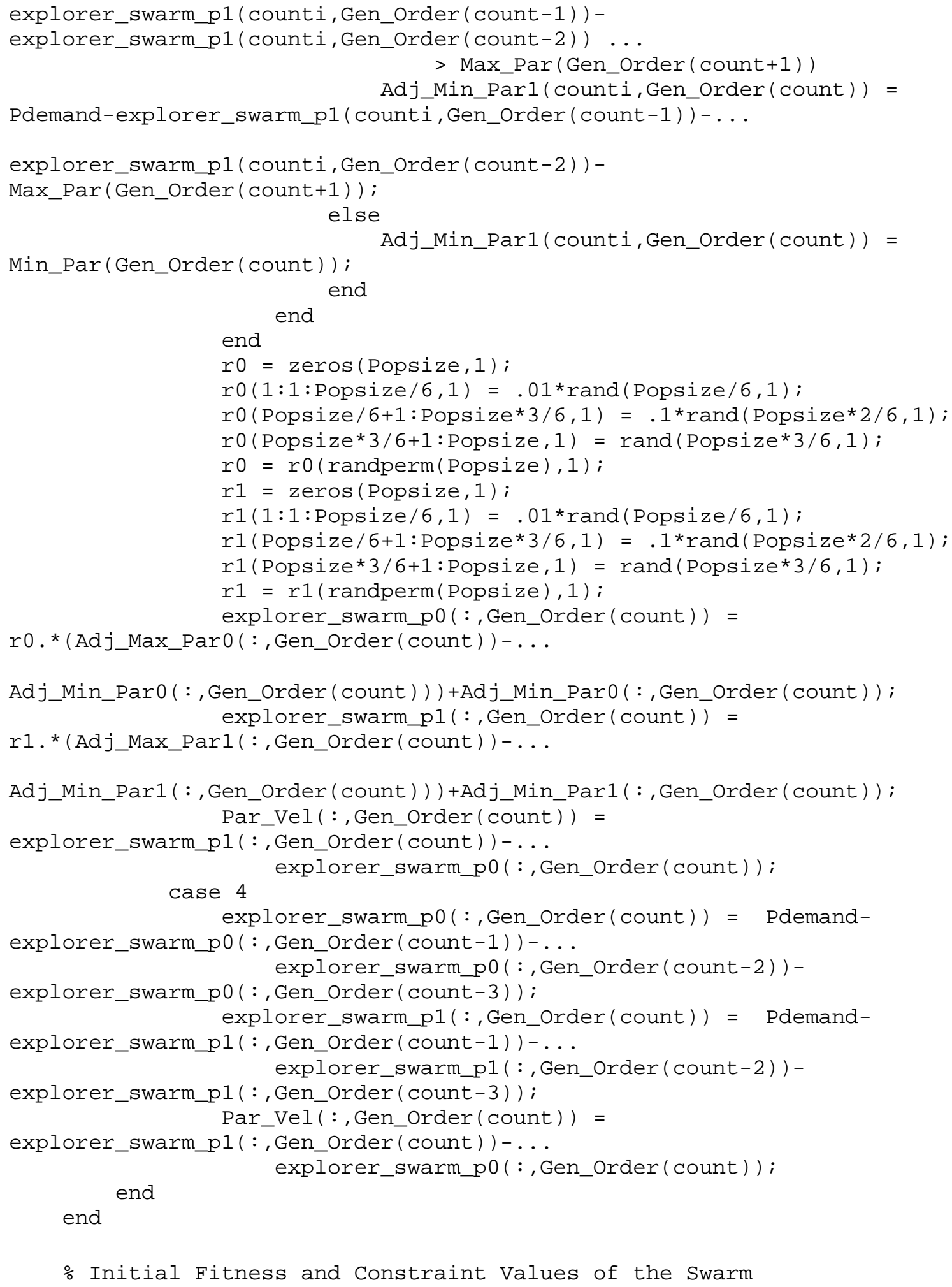




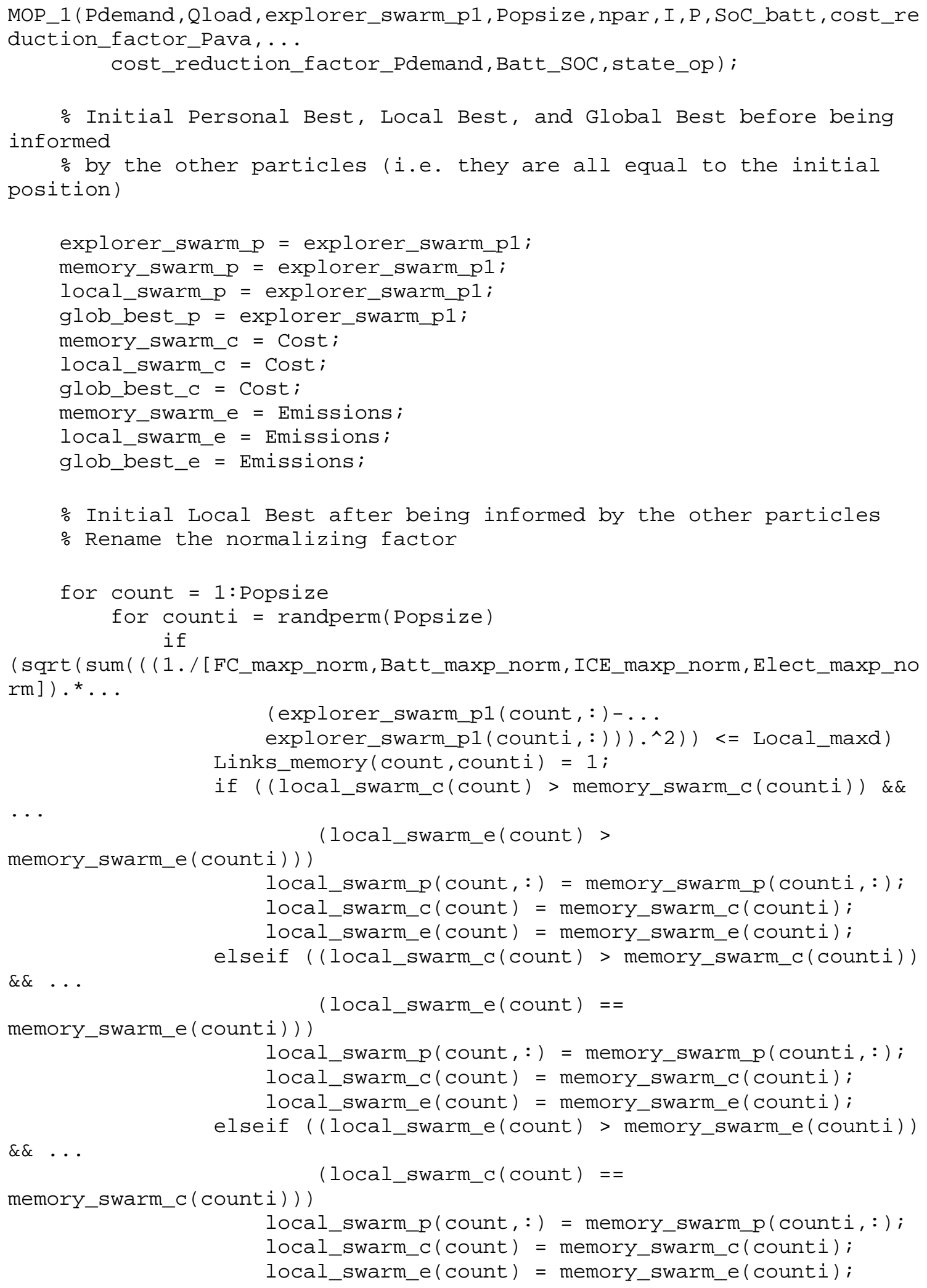




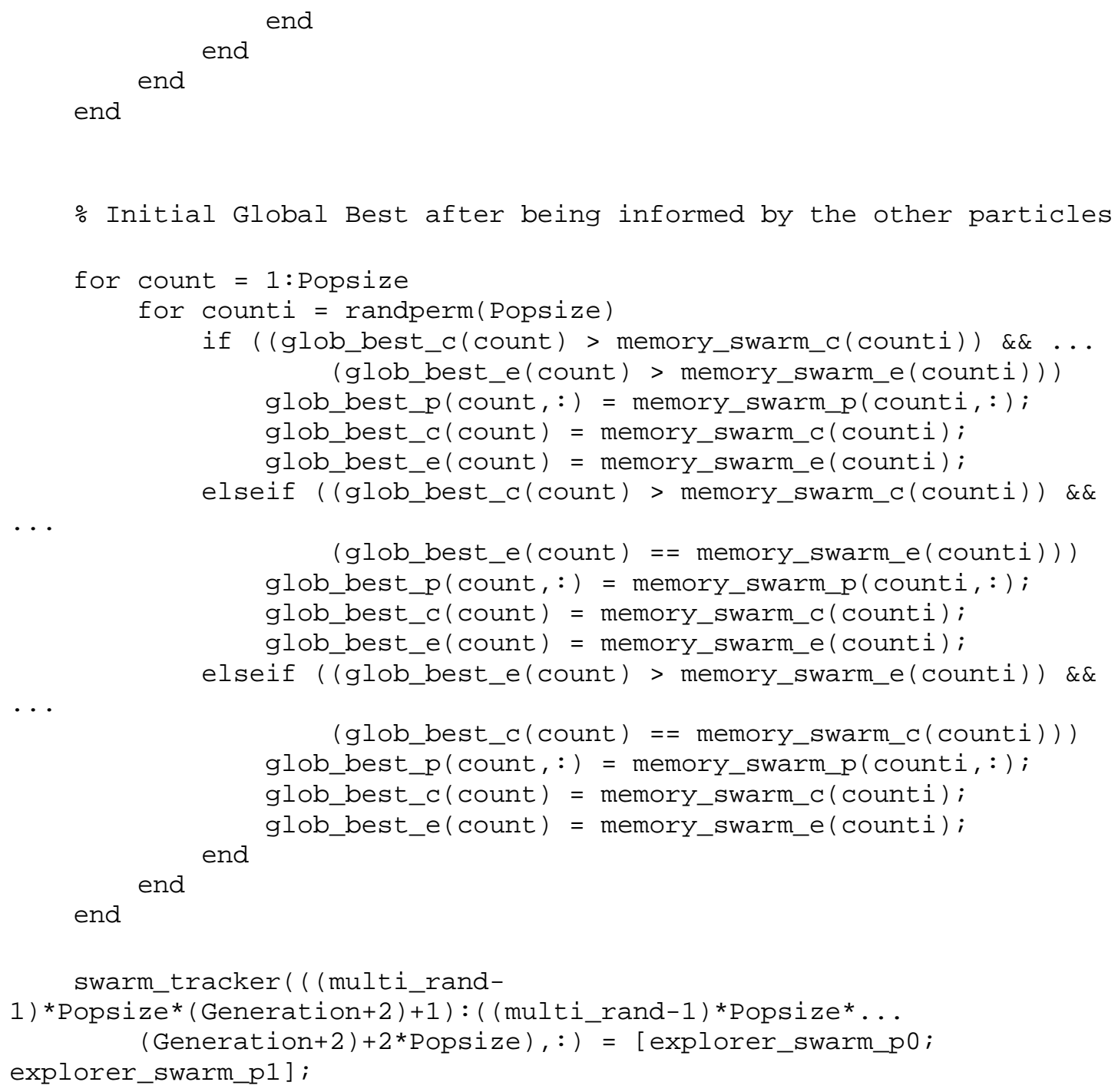




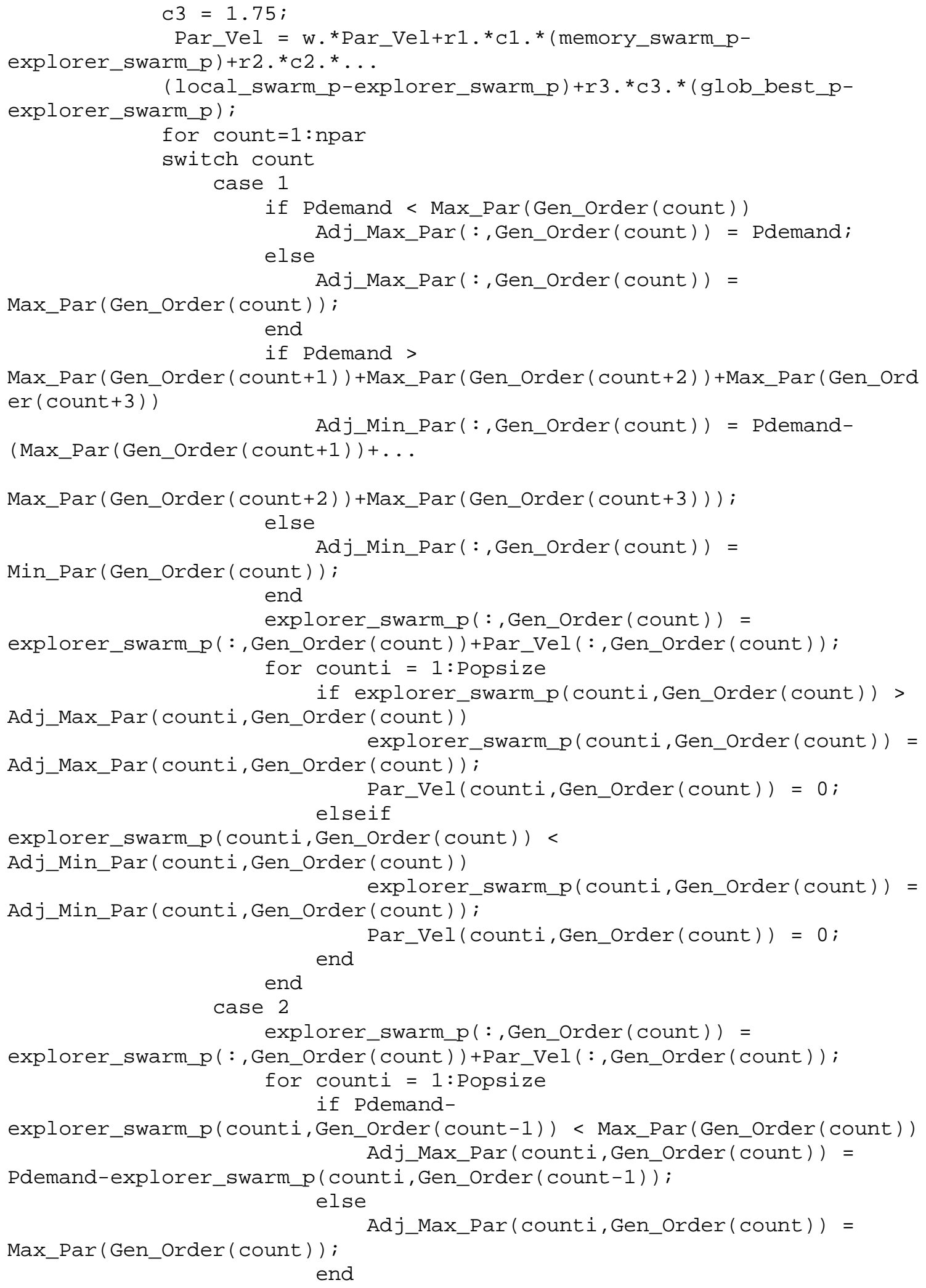


if Pdemand-

explorer_swarm_p (counti,Gen_Order(count-1)) >

Max_Par (Gen_Order (count+1)) +Max_Par (Gen_Order (count+2))

Adj_Min_Par(counti,Gen_Order(count)) =

Pdemand-explorer_swarm_p (counti,Gen_Order (count-1)) ...

Max_Par (Gen_Order (count+2)) ;

-Max_Par (Gen_Order (count+1)) -

else

Adj_Min_Par (counti,Gen_Order (count) ) =

Min_Par(Gen_Order(count)) ;

end

if explorer_swarm_p(counti,Gen_order(count)) >

Adj_Max_Par(counti,Gen_Order(count))

explorer_swarm_p (counti,Gen_order $($ count $))=$

Adj_Max_Par(counti,Gen_Order(count)); elseif

Par_Vel (counti,Gen_Order(count)) = 0 ;

explorer_swarm_p (counti,Gen_Order(count)) <

Adj_Min_Par(counti,Gen_Order(count)) explorer_swarm_p (counti,Gen_order $($ count $))=$

Adj_Min_Par(counti,Gen_order(count)); end

Par_Vel (counti,Gen_Order(count)) = 0 ;

end

case 3

explorer_swarm_p (:,Gen_Order(count)) =

explorer_swarm_p (:,Gen_Order(count)) +Par_Vel (:,Gen_Order (count)) ;

for counti = 1 :Popsize

if Pdemand-

explorer_swarm_p (counti,Gen_Order (count-1)) -

explorer_swarm_p (counti,Gen_Order (count-2)) ...

$<$ Max_Par (Gen_Order(count))

Adj_Max_Par (counti,Gen_Order(count)) =

Pdemand-explorer_swarm_p (counti,Gen_Order (count-1)) - . .

explorer_swarm_p (counti,Gen_order(count-2));

else

Adj_Max_Par (counti,Gen_Order (count)) =

Max_Par(Gen_Order(count)) ;

end

if (state_op $==1|| 2|| 3)$ \& \& multi_rand $==6$ if (Pdemand-

explorer_swarm_p (counti,Gen_Order(count-1)) -

explorer_swarm_p (counti,Gen_order (count-2)) ... $<=$ Max_Par (Gen_Order $($ count +1$))) \ldots$

$\& \& \quad$ (Pdemand-

explorer_swarm_p (counti,Gen_order (count-1)) -

explorer_swarm_p (counti,Gen_order (count-2)) ...

$>$

(Max_Par (Gen_Order (count+1)) +Min_Par (Gen_Order (count))))

Adj_Min_Par(counti,Gen_Order(count)) =

(Pdemand-explorer_swarm_p (counti,Gen_Order (count-1) ) - . . 


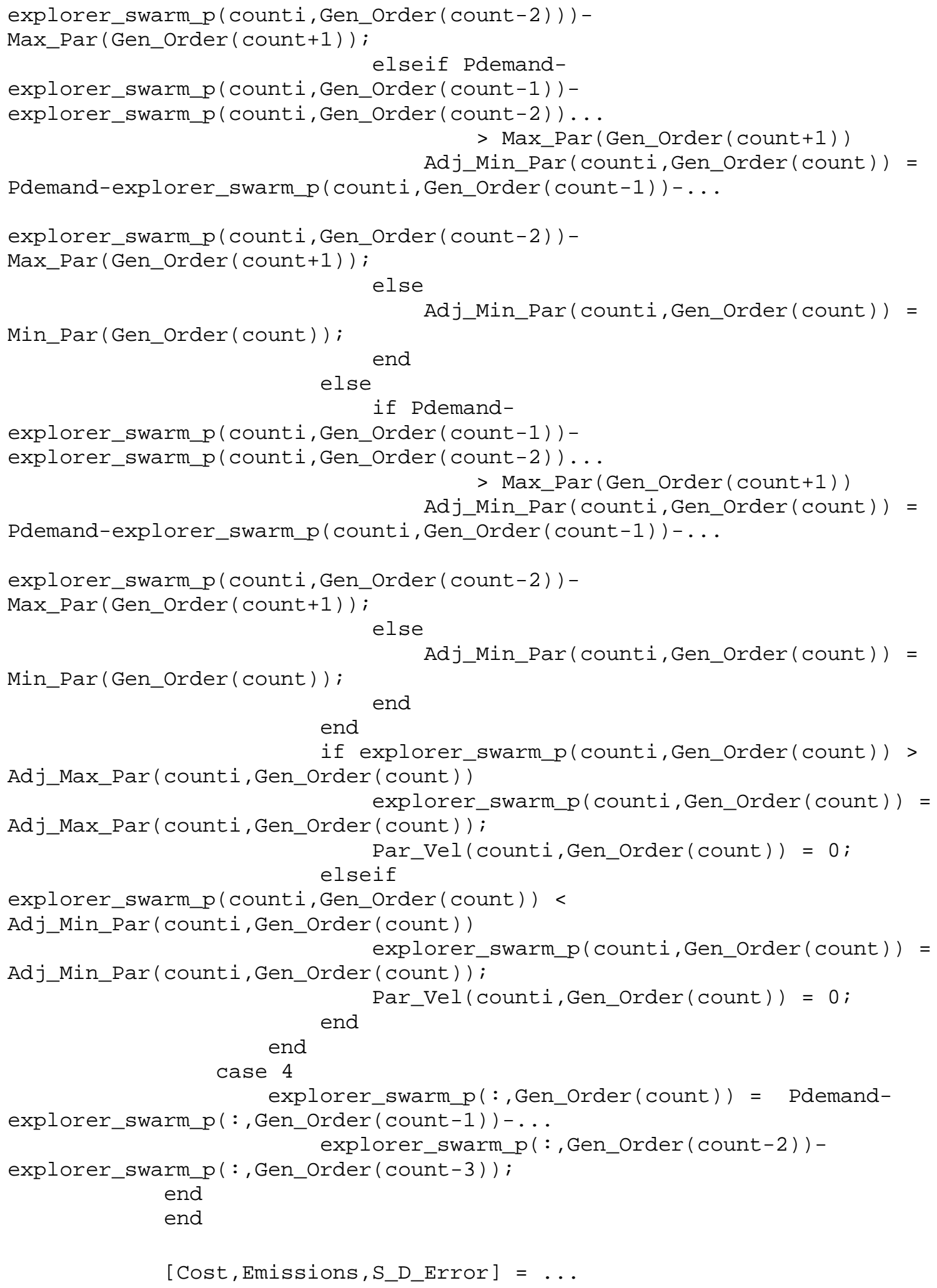




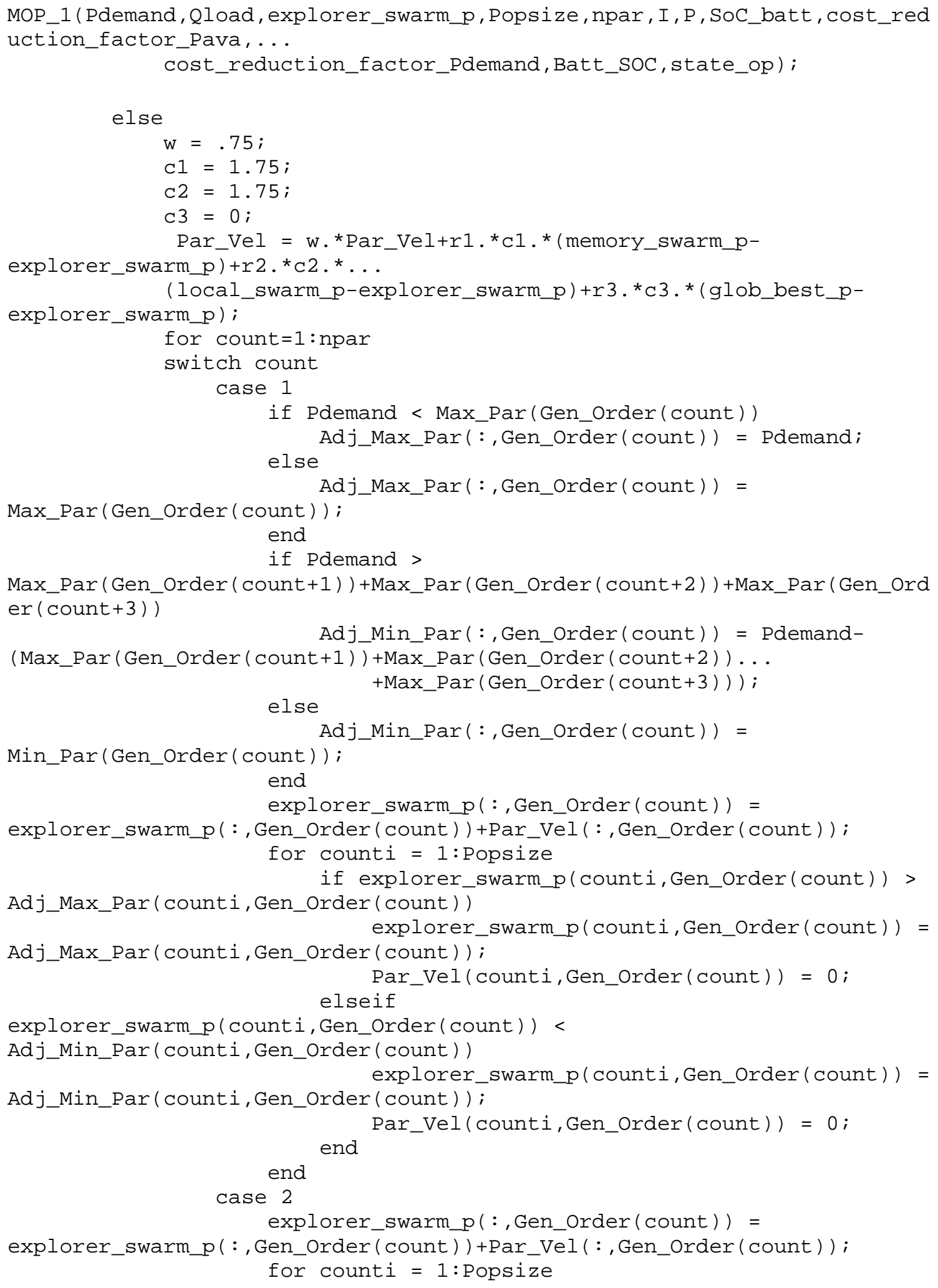




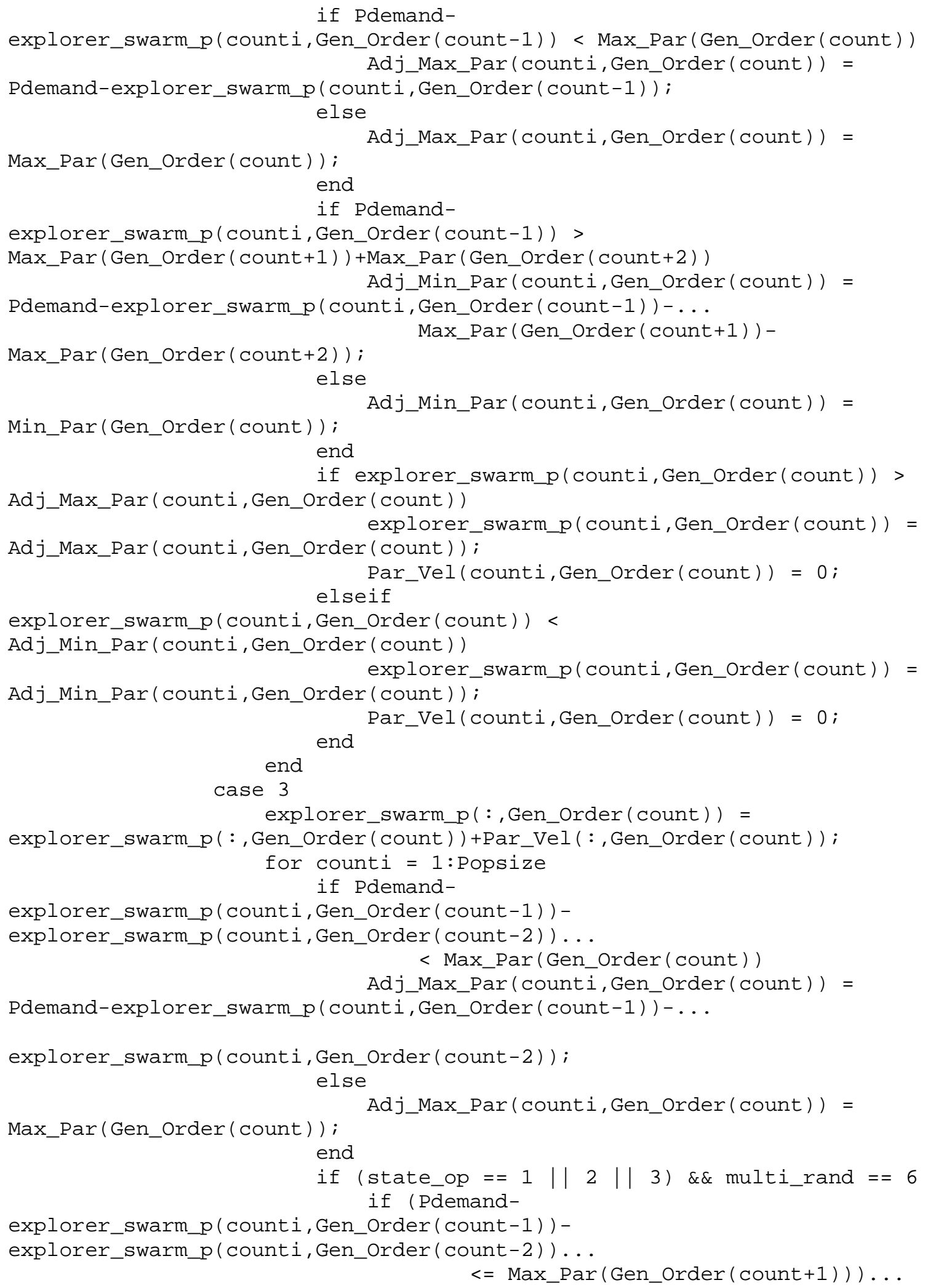




\section{8}

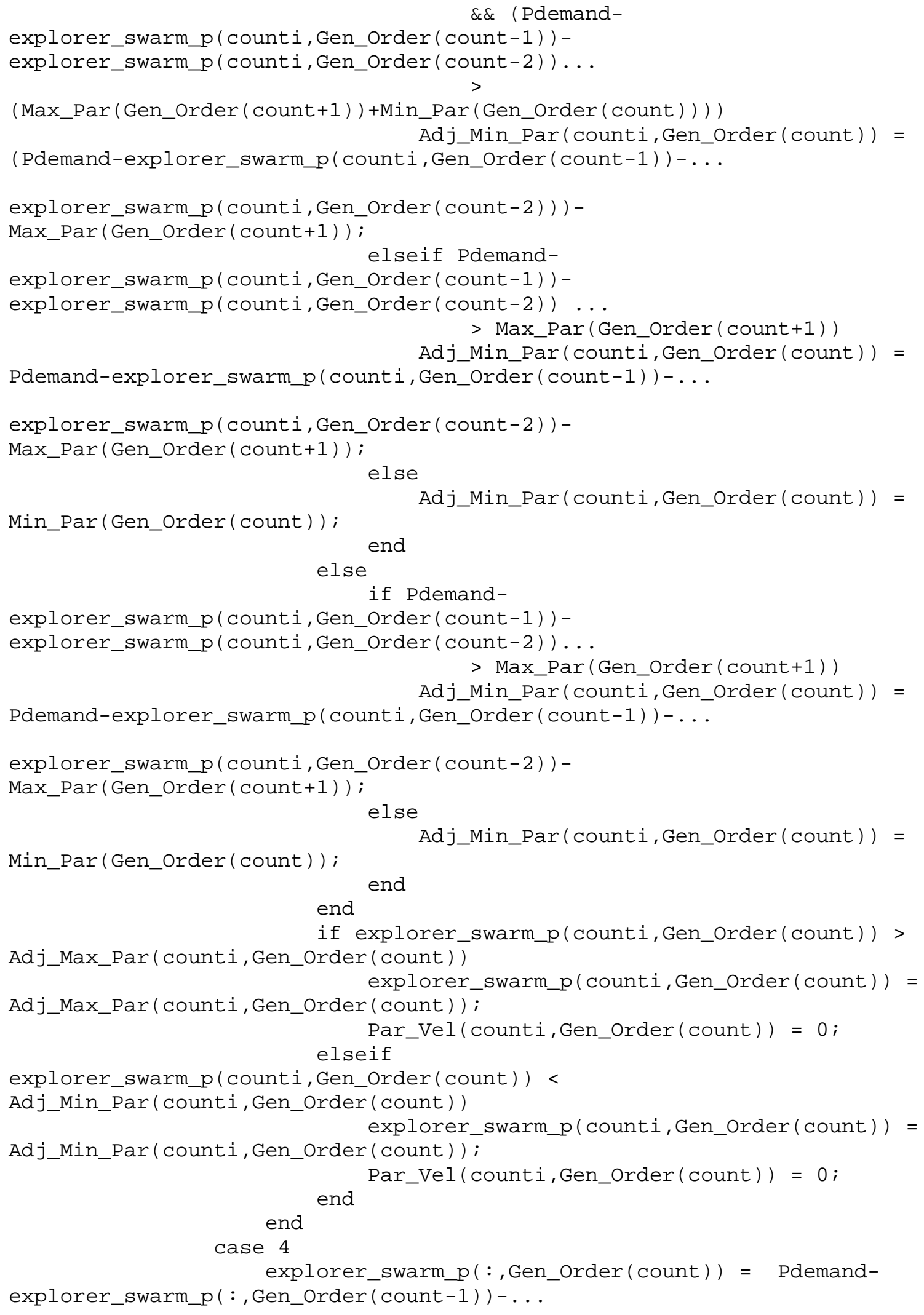




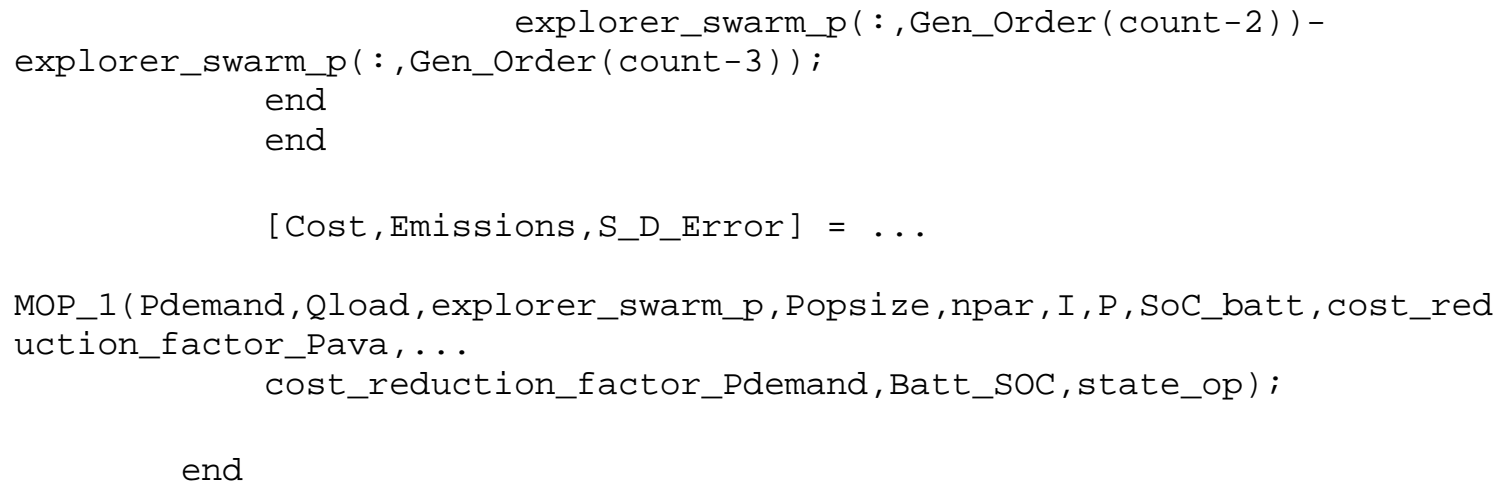




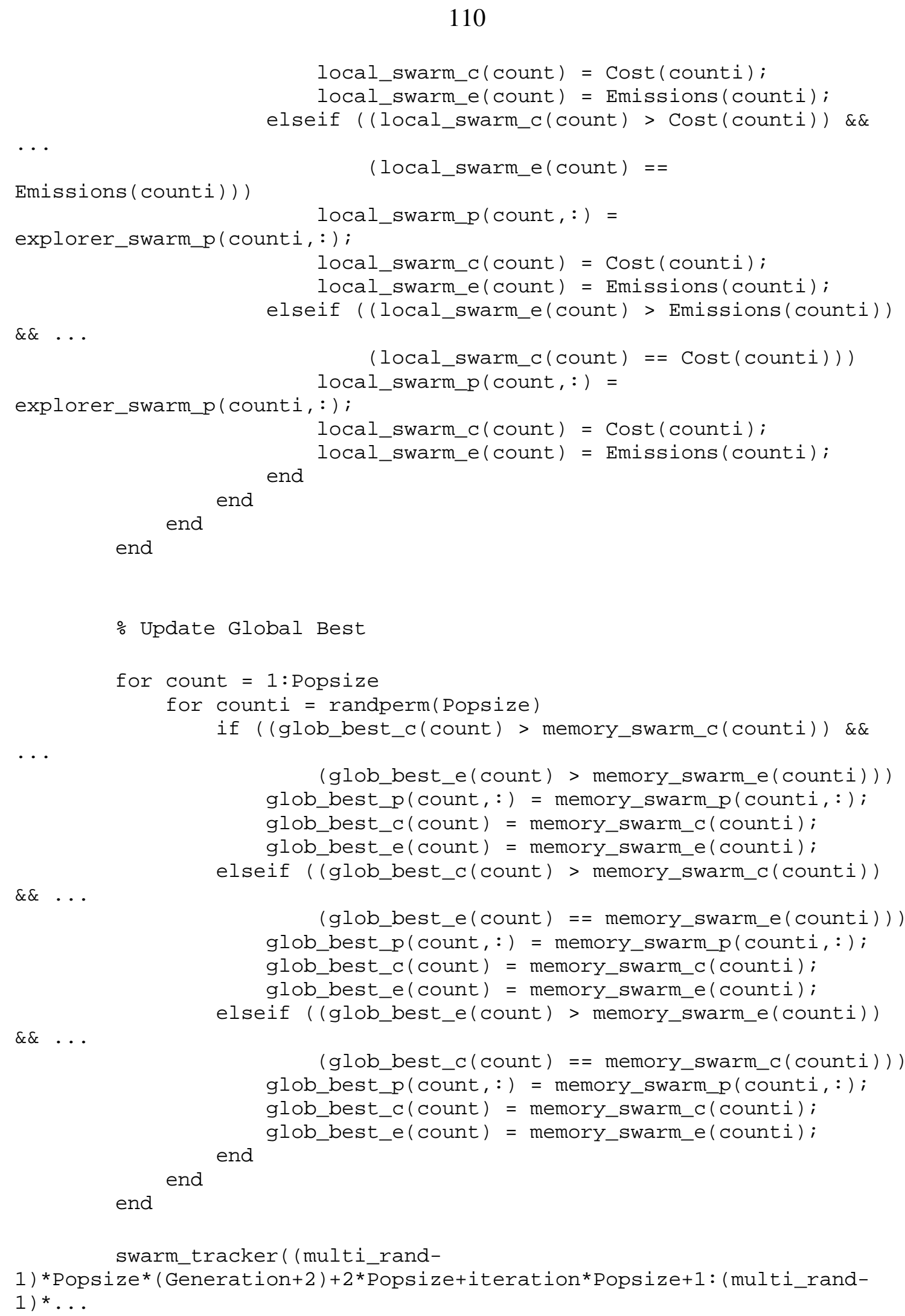


Popsize* (Generation +2$)+2$ *Popsize+iteration*Popsize+Popsize, : ) = explorer_swarm_p;

iteration = iteration+1;

end

end

end 
APPENDIX D

ENERGY MANAGEMENT AND MODIFIED MOPSO ALGORITHM FUNCTION 3 


\section{3}

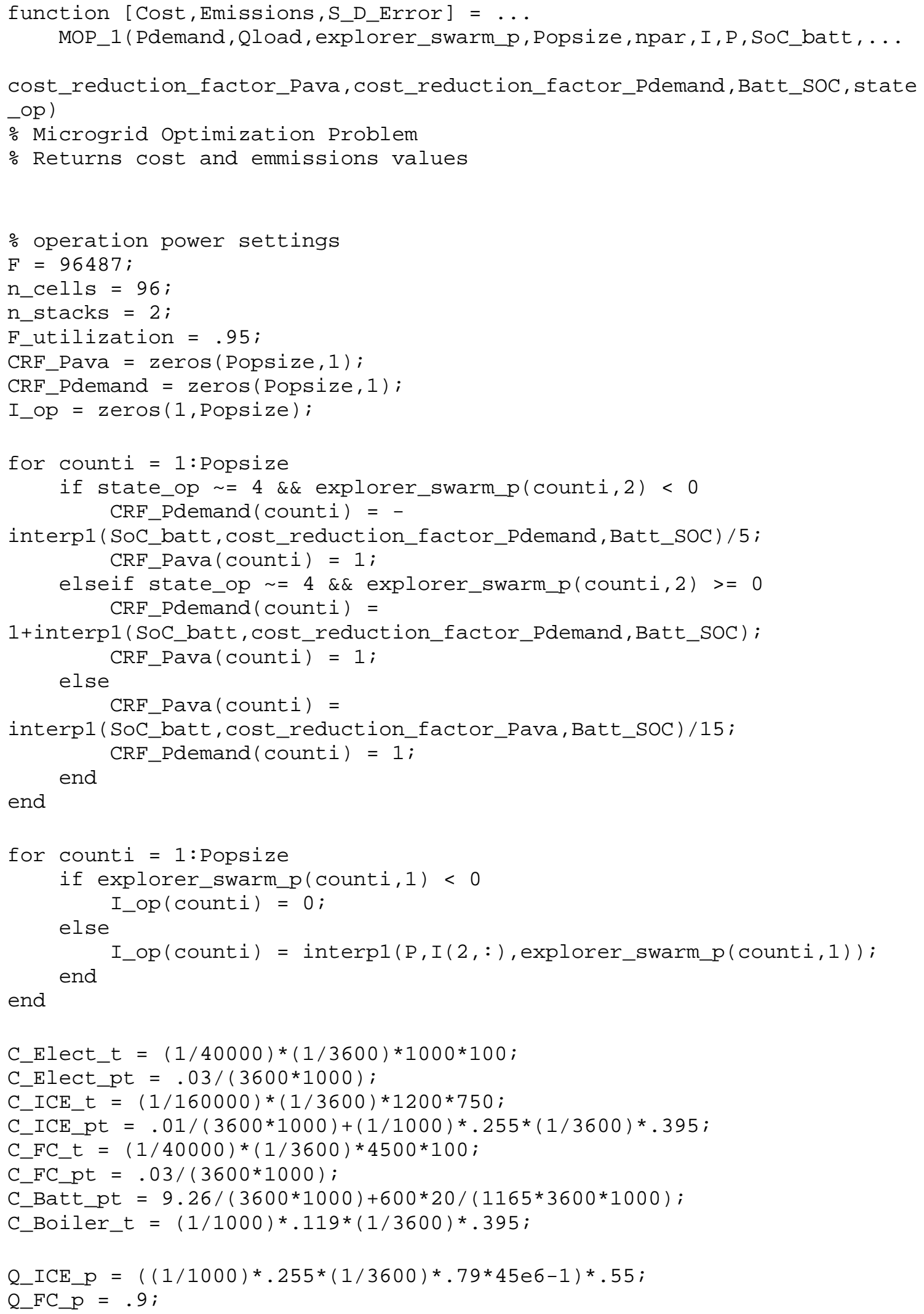




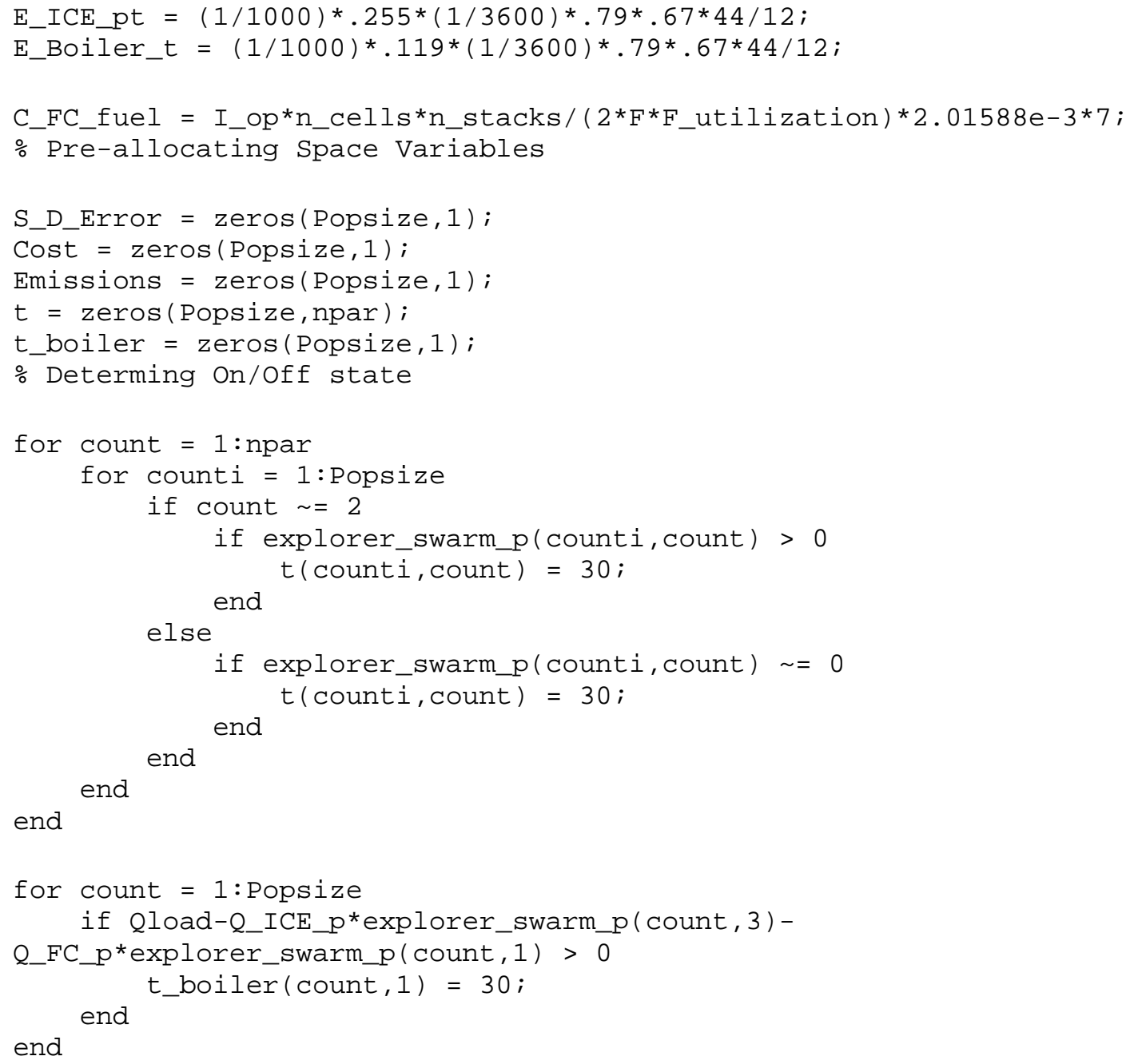




\section{5}

t_boiler(count, 1) * (Qload-Q_ICE_p*explorer_swarm_p (count, 3) Q_FC_p*explorer_swarm_p (count, 1));

Emissions (count) =

E_ICE_pt*t (count, 3) *explorer_swarm_p (count, 3) +E_Boiler_t*...

t_boiler(count, 1$)$ * (Qload-Q_ICE_p*explorer_swarm_p (count, 3) Q_FC_p*explorer_swarm_p (count, 1));

end

end 